\title{
Glutamate-induced reversal of dopamine transport is mediated by the PKC signaling pathway
}

\author{
$\mathrm{PhD}$ thesis \\ in partial fulfilment of the requirements \\ for the degree "Doctor of Philosophy $(\mathrm{PhD}) / \mathrm{Dr}$. rer. nat." \\ International Max Planck Research School \\ Msc / PhD Graduate program in Neuroscience \\ Georg August University Göttingen, \\ Faculty of Biology
}

March 2008

Submitted by Luis Felipe Opazo Dávila, born in Buenos Aires, Mayo 22, 1978 


\section{DECLARATION}

The thesis has been written independently and with no other sources and aids than quoted.

Luis Felipe Opazo Dávila

March 2008

The work presented here constitutes only part of the work done during my $\mathrm{PhD}$ period. The other project that I worked on will not be addressed in this thesis because the two topics are not related. It resulted in a manuscript that is in the process of being published in a peer-reviewed journal (see $\mathrm{CV}$ at the end of the thesis). 


\section{TABLE OF CONTENT}

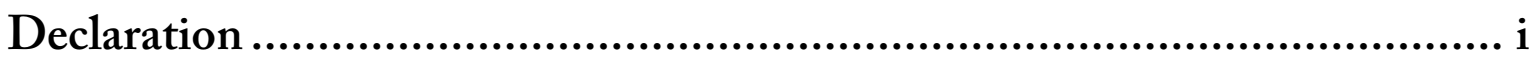

Table of Content ................................................................................ ii

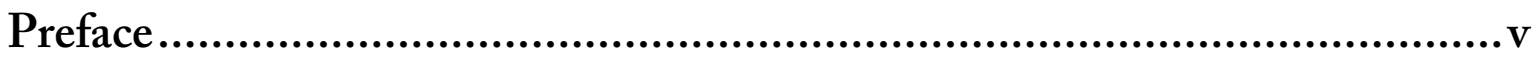

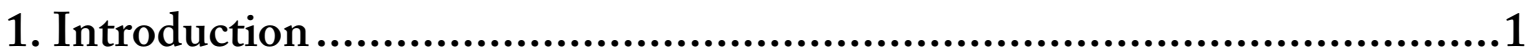

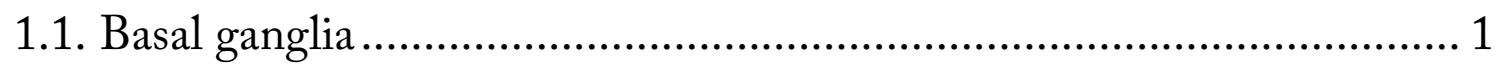

1.1.1. The Basal ganglia functions ............................................................... 1

1.1.2. Basal ganglia nuclei and their connections...............................................

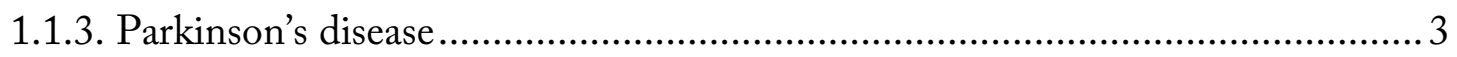

1.1.3.1. Epidemiology of Parkinson's disease.............................................. 4

1.1.3.2. Parkinson's disease clinical symptoms............................................ 4

1.1.3.3. Etiology of Parkinson's disease ...................................................... 4

1.1.3.4. Pathophysiology of Parkinson's disease.......................................... 6

1.2. Dendritic release of dopamine in the $\mathrm{SN}$....................................... 7

1.2.1. Anatomy of substantia nigra pars reticulata ............................................... 7

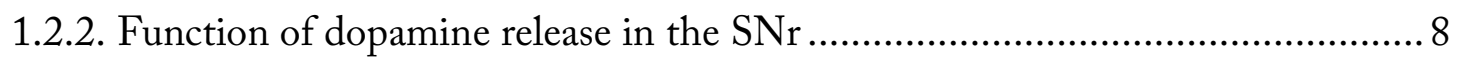

1.2.3. Mechanism of dendritic dopamine release in the $\mathrm{SNr}$............................... 8

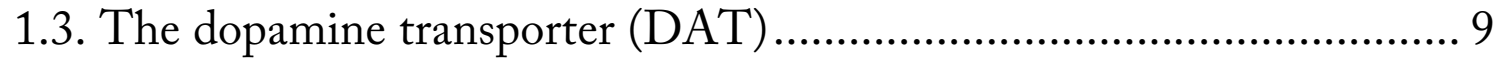

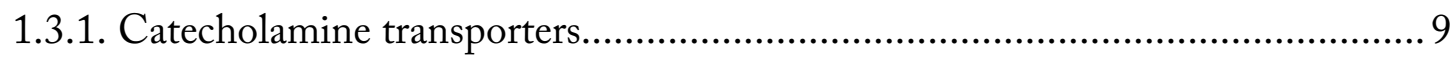

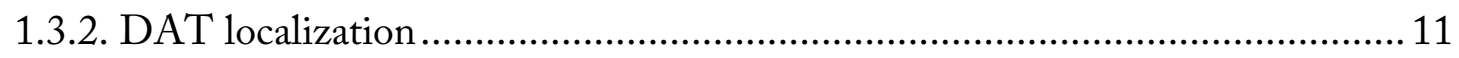

1.3.3. The dopamine transporter's functional properties....................................... 11

1.3.4. Amphetamine-induced dopamine release ................................................ 12 
1.3.4.1. Facilitated exchange diffusion theory .......................................... 13

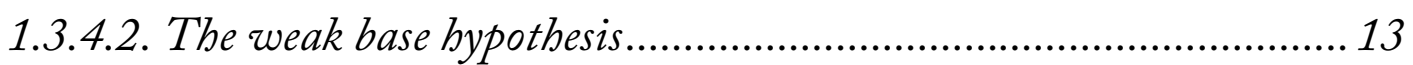

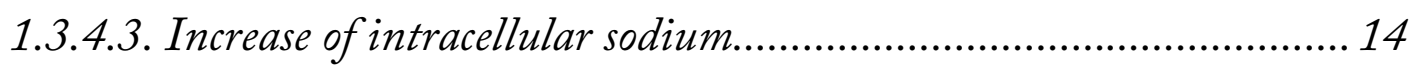

1.3.4.4. Transient channel-like mode of the DAT .................................... 14

1.3.4.5. Role of DAT phosphorylation ....................................................... 15

1.3.5. Glutamate-induced DAT reversal............................................................... 15

1.3.6. Role of the DAT in Parkinson's disease ........................................................16

1.3.7. Role of the DAT in drugs of abuse ..............................................................16

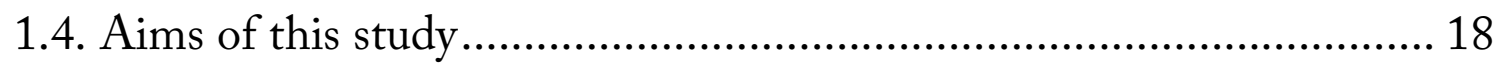

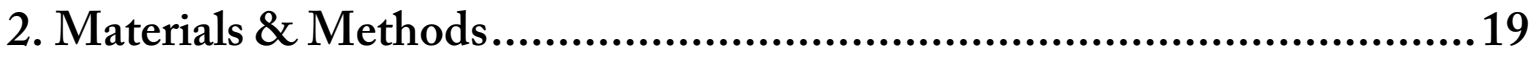

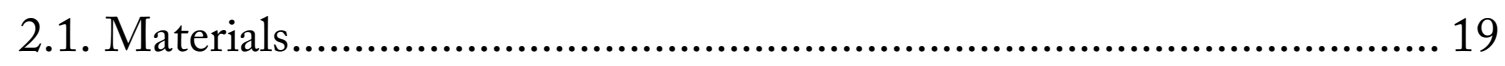

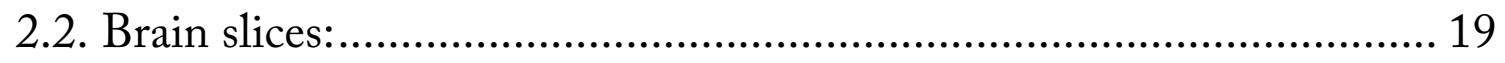

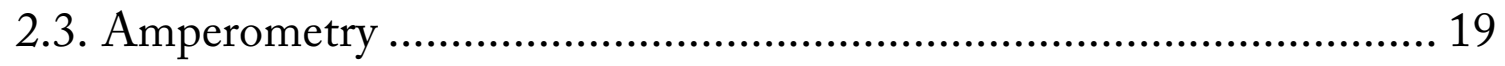

2.4. Molecular biology and Cell culture .................................................... 20

2.5. Measuring dopamine uptake and release by HPLC .......................... 21

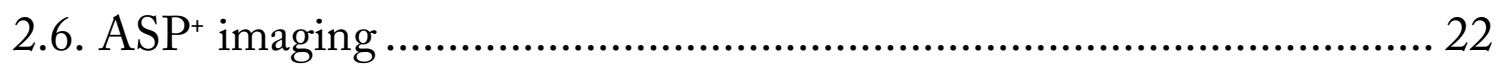

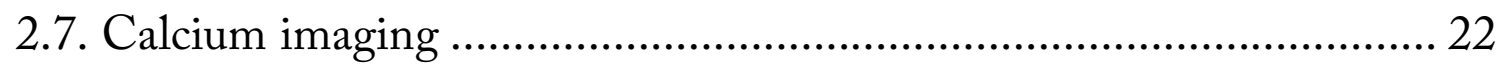

2.8. Electrophysiological Recordings .................................................... 23

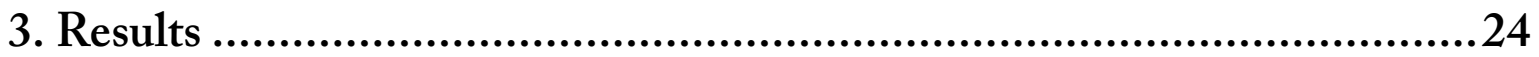

3.1. Glutamate-induced release of dopamine requires DAT and PKC..... 24 
3.2. $\mathrm{G}_{\mathrm{q}}-\mathrm{PLC}$ signalling induces DAT-mediated dopamine release in a cell line. 29

3.3. Studying dopamine transporter kinetics by fluorescence imaging ...... 42 3.4. Physiological release of dopamine in the $\mathrm{SN}$ is mediated by the DAT

4.2. Second messenger cascade is involved in the reversal of the DAT ..... 50

4.2.1. metabotropic glutamate receptors.................................................................. 50

4.2.2. Dissecting the signalling which induce the reversal of the DAT.....................5 51

4.3. How does PKC activity induce DAT-mediated dopamine efflux? .... 53

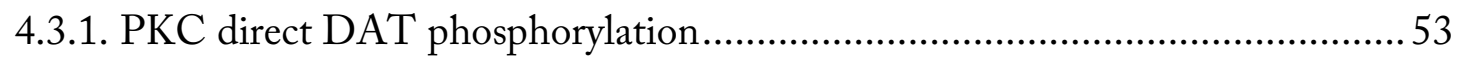

4.3.2. Activation of $\mathrm{PKC}$ induced changes in sodium gradients ................................5 54

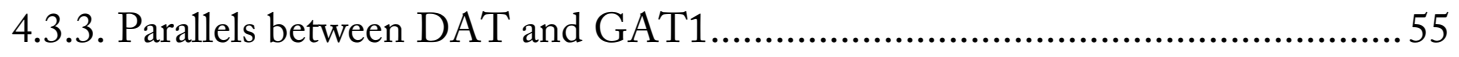

4.4. Physiological implications of the DAT reversal ................................ 55

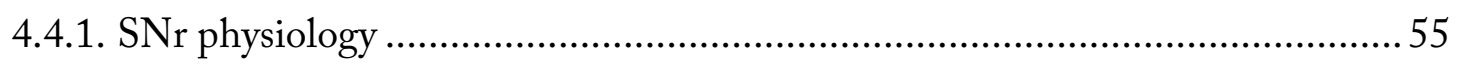

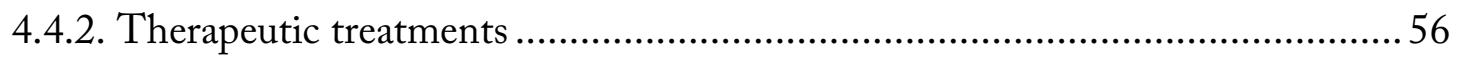

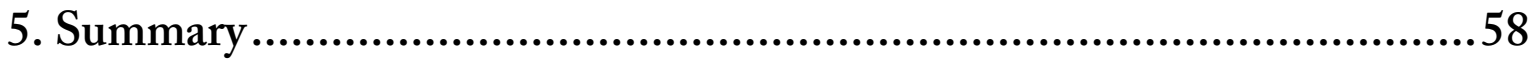

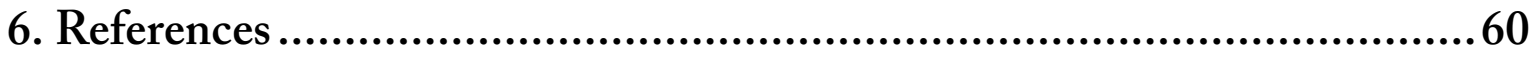

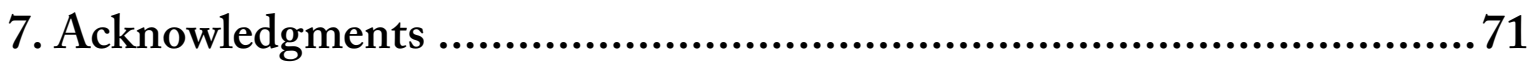

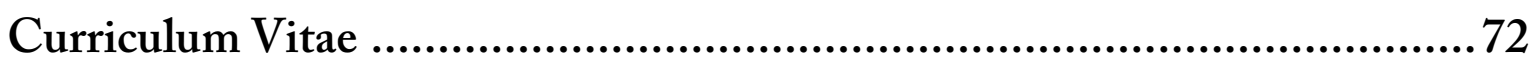

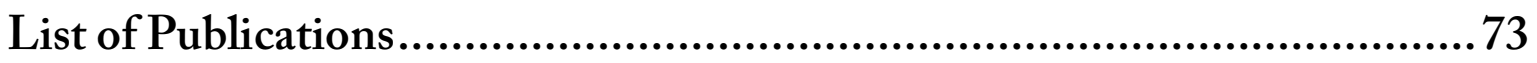




\section{PREFACE}

Movement is a concept we often use with many different meanings. For instance, "a movement" among musicians would refer to one division of a larger composition, whereas among physicists "movement" would be principally described as a continuous change in the location of a body. We also commonly refer to cultural, religious, artistic and philosophical "movements".

However, in the following thesis we will study elements involved in the generation of our body movements, our ability of motion.

To achieve simple tasks we need to have our sensory system guiding our movements. In order to pick up an apple you must have a visual representation of where the apple is located in space. It also requires that you know where your hand is in space. Thus to pick up the apple is only possible when the brain areas in charge of the motor movement are constantly informed by the ongoing stream of information acquired by our sensory systems. Broadly speaking, voluntary movements are initiated in our cerebral cortex. They pass through several intermediate regulatory stations and finally reach the spinal cord where the movement commands are targeted to the necessary muscles.

In this work I focus on one of these "regulatory stations", the basal ganglia, more specifically on one of its nuclei: the substantia nigra. The substantia nigra is mainly known for its neurons that use dopamine as a neurotransmitter, and their degeneration is associated with Parkinson's disease.

My work aims to understand more about the molecular mechanism of a relevant protein that these neurons express, namely the dopamine transporter.

With the following work I hope to contribute at least a little piece of information to the physiology of the basal ganglia by investigating the mechanism of dopamine release mediated by the dopamine transporter in the substantia nigra. 


\section{INTRODUCTION}

\subsection{Basal ganglia}

\subsubsection{The Basal ganglia functions}

The main structures and circuits involved in our everyday movement behaviour are (i) the motor areas in the cerebral cortex and its pyramidal track connecting the brain and the spinal cord, (ii) the cerebellum, which among other functions has several feedback circuits sensing the body position in space giving equilibrium and finetuning movements, and (iii) finally the ganglia-thalamocortical system that plays an important role in execution, modulation and correction of voluntary movements.

The basal ganglia have been associated with sensorimotor functions and their failure leads to movement disorders, such as Huntington's disease, Hemiballism and Parkinson's disease (PD). PD is characterized by hypokinesia, which consist in slow movements (bradykinesia), difficulty in initiating willing movements (akinesia), increased muscled tone (rigidity) and resting tremor. The main degenerative process occurring in $\mathrm{PD}$ is the loss of dopaminergic neurons in the substantia nigra (SN) (see section 1.1.3.). Huntington's disease is a hereditary and progressive disorder associated not only with abnormal movements in the sense of hyperkinesias and chorea (involuntary uncontrollable movements), but also with psychiatric symptoms and eventually dementia. Huntington's pathology is characterized by neuronal loss in several basal ganglia nuclei (caudate nucleus, putamen, glubus pallidus), cerebral cortex and other areas. Hemiballism is another hyperkinetic movement disorder with fast, unwilled flinging of the limbs caused by a lesion in subthalamic nucleus (STN).

The neuronal activity leading to voluntary movement originates from motor areas in the cortex (motor area M1 and sensory motor area SMA). The basal ganglia act as a modulator or "filter" and inhibit inappropriate movements from being executed. 


\subsubsection{Basal ganglia nuclei and their connections}

The anatomical circuits within the basal ganglia consist of several interconnected nuclei, which receive principal afferents from the prefrontal, motor and sensory cortex and send various ascending and descending efferents to thalamic and mesensephalic structures.

The basal ganglia consist of four nuclei; the striatum, the pallidum, the subthalamic nucleus (STN) and the substantia nigra (SN) (Figure 1). The striatum can be divided in three subregions: the caudate nucleus, the putamen and the ventral striatum, which includes the nucleus accumbens. The pallidum has two subdivisions, the external (GPe) and internal (GPi) segment. The substantia nigra can be divided also in two areas, the subtantia nigra pars compacta $(\mathrm{SNc})$ and pars reticulata $(\mathrm{SNr})$

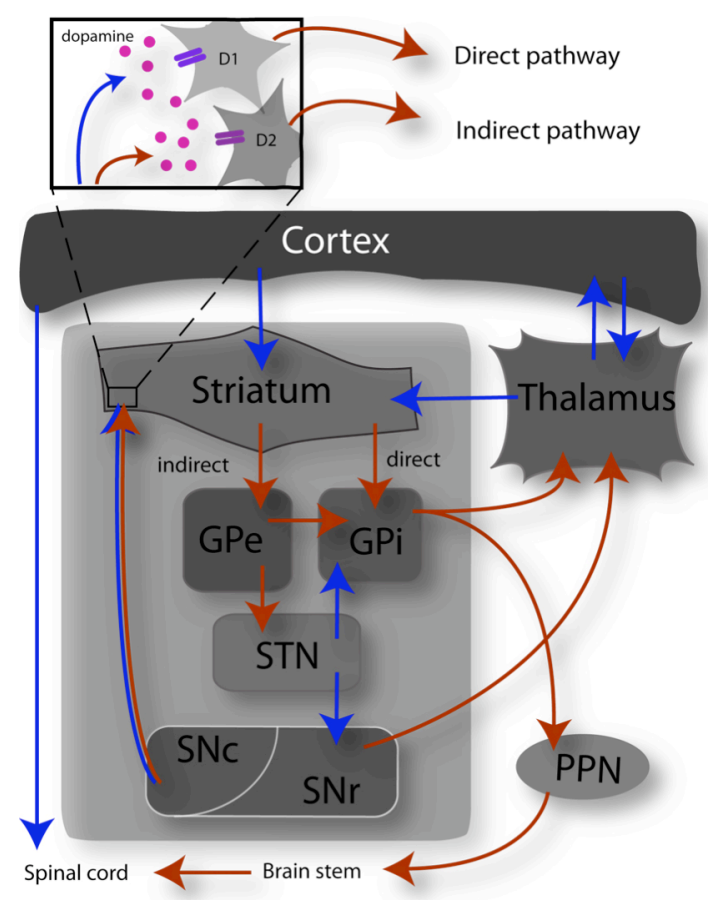

FIGURE 1 | Schematic representation of some basal ganglia nuclei and their connections. Two types of dopamine receptors (D1 and D2) are presented in different sets of outputs neurons in the striatum. The striatal neurons define what are known as direct and indirect pathways (referring to the way they reach the thalamus). Excitatory pathways are shown in blue, and inhibitory pathways in red. $\mathrm{GPe}=$ external segment of the globus pallidus; $\mathrm{GPi}=$ internal segment of the globus pallidus; STN=subthalamic nucleus; $\mathrm{SNc}=$ substansia nigra pars compacta; $\mathrm{SNr}=$ substansia nigra pars reticulata; $\mathrm{PPN}=$ pedunculopontine nucleus.

The striatum is the major recipient of inputs to the basal ganglia, coming principally from the prefrontal, motor and sensory cortex. The striatal inputs are strongly modulated by the dopaminergic neurons that reside in the SNc. This projection from the $\mathrm{SNc}$ into the striatum is known as the nigrostriatal track. It is topographically 
organized. The striatum contains mainly GABAergic neurons which project to the basal ganglia output nuclei via the so called direct and indirect pathways (Figure 1). In the classical view of basal ganglia function (DeLong, 1990) these two pathways are affected differently by the dopaminergic projection from the SNc: Neurons of the direct pathway express the D1 dopamine receptors and neurons of the indirect pathway express D2 dopamine receptors. There are however some studies that contradict this classical view (Bergman et al., 1990; Wang et al., 2006)..

The expression of motor behaviours depends very much on the basal ganglia loop, which is in turn strongly regulated by the $\mathrm{SNc}$ dopaminergic afferents. The human $\mathrm{SNc}$ contains approximately between 3 to $6 \times 10^{5}$ dopaminergic neurons (German and Manaye, 1993), which mainly project to the striatum. Each SNc neuron might have up to 150,000 presynaptic terminals in the striatum (Oorschot, 1996; Roberts et al., 2002). Additionally, the SNc neurons have a long apical dendrite extended ventrally into the subtantia nigra pars reticulata.

The $\mathrm{SNr}$ and the GPi are the main output structures of the basal ganglia. They are GABAergic and project principally to the ventro-lateral thalamus (VLo) and the pedunculopontine nucleus (PPN) (Figure 1).

\subsubsection{Parkinson's disease}

One of the most frequent movement disorders today in the world is Parkinson's disease (PD). It is named after James Parkinson who first described some of the symptoms in 1817. The cardinal symptoms in PD are muscular rigidity, tremor and akinesia. Depending on its cause, Parkinson's disease is principally divided into symptomatic, idiopathic and hereditary PD. Age is the most important risk factor to develop PD. 


\subsubsection{Epidemiology of Parkinson's disease}

Parkinson's disease is extensively spread. Reports indicate a prevalence of 250 cases per 100,000 (in the USA) and 1,700 cases per 100,000 (in China) in people older that 65 years (Zhang et al., 2005). An aged and gender adjusted incident rate of 13,4 per 100,000 was established by other group in the USA (Van Den Eeden et al., 2003). The incidence rapidly increases over the age of 60 years, with only $4 \%$ of the patients being under the age of 50 years. The rate for men was $91 \%$ higher than for women (Van Den Eeden et al., 2003). PD cases are reported at all ages, however is very uncommon in people under 40 . The average age at which the symptoms begin in the USA is 58-60 years (Fahn and Sulzer, 2004). PD is rare in young patients and often caused by an inherited or spontaneous genetic defect.

\subsubsection{Parkinson's disease clinical symptoms}

Normally, PD is diagnosed when the motor parkinsonism symptoms become explicit and dopamine agonists are found to reduce those symptoms. The clinical characteristics of PD are: slowing down movement (bradykinesia), akinesias or no movement, rigidity and tremor. Many spontaneous movements like arm swinging, blinking and swallowing are reduced or totally lost. Tremor will be maximal when the limb is at rest, and reduced with voluntary movement. Later during the disease there is a notorious failure in postural reflexes, impaired balance and general instability. Non-motor symptoms are also presents and some of them are: autonomic dysfunctions, apathy, depressions, sleep disorders, fatigue, pain and dementia.

\subsubsection{Etiology of Parkinson's disease}

For the vast majority of PD patients, the syndrome only correlates with age and there is no clear explanation yet of its etiology (idiopathic PD). Only in a minority of patients, PD is caused by genetic and/or environmental factors (hereditary and symptomatic $\mathrm{PD}$ respectively). 
Several gene loci have been implicated in autosomal dominant forms of PD including duplications or/and mutations in alpha-synuclein (Polymeropoulos et al., 1997) and in LRRK2 (Zimprich et al., 2004). Other gene loci have been found to cause autosomal recessive form of PD, such as the gene mutations in parkin (Kitada et al., 1998) and in DJ-1 (Bonifati et al., 2003). Both autosomal dominant and recessive forms of parkinsonism usually have an early onset as compared with the idiopathic PD.

There are also several environmental factors known to cause parkinsonian symptoms. Exposure to iron or manganese has been shown to generate reactive oxygen species and have been used to induce parkinsonism in laboratory animals (Jenner, 1998). Two important chemical examples are 1-methyl-4-phenyl-1,2,3,6tetra-hydropridine (MPTP) and the herbicide paraquat, which both concentrate in dopaminergic neurons and eventually will kill them (Langston et al., 1983; Javitch et al., 1985; McCormack et al., 2002). MPTP was found in poorly purified MPPP, an opioid analgesic drug. It is not used in clinical practice, but has been illegally manufactured for illicit drug use. In the early 80's Californian drug abusers were notoriously more affected with parkinsonian symptoms than the rest of the population, which led to the identification of MPTP. The MPTP metabolite MPP+ is selectively taken up by dopaminergic neurons through the dopamine transporter (DAT) (Langston et al., 1983; Javitch et al., 1985). MPP+ inhibits the mitochondrial respiratory chain, depleting the neuron from ATP. Because of its selective uptake this neurotoxin kills SNc neurons and causes a parkinsonian-like syndrome in humans and animals. It is today the best characterized animal model for PD.

With the intention to explain idiopathic causes of PD, it has also been suggested that dopamine can be oxidized and generate a toxic derivative, dopamine quinone. In this reactive form, dopamine quinone can covalently bind to cysteins forming 5cysteinidyl-dopamine (Fornstedt et al., 1986). Cystein residues are commonly located in active sites of enzymes and the covalent modification of them might lead 
to a general malfunction of the neuron. In this respect high expression levels of the dopamine transporter (DAT) have been suggested to increase the toxic load of SNc neurons by increasing cytosolic dopamine (Uhl, 1998; LaVoie and Hastings, 1999). These processes can occur gradually and naturally, which might up to some extent account for the late onset of the idiopathic form of PD.

\subsubsection{Pathophysiology of Parkinson's disease}

Post-mortem brains of PD patients showed a strong loss of dopaminergic neurons in the SNc. Humans need to loose between $50-70 \%$ of their SNc neurons to start evidencing parkinsonian symptoms (Zarow et al., 2003). The missing dopaminergic neurons in the SNc result in hyperactivity of STN (by less inhibition), which then excite excessively the inhibitory basal ganglia outputs GPi and $\mathrm{SNr}$ (Figure 2).

The STN hyperactivity inhibits in a disproportionate manner the thalamus and the PPN. The excessive inhibition of the thalamus caused by the loss or malfunction of the SNc neurons, leads to a reduced excitation of the cortical motor areas (Figure 2). The strong inhibition of the thalamocortical system is most probably associated with bradykinesia and akinesia, characteristic symptoms of PD. The strong inhibition of the pedunculopontine nucleus (PPN) may be associated with rigidity, but this model (DeLong, 1990)(Figure 2) cannot explain very well the typical parkinsonian tremor. 

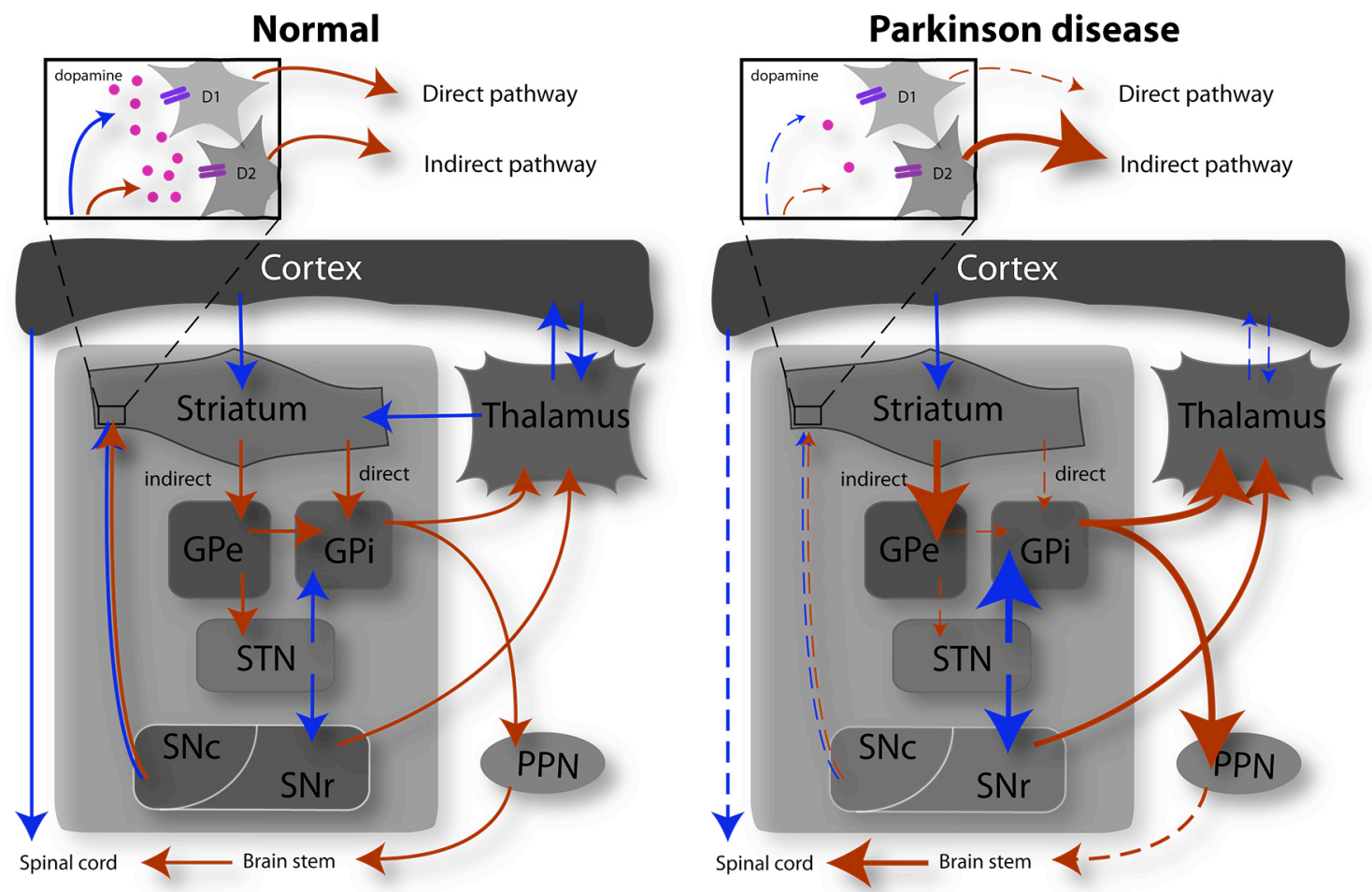

FIGURE 2 Schematic representation of the principal pathways affected by the loss of dopaminergic neurons in the Parkinson disease. Two types of dopamine receptors (D1 and D2) are presented in different sets of outputs neurons in the striatum. The striatal neurons output define what are known as direct and indirect pathways (referring to the way they reach the thalamus). Excitatory pathways are shown in blue, and inhibitory pathways in red. The dashed arrows represent an impaired projection and the sizes of the arrows suggest the strength of the signal. The excessive inhibition of the thalamus caused by the loss of SNc neurons result in a poor excitation of the motor areas in the cortex. $\mathrm{GPe}=$ external segment of the globus pallidus; $\mathrm{GPi}=$ internal segment of the globus pallidus; $\mathrm{STN}=$ subthalamic nucleus; $\mathrm{SNc}=$ substansia nigra pars compacta; $\mathrm{SNr}=$ substansia nigra pars reticulata; $\mathrm{PPN}=$ pedunculopontine nucleus.

\subsection{Dendritic release of dopamine in the $\mathrm{SN}$}

\subsubsection{Anatomy of substantia nigra pars reticulata}

The substantia nigra pars compacta consists of packed large dopaminergic neurons projecting to the striatum. Neurons in the adjacent pars reticulata $(\mathrm{SNr})$ are GABAergic and project mainly to the thalamus and the pedunculopontine nucleus (PPN) (Figure 1). The long apical dopaminergic dendrites of SNc extend mainly into the SNr. Many different afferents converge in the $\mathrm{SNr}$, since it is an output nucleus of the basal ganglia. The principal afferent fibers projected to the $\mathrm{SNr}$ originate from the striatum, the pallidum and from the STN. The STN is the only excitatory nucleus of the basal ganglia. 
Interestingly, dopamine is not only found at the $\mathrm{SNc}$ axon terminals in the striatum, but also in the SNr dopaminergic dendrites (Björklund and Lindvall, 1975). Even more, it has been shown that $\mathrm{SN}$ neurons can release dopamine from their dendrites in the $\mathrm{SNr}$ (Geffen et al., 1976). Accordingly, dendritic release of dopamine in the $\mathrm{SNr}$ has been observed by several groups (Geffen et al., 1976; Cheramy et al., 1981; Mintz et al., 1986; Rosales et al., 1994; Falkenburger et al., 2001).

Dopamine release in the $\mathrm{SNr}$ has been shown to be modulated by GABAergic afferents from the internal segment of the globus pallidus (Cobb and Abercrombie, 2003) and enhanced by stimulation of the glutamatergic subthalamic nucleus afferents (Mintz et al., 1986; Rosales et al., 1994; Falkenburger et al., 2001).

\subsubsection{Function of dopamine release in the $\mathrm{SNr}$}

It is one of the most striking findings that dopamine can alter the activity of $\mathrm{SNr}$ neurons, although there are no formal dopaminergic synapses in this area. Dopamine can modulate $\mathrm{SNr}$ neurons through presynaptic receptors on striatal, pallidal and subthalamic afferents (Ruffieux and Schultz, 1980; Martin and Waszczak, 1994; Trevitt et al., 2002; Ibañez-Sandoval et al., 2006; Windels and Kiyatkin, 2006). Moreover, dopaminergic neurons in the SN express dopamine inhibitory D2 autoreceptors.

Since the $\mathrm{SNr}$ constitutes one of the major output pathways from the basal ganglia, nigral dopamine and dopamine receptors have been shown to affect a variety of behaviours (Robertson and Robertson, 1989; Trevitt et al., 2001; Andersson et al., 2006).

\subsubsection{Mechanism of dendritic dopamine release in the $\mathrm{SNr}$}

Findings on the mechanism of dopamine release in the $\mathrm{SN}$ and on its calciumdependence are controversial. In slices, release from the somata of dopaminergic 
neurons located in the SNc have been reported to be quantal, sensitive to $\mathrm{Cd}^{+2}$ (Jaffe et al., 1998) and dependent on extracellular calcium (Rice et al., 1997). Similarly, somatodendritic release from cultured primary midbrain dopaminergic neurons was reduced (but present) in the absence of extracellular calcium and was sensitive to botoulinum toxin A and B (Fortin et al., 2006).

On the other hand, dendritic dopamine release in the $\mathrm{SNr}$ has been reported to be insensitive to $\mathrm{Cd}^{+2}$ (Hoffman and Gerhardt, 1999), insensitive to blockers of VGCC (Chen et al., 2006), present in the absence of extracellular calcium (Chen and Rice, 2001; Falkenburger et al., 2001) and sensitive to the dopamine transporter blocker GBR12935 (Falkenburger et al., 2001).

Taken together, these findings support the existence of exocytotic release from the somata of dopaminergic neurons in the $\mathrm{SNc}$ and of DAT-mediated release from the long apical dendrites of dopaminergic neurons in the SNr. These two types of nonaxonal release are consistent with the localization of the DAT, which can be found on dendritic but not on perikaryal plasma membranes (Nirenberg et al., 1996). Our further interest will focus in the properties of the DAT to mediate dopamine release in the $\mathrm{SNr}$.

\subsection{The dopamine transporter (DAT)}

\subsubsection{Catecholamine transporters}

The family of catecholamine transporters share a high identity in their amino acid sequence (Figure 3). The DAT belongs to the SCL6 family of $\mathrm{Na}^{+}$symporters, which also includes transporters for the biogenic amines serotonin and norepinephrine (SERT and NET respectively) as well as for the inhibitory transmitters GABA and glycin (Masson et al., 1999).

The dopamine transporter is an electrogenic, secondary active co-transporter of sodium, chloride and dopamine (Krueger, 1990; McElvain and Schenk, 1992; 
Corey et al., 1994; Gu et al., 1994). Sequence analysis suggested the presence of 12 trans-membrane domains for the DAT and its homologs (Edvardsen and Dahl, 1994). And indeed, the first high resolution $x$-ray structure of a prokaryotic leucine transporter $\left(\mathrm{Leu} \mathrm{T}_{\mathrm{Aa}}\right)$ homolog to the mammalian SCL6 family of transporters shows 12 trans-membrane domains (Yamashita et al., 2005). This has provoked considerable interests in the understanding of substrate binding, channel-like behaviour, non-competitive inhibition, topology and functional molecular mechanism of the mammalian neurotransmitter transporters.

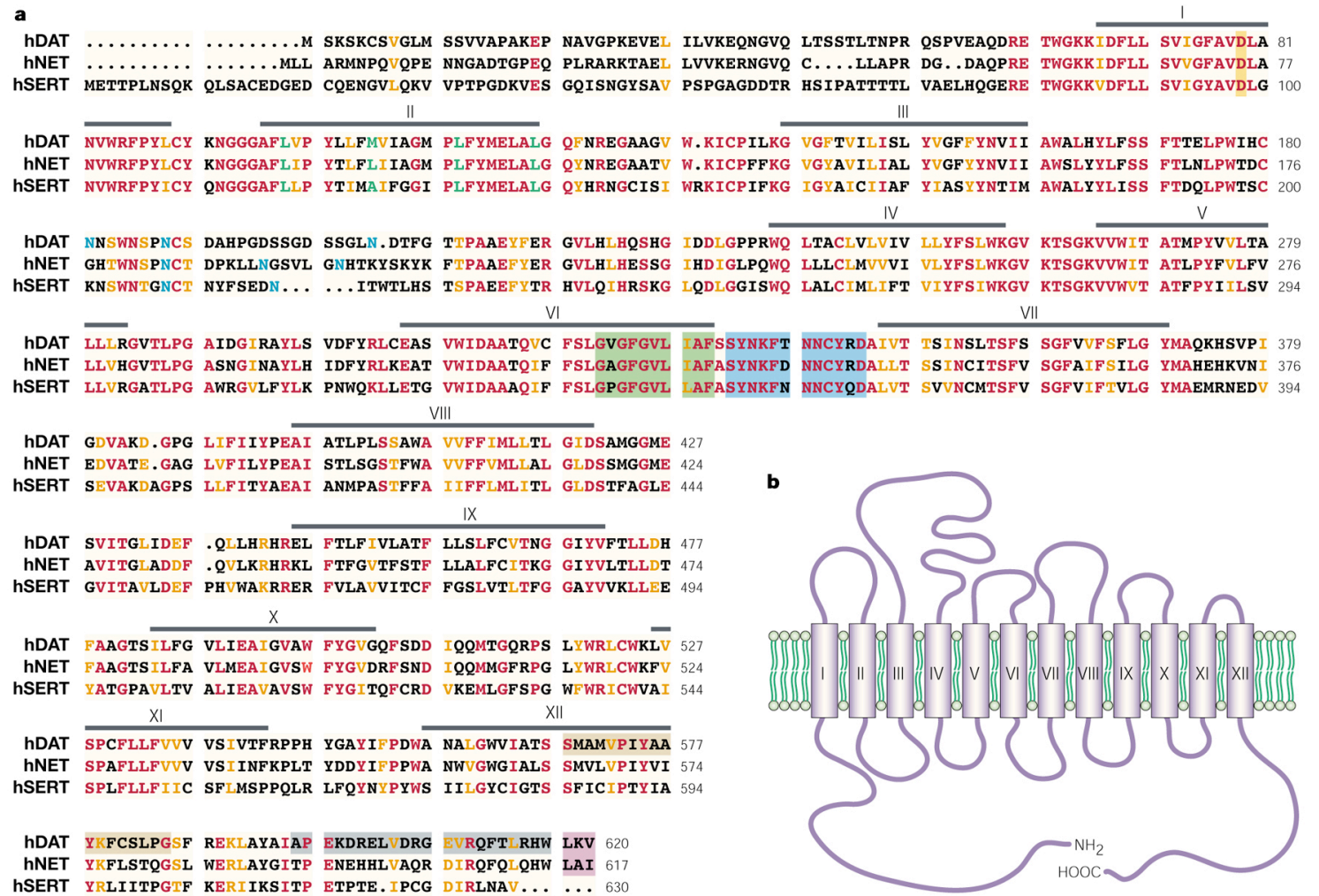

FIGURE 3 Amino acid sequence and topology of monoamine transporter proteins. A: Amino acid alignment of the human dopamine transporter, noradrenaline transporter and 5-HT transporter. Identical residues are shown in red, whereas similar residues $(\mathrm{V}, \mathrm{L}$, and $\mathrm{I}, \mathrm{K}$ and $\mathrm{R}, \mathrm{F}$ and $\mathrm{Y}$, or $\mathrm{D}$ and $\mathrm{E}$ ) are shown in orange. Asparagine residues that form part of N-linked glycosylation consensus sequences are shown in blue. A conserved aspartate residue in transmembrane domain 1 that is presumably involved in the interaction with monoamines is shown as a yellow box. A leucine-repeat in transmembrane domain 2, and a glycophorin-like motif in transmembrane domain 6 are shown in green. The intracellular loop between transmembrane domain 6 and 7 contains several residues involved in conformational changes during substrate binding and translocation is shown in blue. Black bars represent putative transmembrane domains. The colour boxes covering the parts of the intracellular carboxyl termini represent interacting sites with Hic-5 (beige), synuclein (grey), and PICK1 (purple). DAT, dopamine transporter; h, human; NET, noradrenaline transporter; SERT, 5-hydroxytryptamine transporter. B: Proposed topology of monoamine transporters depicting 12 transmembrane domains (Torres et al., 2003). 


\subsubsection{DAT localization}

The DAT can be considered a specific marker of dopaminergic neurons since it is exclusively expressed on them (Giros and Caron, 1993; Ciliax et al., 1995). In situ hybridization of human brains showed a prominent DAT expression principally in substantia nigra (SN) and ventral tegmental area (VTA) neurons (Hoffman et al., 1998). In mouse it can be also found in relatively big quantities in the nucleus accumbens, olfactory tubercle and nigrostriatal bundle (Freed et al., 1995). At cellular level, it has been described to be enriched on dendrites and axon terminals. (Nirenberg et al., 1996).

\subsubsection{The dopamine transporter's functional properties}

In general, the catecholamine transporters' classical function is the uptake of monoamines that have been released into the synaptic cleft, thus regulating the neurotransmitters concentration and time of action (Figure 4). One of the firsts hints of the uptake mechanism in catecholamine transporters was envisioned by the work of Krueger in 1990. Today we know that the DAT co-transports two ion of $\mathrm{Na}^{+}$and one of $\mathrm{Cl}^{-}$together with one molecule of dopamine (Krueger, 1990; Gu et al., 1994). The $\mathrm{Cl}^{-}$presence seems not to be critical for its dopamine uptake function. On the contrary the sodium gradient is the main necessary driving force. For this reason the existence of a well-defined $\mathrm{Na}^{+}$gradient is very important. It is normally sustained by the plasma membrane $\mathrm{Na}^{+} / \mathrm{K}^{+}$ATPase pump. 


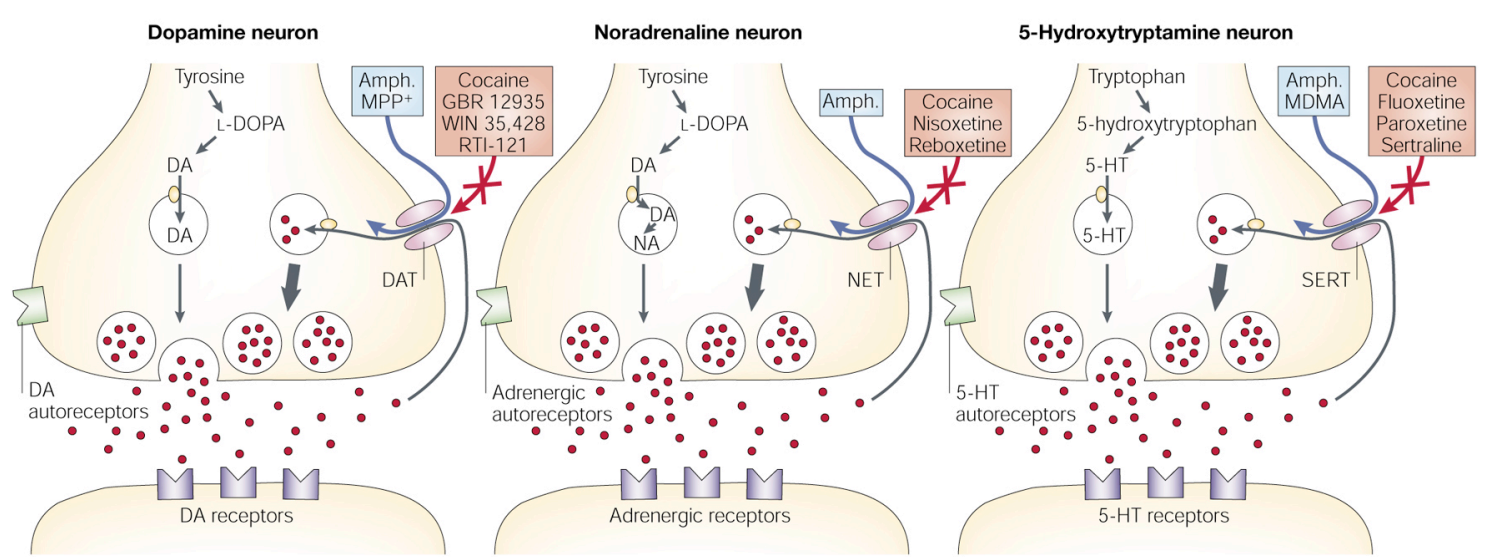

FIGURE 4 Schematic representations of dopamine, noradrenaline and 5-HT synaptic terminals. Monoamine transporters are localized in perisynaptic sites, where they are crucial for the termination of monoamine transmission and the maintenance of presynaptic monoamine storage. Several selective pharmacological agents acting at each monoamine transporter are shown. Amph., amphetamine; DA, dopamine; DAT, Dopamine transporter; L-DOPA, L-3,4dihydroxyphenylalanine; 5-HT, 5-hydroxytryptamine; MPP+, 1-methyl-4-phenylpyridinium; MDMA, (+)-3,4 methylenedioxymethamphetamine; NA, noradrenaline; NET, noradrenaline transporter; SERT, 5-HT transporter. Figure and legend taken entirely from Torres et al. 2003 (Torres et al., 2003)..

In addition to the DAT's classical function, the DAT has been shown to release dopamine. However, the DAT's property of releasing dopamine has not been investigated as thoroughly and mainly as an effect of amphetamine and its derivatives (Heikkila et al., 1975; Melega et al., 1995; Sonders and Amara, 1996), which are among the most widely abused psychostimulants. The mechanism of amphetamine-induced dopamine efflux, has been attributed to a variety of different factors, making this a field of study by it self (Sulzer et al., 2005). In the next section we will review some of the mechanism proposed for amphetamine-stimulated dopamine release.

\subsubsection{Amphetamine-induced dopamine release}

It took several years to differentiate compounds that block the dopamine uptake from the ones that induced a DAT-mediated dopamine release. Cocaine was related to blocking catecholamine transporters in 1960 (Whitby et al., 1960), but it was only in 1997 when Sonders et al. could convincingly differentiate between blocking uptake and inducing release of dopamine. They recorded transport- 
associated ion currents. Since then, amphetamine is believed to be a dopamine transporter substrate and to induce dopamine efflux. However amphetamine's mechanism of action is still not entirely understood. There are at least four hypotheses and one emerging new possibility of how amphetamine may induces the reverse transport.

\subsubsection{Facilitated exchange diffusion theory}

In 1973 Paton (inspired by a work done in glucose transport) described a possible mechanism known as "facilitated exchange diffusion" (Paton, 1973). When amphetamine is transported into the cell through the DAT, then dopamine, which is in higher concentration intracellularly, interacts with the cytosolic binding site of the DAT. When the DAT moves back to its "natural" position (with the binding site facing the extracellular space) it transports the dopamine outside the cell. This would mean that for each molecule of amphetamine that is taken up one molecule of dopamine is released. However, this latter consequence for this model has been difficult to conciliate with many recent studies.

\subsubsection{The weak base hypothesis}

This hypothesis takes into account the chemical properties of amphetamine. Amphetamine is a week base and can freely diffuse through membranes. The vesicular monoamine transporter (VMAT) uses the vesicle $\mathrm{pH}$ gradient to concentrate catecholamines in the vesicle lumen. An alkalinization of the vesicles by the amphetamine base properties was proposed. This would disrupt the $\mathrm{pH}$ gradient and induce the monoamines to move into the cytosol increasing their concentration by several folds (Sulzer and Rayport, 1990). Unfortunately there are some effects that cannot be explained by this model. For example, $3 \mu \mathrm{M}$ amphetamine induced release of $70 \%$ of the previously accumulated dopamine, but it only collapsed the proton gradient by $12 \%$ (Floor and Meng, 1996). This means 
that amphetamine has an effect in vesicular dopamine, but cannot explain the strong release observed.

\subsubsection{Increase of intracellular sodium}

This hypothesis was proposed in 2003 when it was shown using sodium sensitive dyes that the uptake of amphetamine by the DAT leads to a change in cytosolic sodium concentrations. Accordingly the authors showed that amphetamine-induced dopamine efflux was voltage-dependent, electrogenic, and dependent on intracellular $\mathrm{Na}^{+}$concentration in the recording electrode (Khoshbouei et al., 2003). The DAT dopamine uptake is primarily sodium dependent (Krueger, 1990; McElvain and Schenk, 1992; Gu et al., 1994). The maintenance of the sodium gradient, keeps the cytosolic dopamine concentration high. Therefore a loss or reduction of the cellular sodium gradient will result in dopamine efflux. Consistently, dopamine release has been induced by opening sodium channels with veratridine (Elverfors et al., 1997).

\subsubsection{Transient channel-like mode of the DAT}

The next hypothesis is known as the "channel-like mode". Transport-associated ion currents were shown before, but in 1998 Galli and co-workers demonstrated a channel-like opening of the norepinephrine transporter (NET) by combining patch clamp with amperometric recordings (Galli et al., 1998). Recently, using outside-out patches Kahlig et al. (2005) showed that the DAT could perform milliseconds burst of dopamine release in a channel-like behaviour during amphetamine stimulation (Kahlig et al., 2005), 


\subsubsection{Role of DAT phosphorylation}

A new hypothesis is emerging from recent evidences. They suggest that DAT phosphorylation might play a role in reversal of the transport direction. The mutation of 5 serines at the DAT $\mathrm{N}$-terminal abolished amphetamine-induced dopamine efflux (Khoshbouei et al., 2004). It was also suggested that the phosphorylation would shift the DAT from a "reluctant" to a "willing" state that would favour amphetamine-induced dopamine release (Khoshbouei et al., 2004). Furthermore amphetamine-induced dopamine release was inhibited by downregulation or inhibition of protein kinase C (PKC) (Kantor and Gnegy, 1998) and by inhibition of CaMKII (Fog et al., 2006).

Since the $\mathrm{Na}^{+}$and $\mathrm{Cl}^{-}$electrochemical gradients energy drive the DAT monoamine translocation, it would be very interesting to understand how DAT phosphorylation would make dopamine release energetically favourable.

\subsubsection{Glutamate-induced DAT reversal}

Even though the exact mechanism is not entirely resolved, it is important to note that amphetamine revealed the capacity of the DAT to transport in reverse mode, mediating an efflux of dopamine. The field of amphetamine-induced dopamine release now meets with evidences that the DAT can physiologically (without amphetamine) induce DAT-mediated dopamine release. It has been shown that the activation of glutamatergic subthalamic afferent induces a dopamine release into the $\mathrm{SNr}$, which is sensitive to the DAT blocker GBR12935 and independent of extracellular calcium. In addition Falkenburger et al. (2001) have demonstrated that ionotropic glutamate receptors are not necessary for DAT-mediated dopamine efflux, suggesting that the physiological activation of metabotropic glutamate receptor could be sufficient to induce the reversal of the DAT (Falkenburger et al., 2001). The main metabotropic glutamate receptors (mGluRs) found in $\mathrm{SNr}$ were mGluR from the group I (Testa et al., 1994). Group I mGluR characteristics is to 
release intracellular calcium and activates $P K C$ through $G_{q}$ or $G_{q / 11}$ protein. This is interesting, since amphetamine has been recently showed to need PKC activation and DAT phosphorylation to induce DAT-mediated dopamine efflux.

\subsubsection{Role of the DAT in Parkinson's disease}

As we described previously (section 1.1.3.3.), the DAT takes up several neurotoxins selectively into dopaminergic neurons, this might be the responsible for some environmental or symptomatic PD. Some examples of identified compounds are MPTP (widely used for PD animal model)(Langston et al., 1983), paraquat (herbicide)(McCormack et al., 2002), rotenone (insecticide) (Gao et al., 2002), maneb (fungiside) (Thiruchelvam et al., 2000) and other compounds.

Additionally, today the DAT provides an important tool to observe dopaminergic terminal in living subjects, by using single photon emission computed tomography (SPECT) or positron emission tomography (PET). This property has improved the diagnosis of $\mathrm{PD}$.

Even though the DAT is one of the most important elements in the regulation of extracellular dopamine en the striatum, its relevance in Parkinson's has not been entirely elucidated. Moreover, the new findings of DAT-mediated dopamine release in the $\mathrm{SNr}$ imply that the DAT properties might affect animal behaivior by mediating dopamine efflux in the basal ganglia output $\mathrm{SNr}$ (Bergquist et al., 2003; Andersson et al., 2006).

\subsubsection{Role of the DAT in drugs of abuse}

Several natural and synthetic compounds are known to block or act as substrate of the catecholamine transporters (Figure 4). Some of them like fluoxetine (Prozac) are used to treat depressions and methylphenidate (Ritalin) is used to treat attentiondeficit hyperactive disorders, others like cocaine are illegally abused 
psychostimulants.

The relation of the DAT with several drugs of abuse has been in fact the main interest of its investigation. Cocaine blocks the DAT and increases the concentration of dopamine in the synapses over time whereas amphetamine in addition induces dopamine release through the DAT (Figure 4). Although both of them act relatively unselective among the cathecolamine transporters, it seems to that their behavioural and reinforcement effect depend mainly on their interaction with the DAT (Wise, 1996). Another illegal drug is 3,4-methylenedioxy-N-methylamphetamine or MDMA (Ecstasy). It is an amphetamine derivative and similarly it also induces reverse transport, but in this case with a higher affinity to the SERT (Rudnick and Wall, 1992). 


\subsection{Aims of this study}

The aim of this study was to investigate the signalling which mediates the glutamate-induced reversal of dopamine transport in the $\mathrm{SNr}$.

In the light of previous observations, we are exploring the possibility that glutamateinduced dopamine efflux in the $\mathrm{SNr}$ could be mediated by the metabotropic glutamate receptors (mGluRs). Since both glutamate and amphetamine are able to induce reversal of dopamine transport (Sonders et al., 1997; Falkenburger et al., 2001), we tested to which degree the mechanisms used by glutamate and amphetamine were similar or different from one another.

We are exploring the possibility that the activation of a second messenger signalling cascade induces DAT-mediated dopamine release (Figure 5). This possibility is intriguing, since it might not only explain the mechanism of glutamate-induced dopamine release in the $\mathrm{SNr}$ but also could demonstrate that amphetamine uses a physiological signalling cascade to have its effect.

To achieve this end, we used amperometric recordings in brain slices, measurements of dopamine efflux from cell lines engineered to express WT and mutated DAT, a new imaging approach to visualize dopamine uptake and release, and in a collaboration with Lucian Medrihan, patch-clamp recordings of dopaminergic neurons.

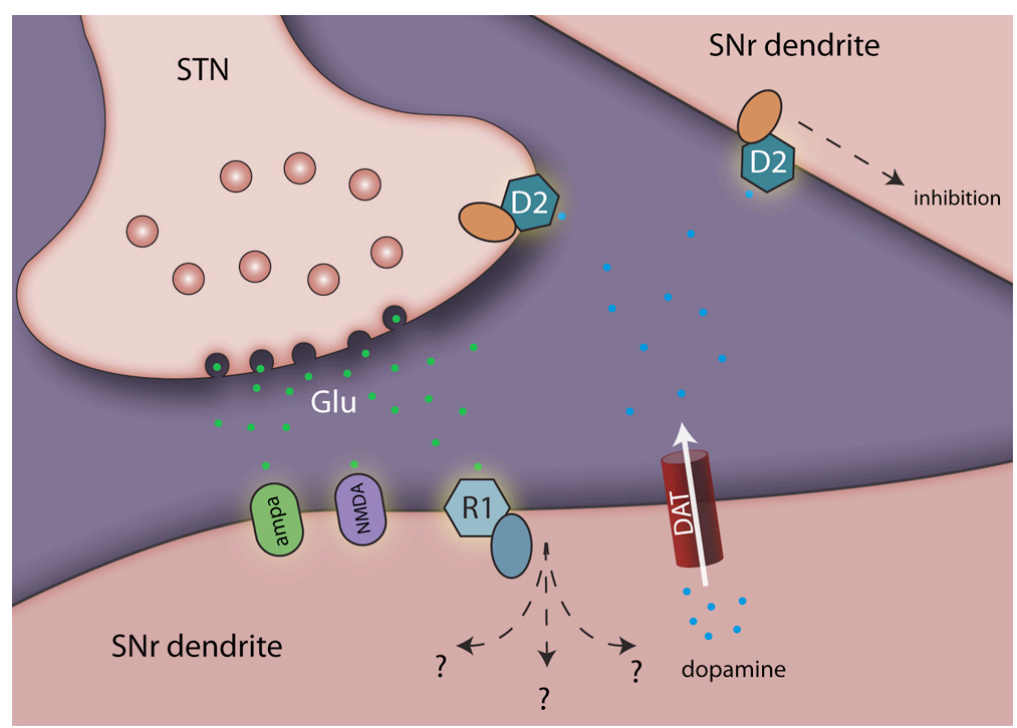

FIGURE 5 The cartoon represents some elements in the $\mathrm{SNr}$ synapsis. It was shown that inhibition of AMPA and NMDA glutamate receptors did not abolish DAT-mediated dopamine release in the SNr. Whether the mGluR group I is the responsible for reversal of the DAT remains unclarified. Dopamine release could activate D2 dopamine receptors in $\mathrm{SNr}$, modulating several neighbours' neurons. 


\section{MATERIALS \& METHODS}

\subsection{Materials}

All Chemicals were obtained from Sigma-Aldrich unless otherwise stated.

\subsection{Brain slices:}

Acute parasaggital rat brain slices were prepared as described previously (Falkenburger et al., 2001). Wistar rats, 10-16 days old, were decapitated and $350 \mu \mathrm{m}$ thick parasaggital slices of substantia nigra cut on a VT1000 vibratome (Leica) in ice cold artificial cerebro-spinal fluid (ACSF) containing: $\mathrm{NaCl} 125 \mathrm{mM}$, $\mathrm{KCl} 2.5 \mathrm{mM}, \mathrm{CaCl}_{2} 2 \mathrm{mM}, \mathrm{MgCl}_{2} 1 \mathrm{mM}, \mathrm{NaHCO}_{2} 26 \mathrm{mM}, \mathrm{Na}_{3} \mathrm{PO}_{4} 1.25 \mathrm{mM}$, glucose $25 \mathrm{mM}$, equilibrated with $95 \% \mathrm{O}_{2}$ and $5 \% \mathrm{CO}_{2}$ resulting in $\mathrm{pH}=7.4$.

\subsection{Amperometry}

Amperometry was performed as previously described (Falkenburger et al., 2001). Currents were recorded at $800 \mathrm{mV}$ using a carbon fiber (SF1A, $30 \mu \mathrm{m}$ diameter, Center for Sensor Technology) and an Axopatch 200B amplifier (Axon Instruments). The carbon fiber was inserted $200-300 \mu \mathrm{m}$ into a substantia nigra slice constantly superfused with calcium-free ACSF, for which $2 \mathrm{mM} \mathrm{CaCl} \mathrm{Cl}_{2}$ was replaced by $2 \mathrm{mM} \mathrm{MgCl} 2$ and $1 \mathrm{mM}$ EGTA (RT, $1 \mathrm{ml} / \mathrm{h}$ ). Glutamate $(1 \mathrm{mM}$ in $0.9 \% \mathrm{NaCl})$, PMA (10 $\mu \mathrm{M}$ in $0.9 \% \mathrm{NaCl}$; stock was $100 \mathrm{mM}$ in DMSO; Tocris, Bristol; UK), trans-ACPD ( $1 \mu \mathrm{M}$ in $0.9 \% \mathrm{NaCl}$; Tocris) were applied at a constant distance to the carbon fiber using a patch pipette and a pressure pulse $(20 \mathrm{psi}, 10 \mathrm{~s}$, Picospritzer). Currents were digitized using a Digidata interface, recorded by pCLAMP 9 (Axon Instruments). IGOR-Pro (WaveMetrics, Oregon, USA) was used for data visualization. Glutamate, PMA and trans-ACPD were applied every 
30 minutes. Antagonists were bath-applied: GBR12935 (20 $\mu \mathrm{M}$ in ACSF) and chelerythrine (10 $\mu \mathrm{M}$ in ACSF).

\subsection{Molecular biology and Cell culture}

To generate cell lines that stably express DAT, the cDNA of the human dopamine transporter (hDAT1, obtained from Ulrik Gether, Department of Pharmacology, University of Copenhagen; Denmark) was subcloned into the pcDNA3.1(+) vector (Invitrogen, Karlsruhe, Germany) using HindIII and XbaI restriction enzymes (Fermentas, St. Leon-Rot, Germany) and the sequence verified. The N-terminal truncation was achieved by using the site directed mutagenesis kit (Stratagene). The primers Fw: CCGTGGAAGCTTCGGC TATGGAGCCCAATGCCG and Rv: CGGCATTGGGCTCCATAGCCG AAGCTTCCACGG, generated a new HindIII restriction site at position 16 (A16) and a starting metionine codon replaced the K19M. Mutated DNA was then digested overnight with HindIII and gel purified (QIAquick Gel Extraction kit, Quiagen). Digested DNA followed an overnight re-ligation with T4 DNA ligase (fermentas). Finally sequence was verified.

SH-SY5Y cells were transfected using nucleofection (amaxa AG, Cologne, Germany), following the manufacturer's instructions. Cells were cultured in Dulbecco's MEM (PAN-Biotech, Aidenbach, Germany) with 15\% fetal calf serum and $1 \%$ penicillin-streptomycin. $24 \mathrm{~h}$ after nucleofection, the medium was supplemented with $1 \mathrm{mg} / \mathrm{ml}$ of G418 (Biochrom AG, Berlin, Germany). Medium with $1 \mathrm{mg} / \mathrm{ml}$ of G418 was exchanged every second day to keep the selection pressure. 


\subsection{Measuring dopamine uptake and release by HPLC}

100x103 DAT-expressing SH-SY5Y cells per well were seeded 12 well plates (Corning). After $24 \mathrm{~h}$ the medium was exchanged with a modified ringer buffer (RB), containing $25 \mathrm{mM}$ HEPES; $120 \mathrm{mM} \mathrm{NaCl} ; 5 \mathrm{mM} \mathrm{KCl} ; 2.5 \mathrm{mM} \mathrm{CaCl} ; 1.2$ $\mathrm{mM} \mathrm{MgSO}$; $2 \mathrm{mg} / \mathrm{ml}$ glucose; $0.2 \mathrm{mg} / \mathrm{ml}$ ascorbic acid and $1 \mu \mathrm{M}$ pargyline $(\mathrm{pH}$ 7.4). For dopamine uptake, RB was supplemented with $15 \mu \mathrm{M}$ DA. After $1 \mathrm{~h}$ incubation at $37^{\circ} \mathrm{C}$ cells were placed on ice. The $\mathrm{RB}$ was removed and cells were washed twice with ice-cold dopamine-free RB. Then $200 \mu 1$ of room temperature $\mathrm{RB}$ containing the drugs or vehicle (control) were added per each well. After 5 min at $37^{\circ} \mathrm{C}, 180 \mu \mathrm{l}$ per well of (extracellular) ringer buffer were transferred to vials containing $20 \mu \mathrm{l}$ of $1 \mathrm{M}$ perchloric acid. The remaining buffer in the well was aspirated and cells were washed once with ice-cold RB free of dopamine. Cells were lysed by addition of $200 \mu \mathrm{l}$ of $3 \%$ trichloroacetic acid. After 10 minutes at room temperature $180 \mu 1$ per well of cell lysate were transfered to vials containing $20 \mu \mathrm{l}$ of $1 \mathrm{M}$ perchloric acid. All vials were centrifuged (5 minutes, $1000 \mathrm{~g}, 4^{\circ} \mathrm{C}$ ) and $20 \mu \mathrm{l}$ of supernatant loaded onto a reverse-phase column (prontosil 120-3-C18, Bischoff, Leonberg, Germany). Dopamine was detected electrochemically using an ESA Coulochem II detector with a 5011A analytical cell $(400 \mathrm{mV})$ as described previously (Kowsky et al., 2007). Each litter of the mobile phase contained $105 \mathrm{ml}$ methanol (MERK) $6.973 \mathrm{~g}$ of sodium acetate; $0.048 \mathrm{~g}$ of EDTA; $7.355 \mathrm{~g}$ of citric acid mono hydrated; $0.105 \mathrm{~g}$ octane sulfonate. $\mathrm{pH} 4.3$ was reached using concentrated citric acid. For each run, standards of $0.15 \mu \mathrm{M}, 0.3 \mu \mathrm{M}$ and $1.5 \mu \mathrm{M}$ of dopamine were measured at the beginning in the middle and at the end of the samples sequence. 


\section{6. $\mathrm{ASP}^{+}$imaging}

Custom-build imaging dishes were used for imaging, consisting of $3 \mathrm{~cm}$ diameter petridishes with a central $20 \mathrm{~mm}$ hole, to which a $25 \mathrm{~mm}$ coverslip was attached using Sylgard 184 (World precision Instrument Inc.). Chambers were sterilized by UV light. 150x10 ${ }^{3}$ DAT-expressing SH-SY5Y cells per dish were seeded and used $24 \mathrm{~h}$ later. Cells were washed with room temperature $\mathrm{RB}$ and superfused with $\mathrm{RB}$ alone, $\mathrm{RB}$ with $10 \mu \mathrm{M} \mathrm{ASP}+$ and $30 \mu \mathrm{M}$ trypan blue or $\mathrm{RB}$ with $10 \mu \mathrm{M} \mathrm{ASP}+, 30$ $\mu \mathrm{M}$ trypan blue and $50 \mu \mathrm{M}$ carbachol or $50 \mu \mathrm{M}$ amphetamine. Basic protocol while acquiring images was: the firs 30 s was only RB, 2 minutes of $10 \mu \mathrm{M}$ ASP $+30 \mu \mathrm{M}$ trypan and then 5 minutes of RB. Followed by 1 minute of $10 \mu \mathrm{M}$ ASP $+30 \mu \mathrm{M}$ trypan and 1 minute of $10 \mu \mathrm{M}$ ASP $+30 \mu \mathrm{M}$ trypan + the Drug (Carbachol or Amphetamine) and then 5 minutes of RB. Then 2 minutes of $10 \mu \mathrm{M}$ ASP $+30 \mu \mathrm{M}$ trypan and then 5 minutes of RB. Images of $512 \times 512$ pixels were acquired every $3 \mathrm{~s}$ using a Zeiss LSM510 confocal microscope. Excitation was done with a $488 \mathrm{~nm}$ argon laser and emission was detected after the LP560 nm long pass filter. Image analysis was done using ImageJ 10.2 software and IGOR-Pro.

\subsection{Calcium imaging}

Cells were cultured in the same custom-build imaging dishes as explained above. They were washed once and incubated for 30 minutes in RB supplemented with 50 $\mu$ M Fluo-4 AM (Molecular Probes, Leiden, The Netherlands). Fluo4 AM stock solution was dissolved in DMSO and Pluronic acid F-127 (Molecular Probes). The final concentrations of DMSO and Pluronic F-127 did not exceed 0.5\% and 0.1\%, respectively. After the 30 minutes incubation cells were washed twice with RB and mounted for imaging them. Calcium was monitored using a Leica DM6000 epifluorescence microscope. One Image every 3 seconds was acquired using the AF Leica software. Image analysis was done using ImageJ and IGOR-Pro software. 


\subsection{Electrophysiological Recordings}

Whole cell patch clamp recordings were performed in pars compacta dopaminergic neurons from acute slices from 12-16 days old Wistar rats. The bath solution in all experiments consisted of ACSF. The pipette solution for all experiments contained: $140 \mathrm{mM} \mathrm{KCl}, 1 \mathrm{mM} \mathrm{CaCl}$, $10 \mathrm{mM}$ EGTA, $2 \mathrm{mM} \mathrm{MgCl}$, 4 mM Na 3 ATP, 0.5 $\mathrm{mM} \mathrm{Na} \mathrm{N}_{3} \mathrm{GTP}, 10 \mathrm{mM}$ HEPES $\mathrm{pH}$ 7.3. Spontaneous excitatory PSCs (sEPSCs) were recorded in the presence of $1 \mu \mathrm{M}$ bicuculine. After stable recordings of 3 minutes, GBR12935 $(20 \mu \mathrm{M})$ and sulpiride $(10 \mu \mathrm{M})$ were subsequently added in the bath. Signals with amplitudes of at least 2 times above the background noise were selected. Patches with a serial resistance of $>20 \mathrm{M} \Omega$, a membrane resistance of $<0.2 \mathrm{G} \Omega$, or leak currents of $>300 \mathrm{pA}$ were excluded. The membrane currents were filtered by a four-pole Bessel filter at a corner frequency of $2 \mathrm{kHz}$, and digitized at a sampling rate of $5 \mathrm{kHz}$ using the DigiData 1322A interface (Molecular Devices, Sunnyvale, CA). Statistical analysis was performed with a two-tailed paired $t$ test. Data acquisition and analysis was done using commercially available software: pClamp 9.2 (Molecular Devices, Sunnyvale, CA), MiniAnalysis (SynaptoSoft, Decatur, GA) and Prism 4 (GraphPad Software, San Diego, CA). 


\section{RESULTS}

\subsection{Glutamate-induced release of dopamine requires DAT and PKC}

We used amperometry to directly measure extracellular levels of dopamine in rat brain slices, specifically in the SNr. To exclude the possibility of dopamine being released by exocytotic events, we kept the slice under continuous flow of artificial cerebro-spinal fluid (ACSF) containing no calcium, $1 \mathrm{mM}$ EGTA and $3 \mathrm{mM}$ magnesium. Local puff application of glutamate evoked a reproducible increase of oxidative current detected by the carbon fiber held at $800 \mathrm{mV}$. This current represents the oxidation of the released dopamine (Figure 6). Glutamate puff application was repeated every 30 minutes, without moving the puff pipette or the carbon fiber. Application of $20 \mu \mathrm{M}$ of the DAT antagonist GBR12935 in the superfusing ACSF resulted in a significant reduction of the glutamate-induced dopamine release (block: $83.2 \pm 14.8 \%, \mathrm{n}=5$ ).
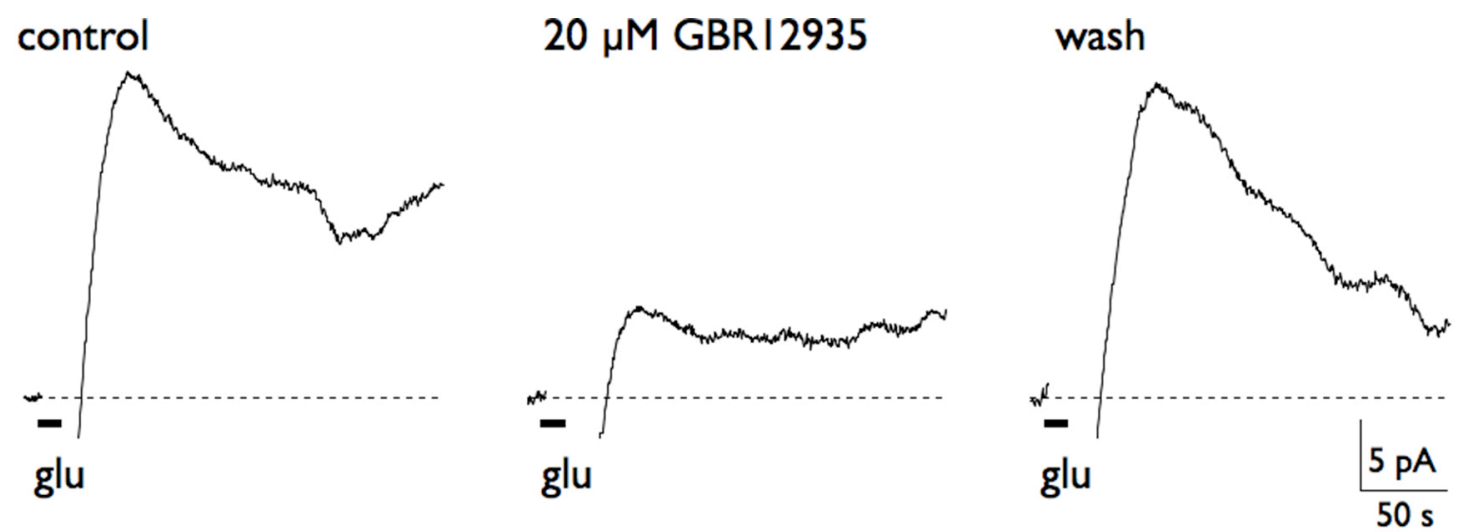

FIGURE 6 | Glutamate induced dopamine release in brain slices. Representative traces of dopamine oxidative currents are shown. Puff locally applied with $1 \mathrm{mM}$ of glutamate, triggered a strong dopamine release (control). After $1 \mathrm{~h}$ of superfusing with $20 \mu \mathrm{M}$ of the DAT antagonist GBR12935, glutamate induced dopamine release is significantly blocked. After $1 \mathrm{~h}$ of washing in control ACFS, glutamate induced dopamine releases showed complete recovery as in the initial control condition (wash). Carbon fiber and the puff application pipettes were positioned in the $\mathrm{SNr}$ and kept there throughout the whole experiment. Carbon fiber was held constantly at $800 \mathrm{mV}$ for dopamine oxidation. Glutamate puff duration was of 10 seconds at 20 psi. All buffers and solutions were calcium free. The dashed horizontal line represents the baseline current. 
If dopamine would go out of the cell by other mechanisms than by reversal of the DAT, extracellular dopamine levels would have been increased by blocking its uptake with GBR12935. Since we observed a decrease of dopamine release with GBR12935, we concluded that dopamine had been released through the DAT. To rule out that the decrease in amplitude after bathing with GBR12935 had resulted from a rundown of the signal, we washed out the inhibitor and dopamine release was fully recovered (Figure 6).

Falkenburger et al. (2001) had shown that glutamate induced dopamine efflux in the $\mathrm{SNr}$ was insensitive to the inhibition of ionotropic glutamate receptors (NMDA and AMPA). Their results suggested but did not prove that metabotropic glutamate receptors (mGluRs) are playing an important role in the reversal of the DAT. In addition, Kosinski in 1998 and Testa in 1994 have shown that mGluR1, a member of the group I mGluRs, is the most abundantly expressed mGluR in dopaminergic neurons. Taking this into account, we decided to apply the selective group I mGluR agonist trans-ACPD locally. The dopamine release triggered by the application of trans-ACPD was not only reproducible but was also reversibly blocked by GBR12935 (block: $70.7 \pm 14.5 \%$, n=3) (Figure 7).
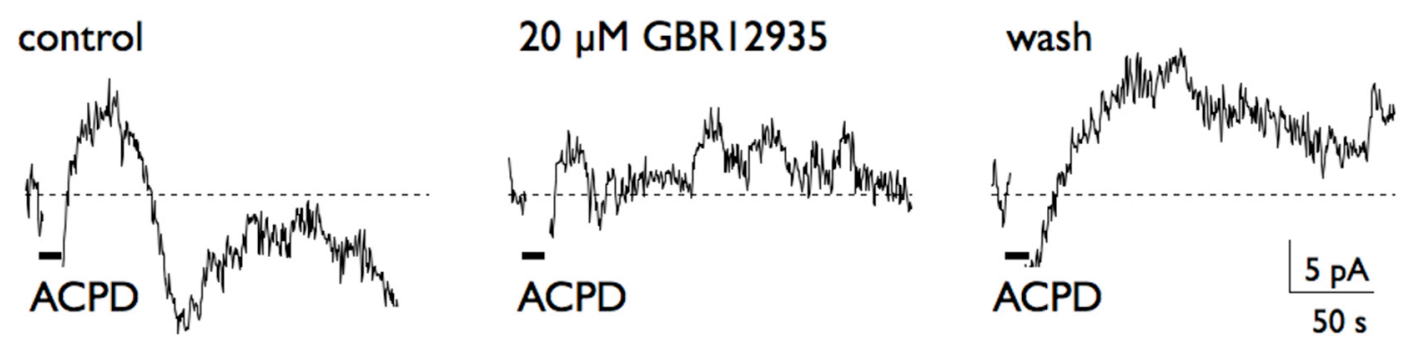

FIGURE 7 | Trans-ACPD induced dopamine release in brain slices. Representative current traces of recorded dopamine oxidative currents. A: Puff locally applied with $1 \mathrm{mM}$ of trans-ACPD, triggered dopamine release (control). After $1 \mathrm{~h}$ of superfusing with $20 \mu \mathrm{M}$ GBR12935, trans-ACPD induced dopamine release is blocked. Finally after $1 \mathrm{~h}$ of washing, trans-ACPD induced dopamine release shows recovery as in control condition (wash). Carbon fiber and the puff application pipettes were positioned in the $\mathrm{SNr}$ and kept there throughout the whole experiment. Carbon fiber was hold constantly at $800 \mathrm{mV}$ for dopamine oxidation. Puff duration was of 10 seconds at 20 psi. All buffers and solutions were calcium free. The dashed horizontal line represents the baseline current. 
Activation of the group I metabotropic glutamate receptors appears to be sufficient to induce dopamine efflux through the DAT in the $\mathrm{SNr}$ of rat brain slices. Although trans-ACPD induced a significant and reproducible dopamine release, the amplitude of the signal was not comparable to the one induced by glutamate, which means that trans-ACPD is less potent or less effective than glutamate in inducing dopamine release. Trans-ACPD has been reported to be 10 folds less potent than glutamate in activating metabotropic receptors (Sayer et al., 1992; Pin and Bockaert, 1995).

The mGluRs are pharmacologically classified into groups (I, II and III). Group I consists of mGluR1 and mGluR5, both are associated with the $G_{q}$ signalling cascade, which activates phospholipase C (PLC), cleaves phosphatidylinositol bisphosphate $\left(\mathrm{PIP}_{2}\right)$ producing dyacylglycerol $(\mathrm{DAG})$ and inositol triphosphate (IP3). IP3 then induces the release of calcium from internal stores; $\mathrm{Ca}^{+2}$ binds to the $\mathrm{C} 2$ domain of the conventional and novel PKC isoforms and induces its migration to the plasma membrane. Once recruited there, it interacts with DAG, which makes PKC ready to phosphorylate its substrate (Newton, 2003)

Since dopamine release can be triggered by the activation of a metabotropic glutamate receptor, it makes sense to explore the role of $\mathrm{PKC}$ for the reversal of the DAT. Therefore we first applied locally in the SN slice the phorbol ester PMA, a PKC activator. The strong release induced by PMA (Figure 8A) was comparable to the dopamine released by glutamate and, similarly, it was reversibly inhibited by GBR12935 (block: $93.7 \pm 7.5 \%, n=6$ ). This showed that PKC activator PMA was sufficient to trigger a strong DAT-mediated dopamine release.

To further test the responsibility of PKC in the reversal of the DAT, we examined whether PKC was necessary for the glutamate-induced dopamine release. And we found that the glutamate-induced release was reversibly inhibited by the selective PKC antagonist chelerythrine (block: $82.3 \pm 20.1 \%, n=6$ ) (Figure $8 B$ ). 
A

control

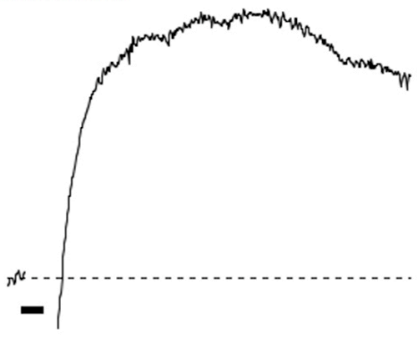

PMA

B
PMA

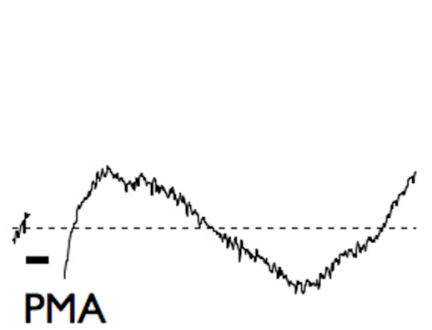

$20 \mu M$ GBR I 2935

I0 $\mu \mathrm{M}$ chelerythrine

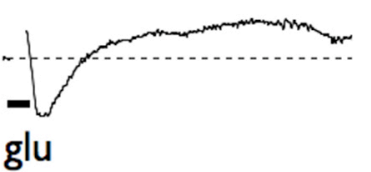

wash

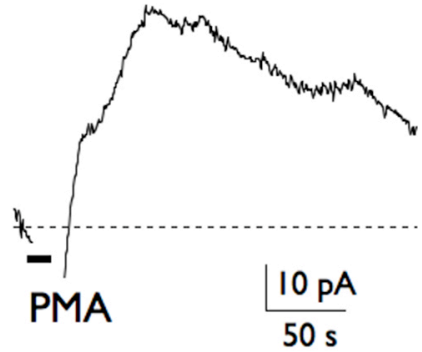

control

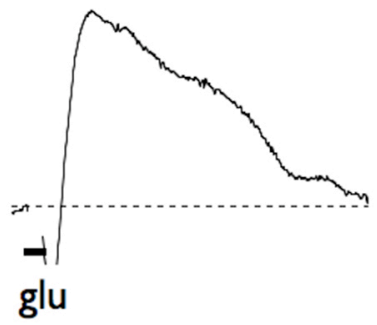

wash

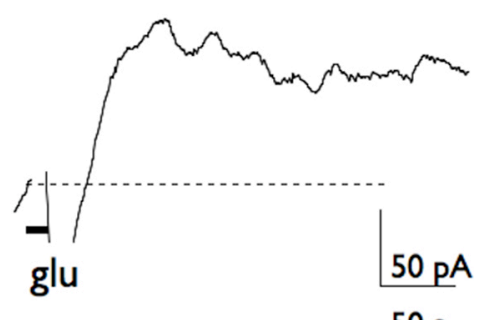

FIGURE 8 | PKC activator induces dopamine release and chelerythrine inhibits glutamateinduced dopamine release. Representative current traces of recorded dopamine oxidative currents. A: Puff locally applied with $10 \mu \mathrm{M}$ of the PKC activator PMA, triggered dopamine release (control). After $1 \mathrm{~h}$ of superfusing with $20 \mu \mathrm{M}$ GBR12935, PMA induced dopamine release is blocked. Finally after $1 \mathrm{~h}$ of washing PMA induced dopamine releases showed recovery as in control condition (wash). B: Puff locally applied with $1 \mathrm{mM}$ of glutamate, triggered a strong dopamine release (control). After $1 \mathrm{~h}$ of superfusing with $10 \mu \mathrm{M}$ selective PKC inhibitor chelerythrine, glutamate induced dopamine release is significantly blocked. After $1 \mathrm{~h}$ of washing, glutamate induced dopamine releases showed almost complete recovery as in the previous control condition (wash). Carbon fiber and the puff application pipettes were positioned in the $\mathrm{SNr}$ and kept there throughout the whole experiment. Carbon fiber was held constantly at $800 \mathrm{mV}$ for dopamine oxidation. Puff duration was of 10 seconds at 20 psi. All buffers and solutions were calcium free. The dashed horizontal line represents the baseline current.

The results presented in this section indicate that $\mathrm{PKC}$ is a crucial player in the reversal of the DAT. These findings are consistent with several studies that showed that PKC activation is necessary for amphetamine-induced dopamine release (Kantor and Gnegy, 1998; Cowell et al., 2000; Johnson et al., 2005; Seidel et al., 2005). Calcium-calmodulin kinase II (CaMKII) has also been recently implicated in the amphetamine-induced dopamine release (Kantor et al., 1999; Fog et al., 2006). In our hands, however, glutamate induced dopamine release in the $\mathrm{SNr}$ was not blocked by the CaMKII inhibitor, KN-93 (block: $13.4 \pm 18.6 \%$, n=5) (data not shown). 
In summary, earlier evidence that dendritic dopamine can be released upon a glutamatergic stimulus in the $\mathrm{SNr}$ are confirmed here. In addition, our data provide new insights into the mechanism of DAT reversal. We showed that the group I mGluR agonist trans-ACPD induces dopamine release mediated by the DAT. Even more, activation of PKC by PMA was sufficient to trigger dopamine release. Glutamate-induced dopamine efflux was blocked by the selective PKC inhibitor chelerythrine, but not by the CaMKII inhibitor KN-93 . 


\section{2. $\mathrm{G}_{\mathrm{q}}-\mathrm{PLC}$ signalling induces DAT-mediated dopamine release in a cell}

line

To reduce the number of variables that have an influence on the release of dopamine, we then turned to a neuronal cell line; SH-SY5Y cells were transfected with a pcDNA3.1(+) plasmid containing the human dopamine transporter and a neomycin resistance gene. Selection was made using the antibiotic G418 to finally obtain stable expression of the DAT (these cells will be called SH-DAT).

To measure uptake of dopamine by the cells, they were incubated with $15 \mu \mathrm{M}$ dopamine in ringer buffer. The results were fit to a one-phase exponential curve (Figure 9). The 95\% confidence interval of the half-life for dopamine uptake was 4.5 -12 minutes.

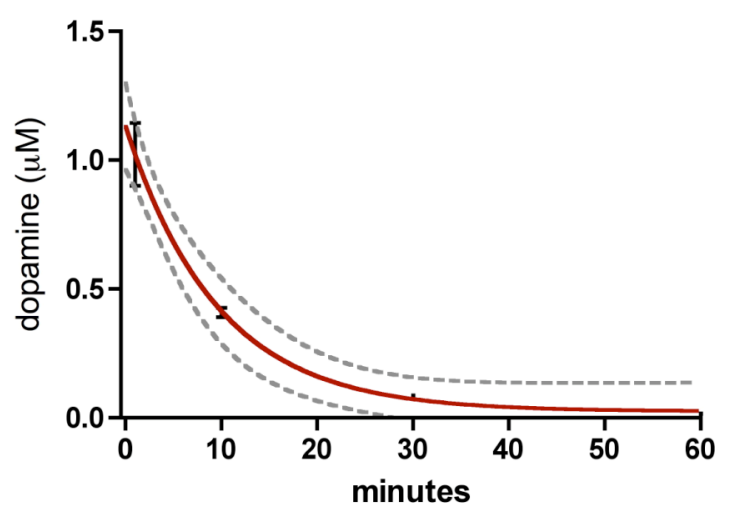

FIGURE 9 Extracellular dopamine is taken up by SH-DAT cells. Black symbols represent average and error bars the standard deviation of a triplicate measurement (three wells, same experiment). The trace in red is the fit to an exponential decay curve. The uptake halflife was 6.6 minutes. The dash-line represents the $95 \%$ confidence interval of the curve.

To investigate release of dopamine, cells were loaded with $15 \mu \mathrm{M}$ dopamine for 60 minutes. Cells were then washed twice with cold dopamine-free ringer solution, followed by the addition of the agent under study or the vehicle control. In each experiment, three wells were analyzed per condition. Extracellular medium was removed to measure the dopamine concentration in it. Then cells were washed again with cold dopamine-free ringer solution and finally lysed to measure the dopamine remaining inside. Note that the absolute concentration of dopamine varied between experiments due to different cell densities and experimental timings. To summarize 
data from different experiments for Tables 1,2 and 3, values were therefore normalized with respect to the control condition.

Amphetamine is known to produce dopamine efflux through the DAT (Sulzer et al., 1995). In order to test our system, we therefore exposed dopamine-loaded SHDAT cells to $50 \mu \mathrm{M}$ of amphetamine. Dopamine was measured in the extracellular buffer and in the cells after lysis (Figure 10A). Amphetamine induced a very strong dopamine release, reflected by the increase of extracellular and the reduction of intracellular dopamine, when compared with control. Additionally, we co-incubated amphetamine with the DAT inhibitor GBR12335, which inhibited dopamine release induced by amphetamine (Figure 10B).

A

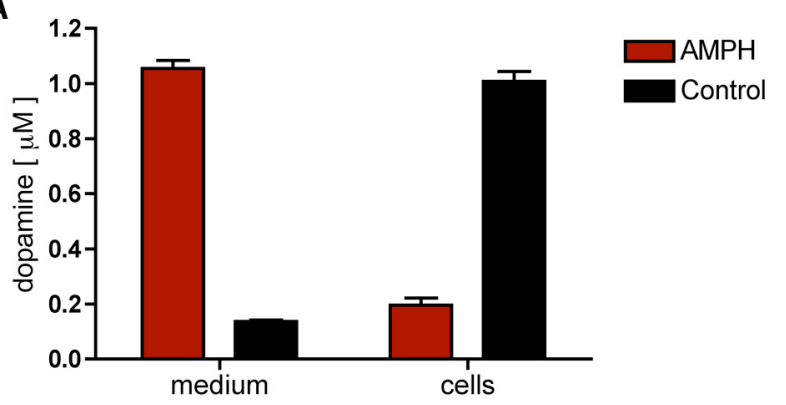

B

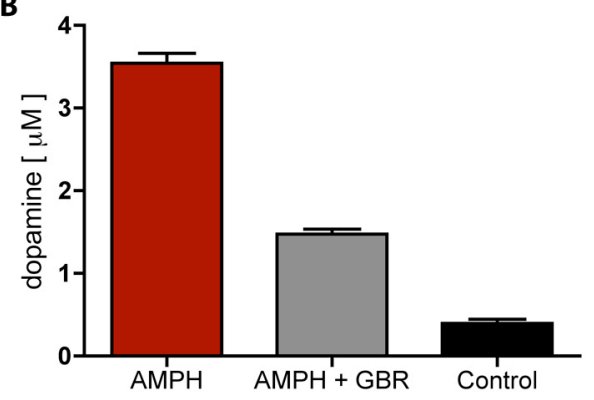

FIGURE 10 Amphetamine stimulated dopamine efflux from SH-DAT cells. Cells were preloaded for $1 \mathrm{~h}$ in $\mathrm{RB}$ with $15 \mu \mathrm{M}$ dopamine at $37^{\circ} \mathrm{C}$. After washing, cells were treated with the respective agent. A: dopamine concentration in the extracellular (medium) and intracellular volume (cells) with and without amphetamine (AMPH) B: Extracellular dopamine after the application for 5 minutes of AMPH alone or with the DAT inhibitor GBR12935. Amphetamine (AMPH) was used at $50 \mu \mathrm{M}$; GBR12935 $20 \mu \mathrm{M}$ and Control is only the ringer buffer. Representative figures done in triplicate wells. The error bars represent the standard deviation of the three wells. One-way ANOVA with Tukey's Multiple Comparison Test was done. All differences were very significant $* * * \mathrm{p}<0.001$. Multiple experiments were summarized in table 1 and 2.

Although the effect of GBR12935 was not a complete block (49.9\% $\pm 11.9 \% ; n=3)$, it reduced extracellular dopamine and showed that the amphetamine-induced dopamine release was through the DAT. Normal SH-SY5Y cells did not uptake dopamine during the loading step and accordingly did not react to amphetamine (data not shown). 
In summary, this outcome demonstrates that the SH-DAT system is capable to take up dopamine. Moreover it reacts as expected to an amphetamine stimulus. With this neuronal cell line expressing a functional DAT, we therefore wanted to take further the results obtained with the amperometric recordings in SNr. Unfortunately, we were not able to detect mGluR in our SH-DAT cells by immunobloting with specific monoclonal antibodies against mGluR1 or mGluR5 (data not shown), and the SH-DAT cells did not change cytosolic calcium in response to glutamate or the mGluR agonist Trans-ACPD (see imaging section below, Figure 23). This indicates that our $\mathrm{SH}$ cell lines do not express $\mathrm{mGluR}$ in functionally sufficient amounts.

However, SH-SY5Y cells express metabotropic acetylcholine receptors (mAChR) (Ding et al., 1998; Leng et al., 2001), specifically the mAChR M3 (Edwardson and Szekeres, 1999), which as $m$ GluR group I activates $G_{q}, P L C$ and its downstream signalling cascade including the rise of cytoplasmatic $\mathrm{Ca}^{+2}$ concentration and activation of PKC. The application of the $\mathrm{mAChR}$ agonist carbachol induced dopamine release from the SH-DAT cells in a dose-dependent manner (Figure 11A). A summary of all agents tested for dopamine release can be found in Table 1.
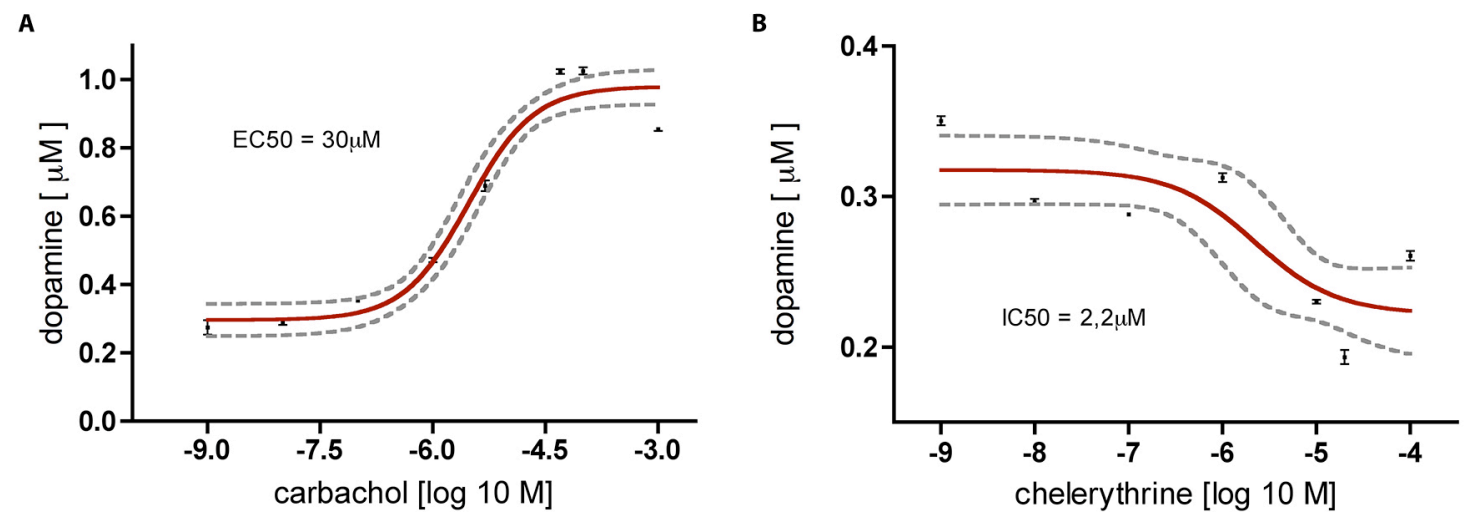

FIGURE $11 \mid$ Dopamine release triggered by the mAChR agonist carbachol and its inhibition with chelerythrine in SH-DAT cells. A: dopamine release under a concentration series of carbachol. Although the EC50 was $30 \mu \mathrm{M}$, all the following experiments were done with $50 \mu \mathrm{M}$. $\mathrm{B}$ : The inhibitory response of chelerythrine when co-incubated at various concentrations with 50 $\mu \mathrm{M}$ of carbachol. Half of the maximum possible inhibition (IC50) was achieved at $2.2 \mu \mathrm{M}$, however we used $4 \mu \mathrm{M}$ for all the further experiments. The dash-line represents the $95 \%$ confidence interval of the curve. Error bars correspond to the standard deviation of a measurement in triplicate wells. 
The findings of this section substantiate our amperometric studies, and strengthen the evidences that a metabotropic neurotransmitter receptor is sufficient to induce the reversal of the DAT.

Above we have shown that inhibition of PKC was sufficient to block the glutamateinduced dopamine release in the SNr. In accordance with the amperometric recordings we were able to block carbachol-induced dopamine efflux in our SHDAT system using the non-selective protein kinase inhibitor staurosporine $(n=4$; $\mathrm{p}<0.01)$ or the selective PKC inhibitor chelerythrine $(n=5 ; p<0.05)$ in a dose dependent fashion (Figure 11B).

Even though we used chelerythrine concentrations that should make it selective to $\mathrm{PKC}$, it could be argued that the effect we observed results from chelerythrine unspecific action. Thus we tested a different PKC inhibitor, bisindolylmaleimide I. And indeed, dopamine release induced by carbachol was also blocked by bisindolylmaleimide I $(n=7 ; p<0.001)$. All three kinase inhibitors showed a significant block of the carbachol-induced dopamine efflux (Figure 12). Table 2 shows different agents that we used to block dopamine-induced release. 

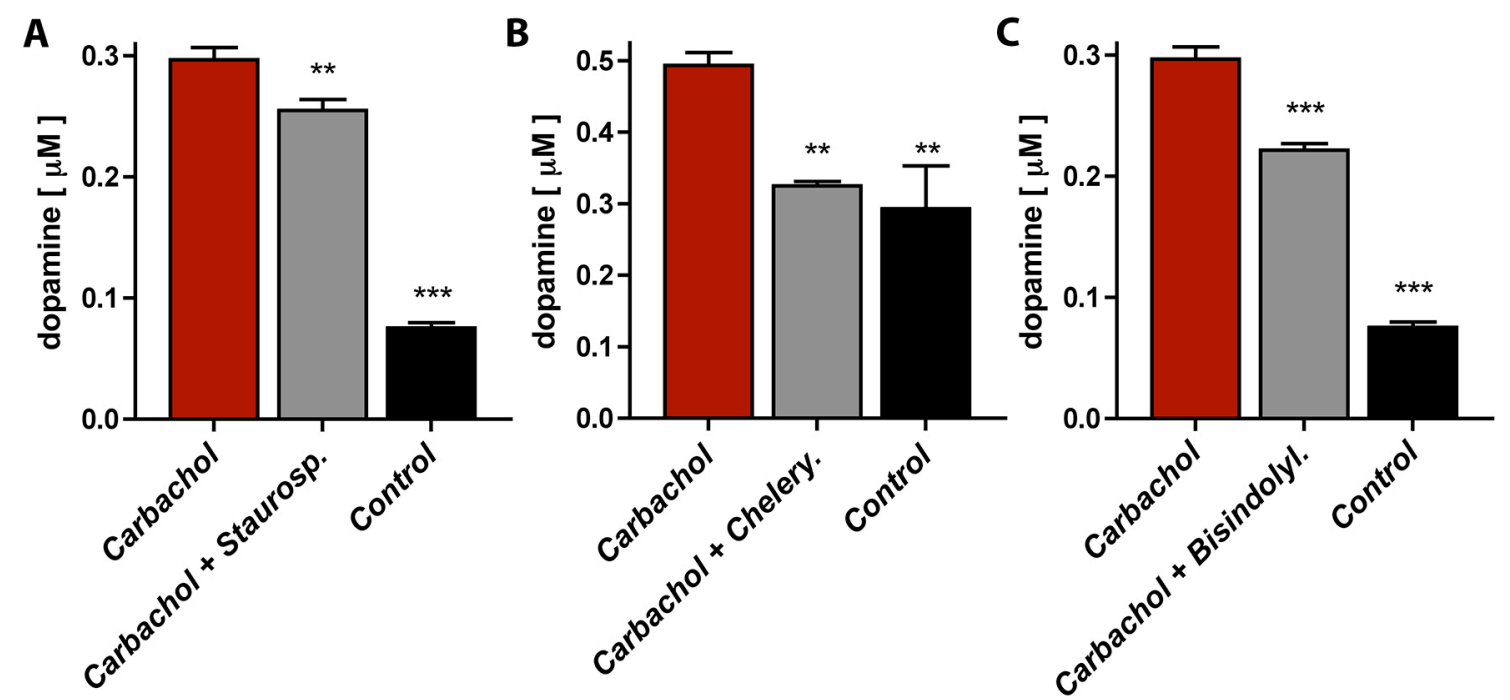

FIGURE 12 | Dopamine release induced by carbachol is blocked by PKC inhibition in SH-

DAT cells. A: $1 \mu \mathrm{M}$ of the non-selective kinase inhibitor staurosporine blocked dopamine release triggered by carbachol. B: Selective PKC inhibitor chelerythrine $(4 \mu \mathrm{M})$ blocked carbachol-induced dopamine release. C: Bisindolylmaleimide I is a selective PKC inhibitor, which binds to the ATPase site, $1 \mu \mathrm{M}$ of it blocks dopamine release induced by carbachol. All graphs are representative for the pharmacological agent assayed. The error bar represents the standard deviation of a triplicate wells measurement. One-way ANOVA with Tukey's Multiple Comparison Test was done. ${ }^{* *} \mathrm{p}<0.01 ;{ }^{* * *} \mathrm{p}<0.001$. Multiple experiments are summarized in table 1 and 2 .

To further investigate the role of PKC in the reversal of the DAT, we next tested alternative ways to activate $\mathrm{PKC}$. We achieved to induce dopamine release from SH-DAT cells by the application of the diacylglicerol (DAG) analog OAG $(n=3$, $\mathrm{p}<0.05)$ and the PKC activator PMA ( $\mathrm{n}=8, \mathrm{p}<0.0001)$. In addition, 3M3FBS, a phospholipase C (PLC) activator, was also able to induce dopamine release $(\mathrm{n}=4$, $\mathrm{p}<0.05)$ as depicted in Figure 13 and Table 1.

In order to strengthen our previous results, dopamine released by any of these three agents was inhibited by $4 \mu \mathrm{M}$ of the PKC inhibitor chelerythrine (Figure 13, Table 2). The data presented up to here not only support that the reversal of the DAT can be induced by activation of a metabotropic receptor, but also that the manipulation of different elements of the signalling cascade indicates once more that $\mathrm{PKC}$ is an important player in this process. 

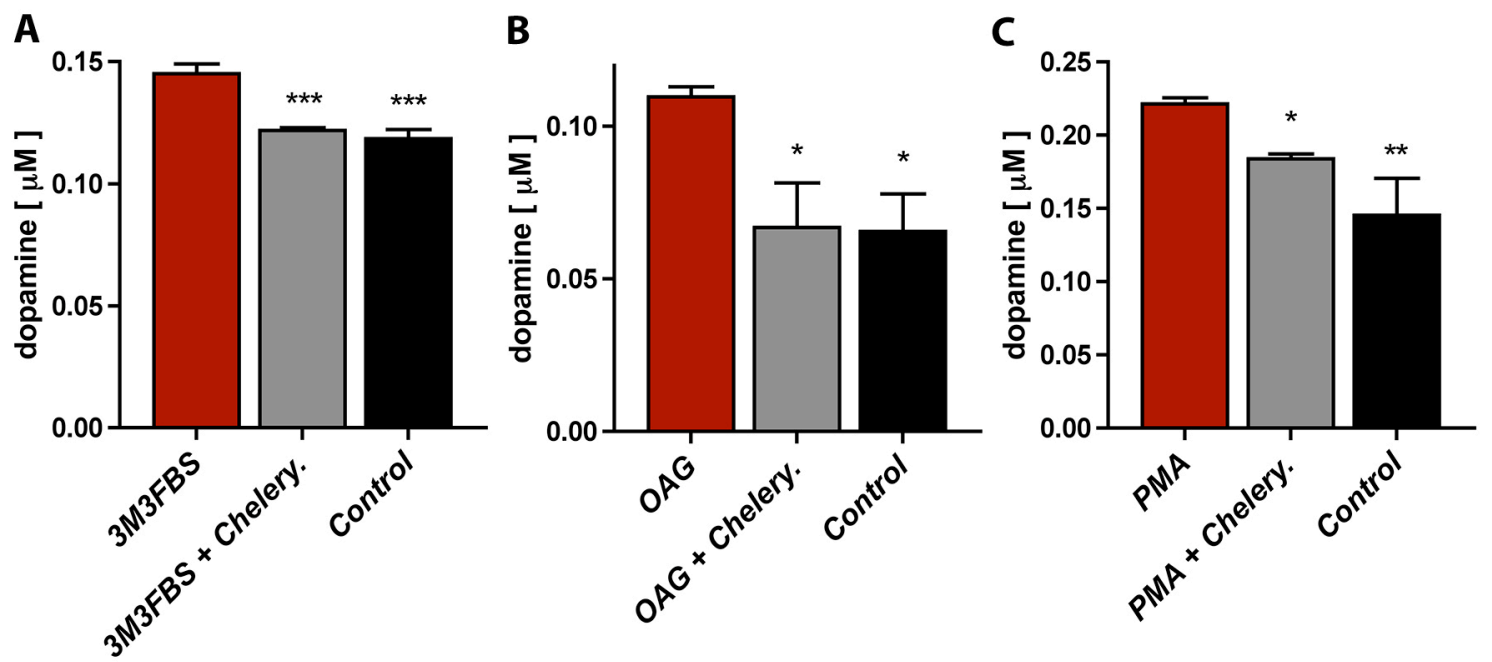

FIGURE 13 | Chelerythrine inhibit all three activators of the $G_{q}$ signalling cascade. A: Chelerythrine blocked the release of dopamine induced by $50 \mu \mathrm{M}$ of the PLC activator 3M3FBS. B: Chelerythrine blocked dopamine release induced by $125 \mu \mathrm{M}$ of the DAG analogue OAG. C: Chelerythrine blocked dopamine release induced by $8 \mu \mathrm{M}$ of the PCK activator PMA. Chelerythrine was used at $4 \mu \mathrm{M}$. All graphs are representative for each pharmacological agent assayed. The error bar represents the standard deviation of a triplicate measurement. One-way ANOVA with Tukey's Multiple Comparison Test was done. ${ }^{*} \mathrm{p}<0.05 ; * * \mathrm{p}<0.01 ; * * * \mathrm{p}<0.001$. Multiple experiments are summarized in Table 1 and 2.

Since exocytosis can be PKC dependent in some cell types, we finally used reserpine to rule out a vesicular release mechanism. Reserpine inhibits the uptake of dopamine into vesicles through the vesicular monoamine transporter (VMAT). Reserpine was therefore added together with dopamine while loading the cells and during release. The presence of reserpine did not alter carbachol-induced dopamine release and did not affect the inhibition of such release by chelerythrine (Figure 14; Table 3). 


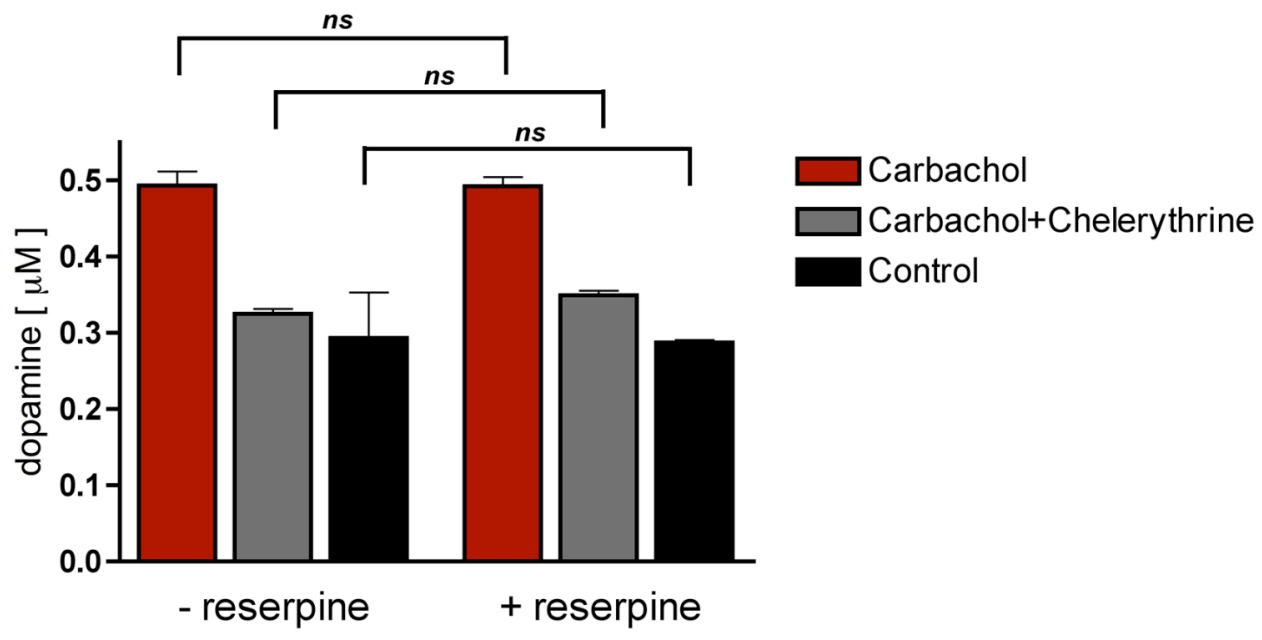

FIGURE $14 \mid$ Reserpine does not affect carbachol-induced dopamine release or chelerythrine inhibition. Dopamine released by $50 \mu \mathrm{M}$ carbachol compared to buffer application (Control) in presence or absence of reserpine. In order to exclude vesicular dopamine release after carbachol application, $10 \mu \mathrm{M}$ of reserpine was used during the whole experiment, including dopamine uptake. One-way ANOVA was performed with Tukey's all columns comparison test. $n s=$ not significant differences.

Recently published data from Gnegy et al. (2004) showed that cytosolic calcium is required for amphetamine-induced dopamine release. We have shown here that the activation of the $G_{q}$ signalling cascade is sufficient to trigger dopamine efflux through the DAT, thus we explored the effect of dopamine release in our system under different calcium conditions.

To test if an increase in cytosolic calcium would be sufficient to induce dopamine release, we tested the calcium ionophore ionomycin. Interestingly, dopamine release could also be induced by ionomycin (Figure 15, Table 1). Ionomycin-induced a robust dopamine release similar to carbachol. Inomycin-induced dopamine release was effectively inhibited by the PLC antagonist U73122 ( $\mathrm{n}=4, \mathrm{p}<0.01)$, by chelerythrine $(n=8, p<0.05)$, but not by the calcium-calmodulin kinase II inhibitor KN-93 ( $n=4, p>0.5)$ (Figure 15, Table 2). 

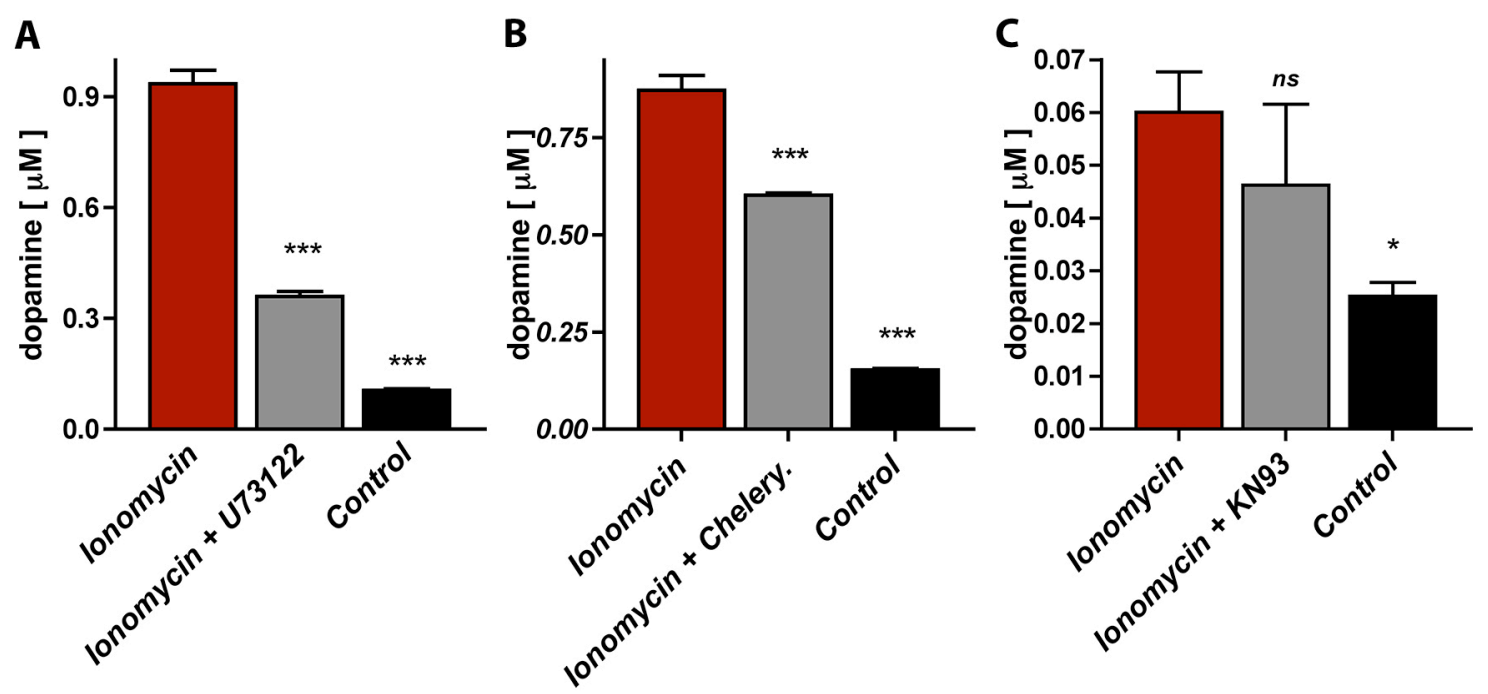

FIGURE $15 \mid \mathrm{Ca}^{+2}$ ionophore ionomycin induced dopamine release in SH-DAT cells. A: Ionomycin dopamine release blocked by $10 \mu \mathrm{M}$ of the PLC antagonist U73122. B: Ionomycin dopamine release blocked by $4 \mu \mathrm{M}$ of the PKC inhibitor chelerythrine. C: The dopamine release induced by ionomycin was not blocked by $10 \mu \mathrm{M}$ the CaMKII inhibitor KN-93. All graphs are representative for each pharmacological agent assayed. One-way ANOVA with Tukey's Multiple Comparison Test was done. ${ }^{*} \mathrm{p}<0.05 ;{ }^{*} \mathrm{p}<0.01 ;{ }^{* *} \mathrm{p}<0.001$.

This data indicates that the increase of intracellular calcium is sufficient to trigger dopamine release. However, the inhibition by U73122 and chelerythrine suggest that rise of intracellular calcium acts to some extent upstream of PKC. Overall, PKC appears to be the main candidate to help reversal of the DAT.

The evidence that cytosolic calcium increase was able to trigger dopamine efflux leads to the question whether calcium influx is necessary for dopamine release. Carbachol-induced dopamine release was not affected when extracellular calcium was removed (Figure 16). This indicates that calcium influx is sufficient but not necessary for dopamine efflux from SH-DAT cells. 


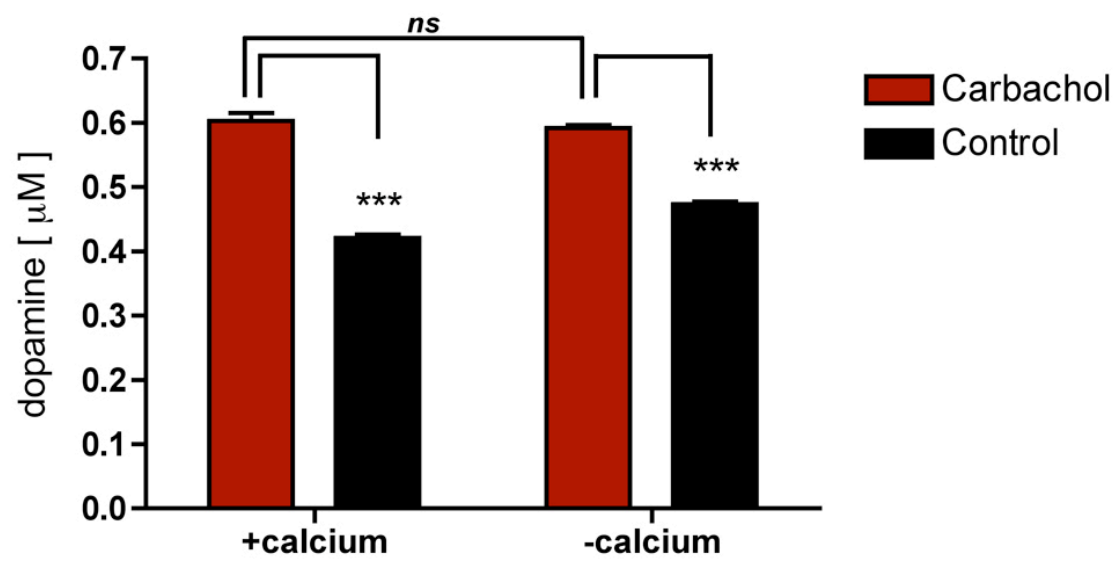

FIGURE 16 Dopamine release induced by carbachol is independent of extracellular calcium in SH-DAT cells. Carbachol induces dopamine to be released when compared to control condition in presence or absence of extracellular calcium. Carbachol-induced dopamine released is not different with or without extracellular calcium. Error bars represent the standard deviation of triplicate wells. One-way ANOVA with Tukey's Multiple Comparison Test was done. $* * * \mathrm{p}<0.001, \mathrm{~ns}=$ not significant. Carbachol was used at $50 \mu \mathrm{M}$ and control is only the ringer buffer.

Up to here we have demonstrated that PKC has a major role in the reversal of the DAT. However, how PKC induces dopamine release is still not answered. Several putative phosphorylation sites of the DAT (Granas et al., 2003) have been suggested. (Khoshbouei et al., 2004) showed that a deletion of the N-terminal first 22 amino acids, harbouring 5 serine residues for potential phosphorylation, abolished the amphetamine-induced dopamine release.

Accordingly, we generated a deletion of the first 19 residues of the DAT Nterminus, which abolished the same putative phosphorylation sites. We then created a SH-SY5Y stable transfected cell line with the new construct, which we called SH-D19.

SH-D19 cells took up dopamine normally (Figure 17A). In addition, carbachol was able to induce a significant dopamine release comparable to SH-DAT (Figure 17B). This interesting finding differs completely from what has been shown for amphetamine (Khoshbouei et al., 2004; Cervinski et al., 2005) and suggests that Nterminal phosphorylation of the DAT is not necessary for carbachol-induced dopamine release. 

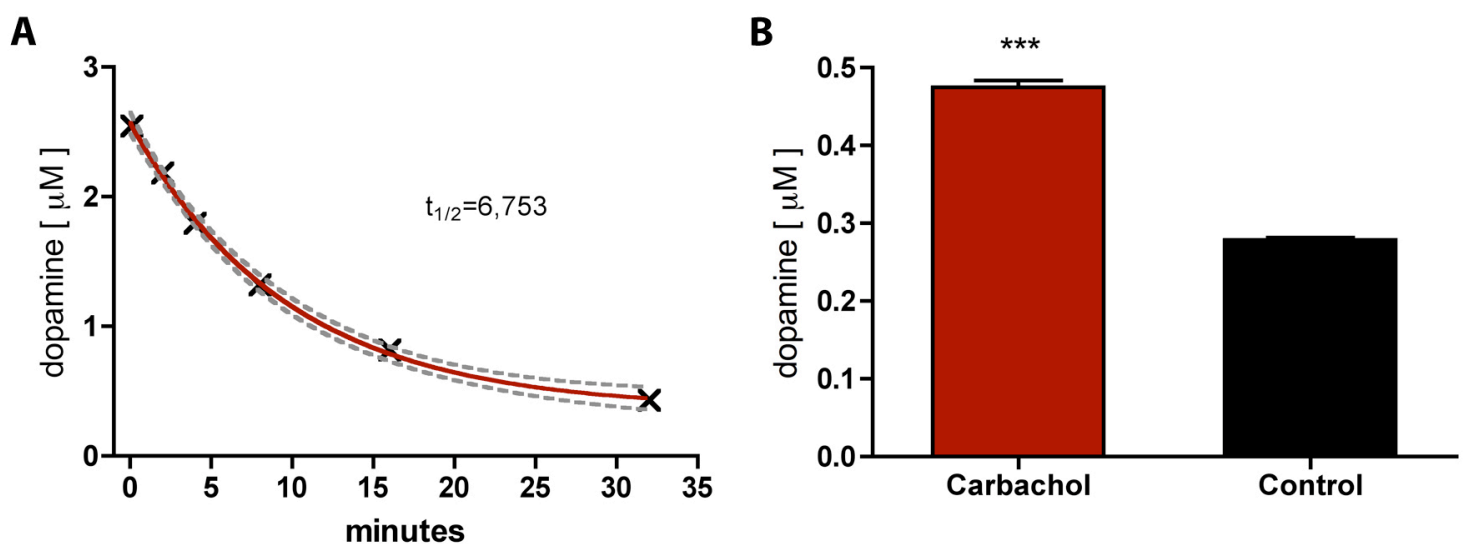

FIGURE 17 | Dopamine uptake and carbachol-induced dopamine released in the DAT mutant SH-D19 cells. A: Dopamine uptake fits almost perfectly to an exponential decay curve. Gray dashed line indicates the $95 \%$ confidence intervals. Half-life of dopamine in the extracellular medium was 6.75minutes. B: Bars represent the standard deviation of triplicate wells measurements. Two-tailed unpaired Student t-test was performed. ${ }^{* * *} \mathrm{p}<0.001$.

We then considered an alternative possible explanation, namely sodium influx through PKC activated ion channels. Since the DAT transports two sodium ions along with each dopamine molecule (Gu et al., 1994), rising intracellular sodium can be sufficient to reverse transport and induce release of dopamine (Elverfors et al., 1997; Sonders et al., 1997; Khoshbouei et al., 2003).

Transient receptor potential (TRP) channels are cation channels activated by PLC signalling. TRPC1, one of the classical subtypes, is phosphorylated by PKC (Ahmmed et al., 2004). Recently there has been evidence that TRPC1 is expressed on dopaminergic dendrites in the SN, colocalized with mGluR1 (Martorana et al., 2006) and activated by mGluR1 in purkinje cells (Kim et al., 2003). Activation of mGluR1 in dopaminergic neurons led to a sodium-dependent EPSC that was blocked by nonselective TRP channel inhibitors, such as SKF98365 (Tozzi et al., 2003). We therefore tested whether carbachol or PMA-induced release of dopamine from SH-DAT cells was sensitive to SKF98365. $20 \mu \mathrm{M}$ of SKF98365 did not block carbachol-induced or PMA-induced dopamine release (Figure $18 \mathrm{~A} \& \mathrm{C})$. In contrast, $100 \mu \mathrm{M}$ of the nonselective cation channel blocker lanthanum (La3+) inhibited dopamine release induced by carbachol or PMA (Figure 18B\&D). 
A

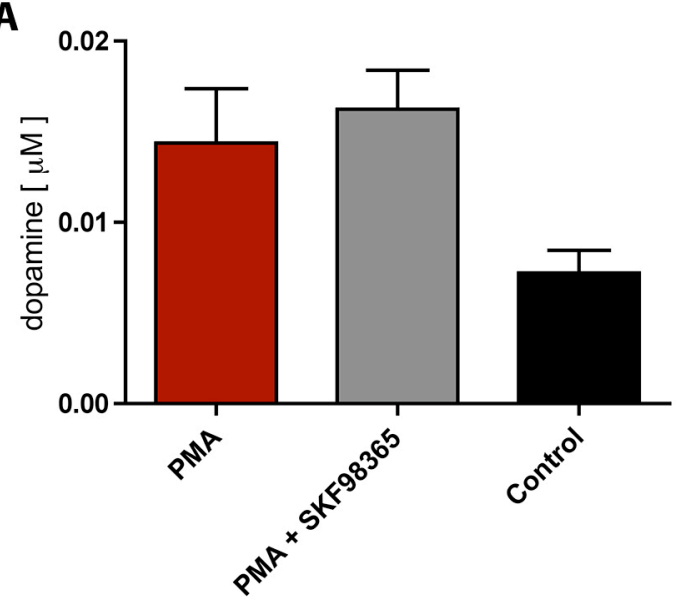

C

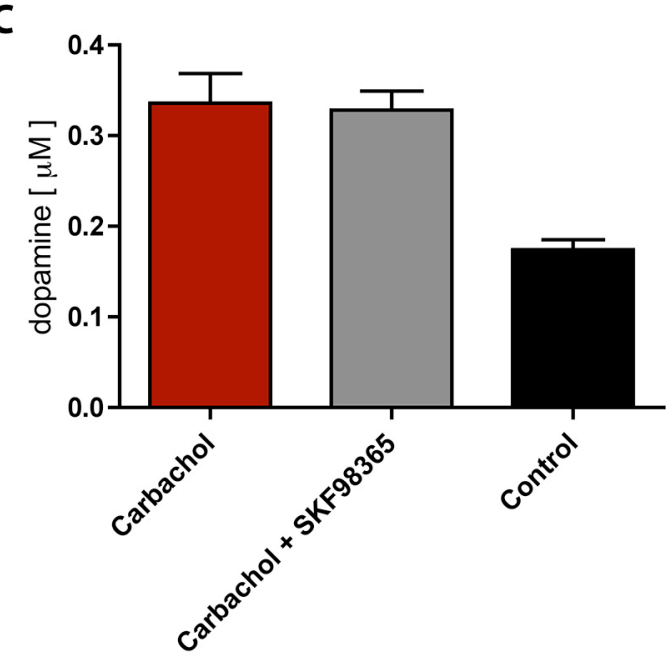

B

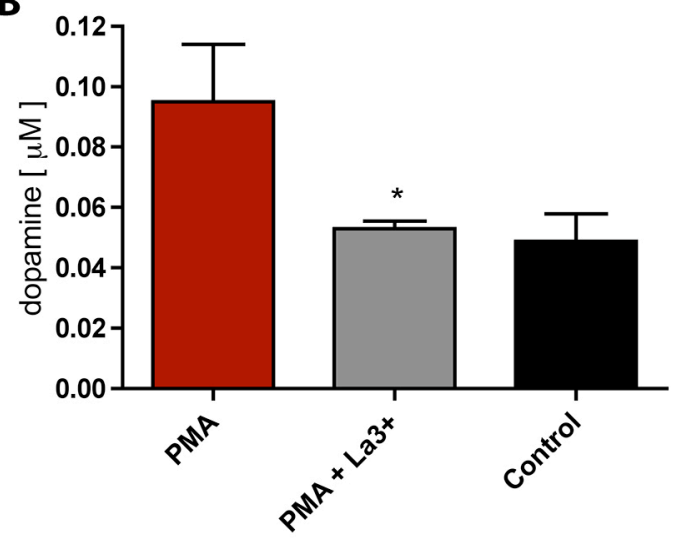

D

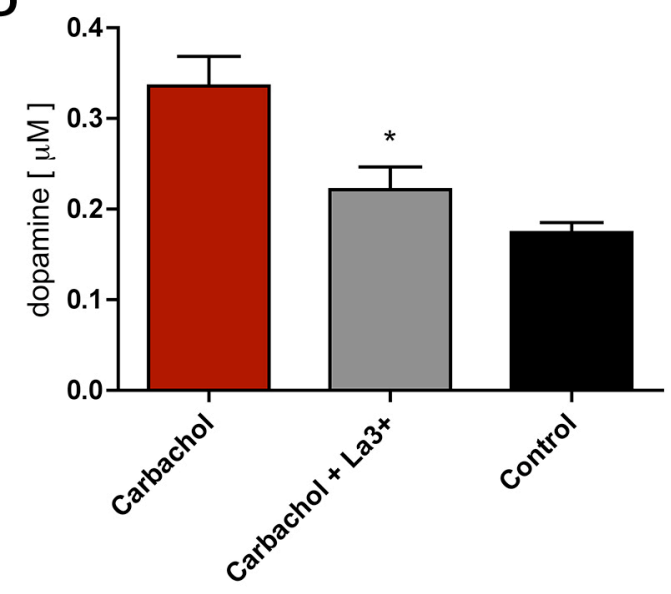

FIGURE 18 | Effects on PMA and carbachol dopamine induced release by SKF98365 and lanthanum (La3+), non-selective TRP and cation channel blockers respectively. A: PMA induced significant dopamine release but is not inhibited by SKF98365. B: La3 + can block dopamine release induced by PMA. C: Carbachol-induced dopamine release is not inhibited by 20 $\mu \mathrm{M}$ of the TRP channel inhibitor. D: Lanthanum block dopamine release induced by carbachol. Error bars represent the standard deviation of triplicate wells measurements. One-way ANOVA with Tukey's Multiple Comparison Test was done. ${ }^{*} \mathrm{p}<0.05$. Concentrations: PMA $8 \mu \mathrm{M}$, carbachol $50 \mu \mathrm{M}, \mathrm{SKF} 9836520 \mu \mathrm{M}, \mathrm{La} 3+100 \mu \mathrm{M}$.

This indicates that possibly a less SKF98365-sensitive TRP channel subtype may mediate PKC-induced sodium entry in DAT-SH cells or a totally different sodium channel is involved, which can also be opened after PKC phosphorylation.

To further explore the role of sodium, we then removed extracellular sodium, after loading the cells with dopamine by replacing it with glucose (to achieve the same RB osmolarity). As expected from the equilibrium at the dopamine transporter, removal 
of extracellular sodium resulted in a greatly increased baseline dopamine efflux, even without addition of any drugs. In this condition, addition of PMA to the $0 \mathrm{mM} \mathrm{Na}^{+}$ medium did not significantly change the amount of dopamine released (Figure 19).

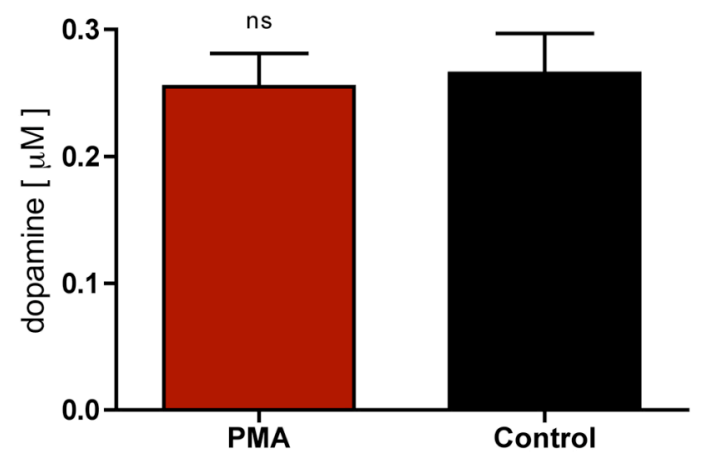

FIGURE $19 \mid$ Effect of PMA in the absence of extracellular $\mathrm{Na}^{+}$. PMA has no effect in dopamine release when the sodium gradient is inversed $(0 \mathrm{mM}$ extracellular sodium). Error bars represent the standard deviation of triplicate wells. Unpaired Student t-test was performed. ns $=$ no significant difference.

This can be interpreted in the sense that PMA and a change in sodium gradient are redundant because PMA acts through modifying the sodium gradient. However, it is also possible that the DAT capacity to release dopamine is completely utilized at $0 \mathrm{mM}$ extracellular sodium, obscuring the PMA action by a ceiling effect.

TABLE 1 Dopamine release in SH-DAT

\begin{tabular}{l|cccc}
\hline \multicolumn{1}{c}{ Agent name } & Used concentration & $\begin{array}{c}\text { Dopamine release relative } \\
\text { to the control (\%) }\end{array}$ & $\mathbf{n}$ & p value \\
\hline 3M3FBS & $50 \mu \mathrm{M}$ & $210.0 \pm 38$ & $\mathrm{n}=4$ & $<0.05$ \\
OAG & $125 \mu \mathrm{M}$ & $123.4 \pm 16$ & $\mathrm{n}=3$ & $<0.05$ \\
PMA & $8 \mu \mathrm{M}$ & $151.9 \pm 16$ & $\mathrm{n}=8$ & $<0.0001$ \\
Ionomycin & $5 \mu \mathrm{M}$ & $486 \pm 106.5$ & $\mathrm{n}=16$ & $<0.001$ \\
Carbachol & $50 \mu \mathrm{M}$ & $236.7 \pm 46.9$ & $\mathrm{n}=7$ & $<0.001$
\end{tabular}

TABLE 1 Summary of different agents that triggered dopamine release in SH-DAT cells. 3M3FBS is a PLC activator; OAG is a DAG analogue; PMA is a PKC activator; Ionomycin is a $\mathrm{Ca}^{+2}$ ionophore; Carbachol is a mAChR agonist. Cells were exposed to individual agents for $5 \mathrm{~min}$ in a humidified incubator at $37^{\circ} \mathrm{C}$ and $5 \% \mathrm{CO}_{2}$. After this time extracellular dopamine was measured by HPLC with electrochemical detection. Statistic: $\mathrm{n}=$ independent experiment (each one with triplicate wells), $p$ values were obtained using paired Student's t-test between the agent and it respective control (buffer alone or with the vehicle of the agent; usually DMSO). 
TABLE 2 Inhibition of induced dopamine release in SH-DAT cells.

\begin{tabular}{cc|ccccc}
\hline \multicolumn{2}{c|}{ Inhibitors } & \multicolumn{4}{|c}{ Agents that induce dopamine release in SH-DAT } \\
\hline$\mu \mathrm{M}$ & Names & Carbachol & Ionomycin & 3M3FBS & OAG & PMA \\
\hline 1 & Staurosporine & $\mathrm{n}=4 ; * *$ & - & - & $\mathrm{n}=3, *$ & $\mathrm{n}=4 ; * *$ \\
4 & Chelerythrine & $\mathrm{n}=5 ; * *$ & $\mathrm{n}=8, *$ & $\mathrm{n}=7, *$ & $\mathrm{n}=5, *$ & $\mathrm{n}=4 ; * *$ \\
1 & Bisindolyl & $\mathrm{n}=7 ; * * *$ & - & - & - & - \\
10 & $\mathbf{U 7 3 1 2 2}$ & - & $\mathrm{n}=4, * *$ & - & - & - \\
10 & $\mathbf{K N - 9 3}$ & - & $\mathrm{n}=4, \mathrm{~ns}$ & - & - & -
\end{tabular}

TABLE 2 Summary of different blockers and agents that triggered dopamine release in SHDAT cells. Inhibitors: Staurosporine is a non-selective kinase inhibitor; Chelerythrine PKC C2 agonist; Bisindolyl= bisindolylmaleimide I, selective PKC inhibitor (ATPase domain); U73122 is a PLC inhibitor; KN93 is a CaMKII inhibitor. Dopamine release inducers: 3M3FBS is a PLC activator; $\mathrm{OAG}$ is a DAG analogue; PMA is a PKC activator; Ionomycin is a $\mathrm{Ca}^{+2}$ ionophore; Carbachol is a $\mathrm{mAChR}$ agonist. Statistics: $\mathrm{n}=$ independent experiment (each one in triplicate), $\mathrm{p}$ values were obtained using paired Student's t-test between the agent and its respective control (buffer alone or with the vehicle of the agent; usually DMSO). ${ }^{*} \mathrm{p}<0.05 ;{ }^{*} \mathrm{p}<0.01 ;{ }^{* * *} \mathrm{p}<0.001$

TABLE 3 | Effect of reserpine, in induced dopamine release and blockade

\begin{tabular}{|c|c|c|c|}
\hline Parameter & + reserpine & - reserpine & Comp. \\
\hline Release by carbachol & $\begin{array}{c}1.8 \times \text { ctrl } \\
(n=5)\end{array}$ & $\begin{array}{c}2.7 \times \text { ctrl } \\
(n=12)\end{array}$ & ns \\
\hline Release by ionomycin & $\begin{array}{c}5.1 \times \text { ctrl } \\
(n=4)\end{array}$ & $\begin{array}{c}5.7 \times \text { ctrl } \\
(n=11)\end{array}$ & ns \\
\hline Block of carbachol by chelerythrine & $\begin{array}{c}35 \% \\
(n=2)\end{array}$ & $\begin{array}{c}39 \% \\
(n=5)\end{array}$ & ns \\
\hline Block of ionomycin by chelerythrine & $\begin{array}{l}22 \% \\
(n=2)\end{array}$ & $\begin{array}{c}34 \% \\
(n=8)\end{array}$ & ns \\
\hline
\end{tabular}

TABLE 3 Summary of the effect of reserpine in carbachol and ionomycin induced dopamine release and when they were blocked by chelerythrine. Carbachol is a mAChR agonist and was used at $50 \mu \mathrm{M}$; Ionomycin is a $\mathrm{Ca}^{+2}$ ionophore and was used at $5 \mu \mathrm{M}$; Chelerythrine is PKC antagonist and was used at $10 \mu \mathrm{M}$. Statistics: $\mathrm{n}=$ independent experiment (each one in triplicate). Comp. is the comparison obtained using two tailed and unpaired Student's t-test; ns= no significant difference between the +reserpine and -reserpine. (buffer alone or with the vehicle of the agent; usually DMSO). 


\subsection{Studying dopamine transporter kinetics by fluorescence imaging}

As a new method to study dopamine transport, we used the fluorescent DAT substrate ASP+. This molecule is chemically similar to the toxic DAT substrate $\mathrm{MPP}+$ and has been used to characterize binding and uptake by the transporters for dopamine and norepinephrine (Schwartz et al., 2003; Mason et al., 2005). ASP+ was applied to the extracellular buffer together with the cell-impermeable trypan blue, which quenched extracellular ASP+.

In order to test the system, we had transiently transfected HEK293 cells with a plasmid that encodes the DAT and EGFP as separate proteins. This allowed us to have a mixed population of transfected and untransfected cells, where the EGFP positive cells expressed the DAT and the EGFP negative did not. The cells were exposed for several minutes to ASP+ in the presence of trypan blue. ASP+ was selectively taken up into DAT-expressing cells, reflected by an increase in intracellular ASP+ (figure 20).
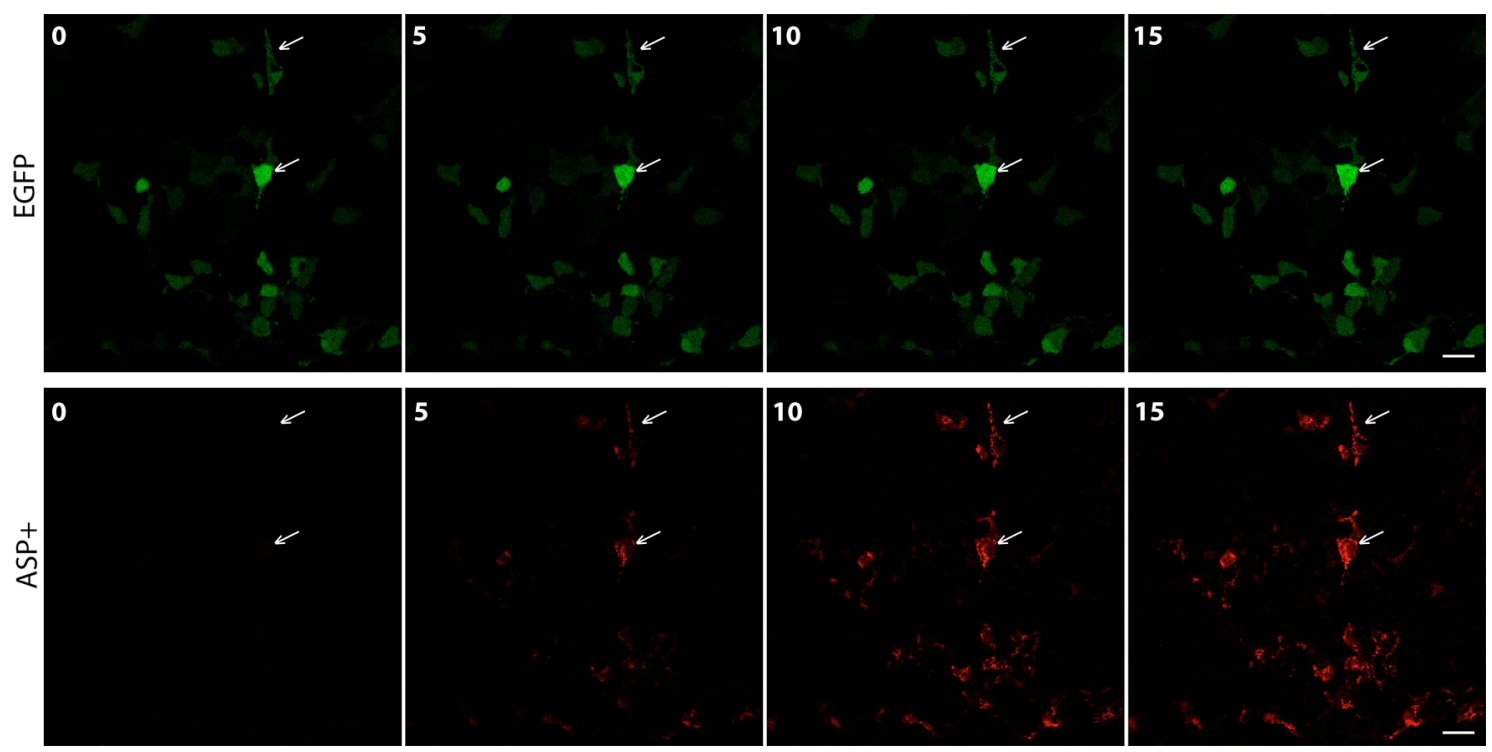

FIGURE 20 | ASP+ is selective uptake by the DAT transfected HEK293 cells. Cells were transfected with a plasmid that encodes the DAT and EGFP as separate proteins. Images were acquired every 30 seconds. Cells were superfused with ringer buffer (RB) after 3 minutes $10 \mu \mathrm{M}$ ASP and $30 \mu \mathrm{M}$ trypan blue was superfused until the end of the experiment. The same 488-argon laser exited ASP+ and EGFP, but their emission maximums were well separated around $509 \mathrm{~nm}$ for EGFP and $580 \mathrm{~nm}$ for ASP+. Numbers in the figure represent minutes and the bar represents 20 $\mu \mathrm{M}$. The arrows point at examples of EGFP positives cells, which accumulated ASP+. 
The characterization of Asp + uptake by Schwartz and co-workers described first a very rapid increase in fluorescence that most likely represents the binding of ASP+ to the DAT. We observed the same conduct (Figure 21; box "a"). The second, a more gradual increase has been interpreted as the uptake of ASP+ into the cells (Figure 21; box "b"). Fluorescence increases because ASP+ is no longer quenched when it is bound to the DAT or taken up into the cells (Schwartz et al., 2003).

$\mathrm{ASP}+$ has so far not been considered as a tool to study release by transport, because once inside the cell, it rapidly binds to membranes and is taken up by mitochondria (Schwartz et al., 2003).

However, when we applied amphetamine after only 1 minute of ASP+ uptake, this resulted in a strong (but not complete) release of the intracellular ASP+, reflected by the decrease of fluorescence intensity (Figure 21).

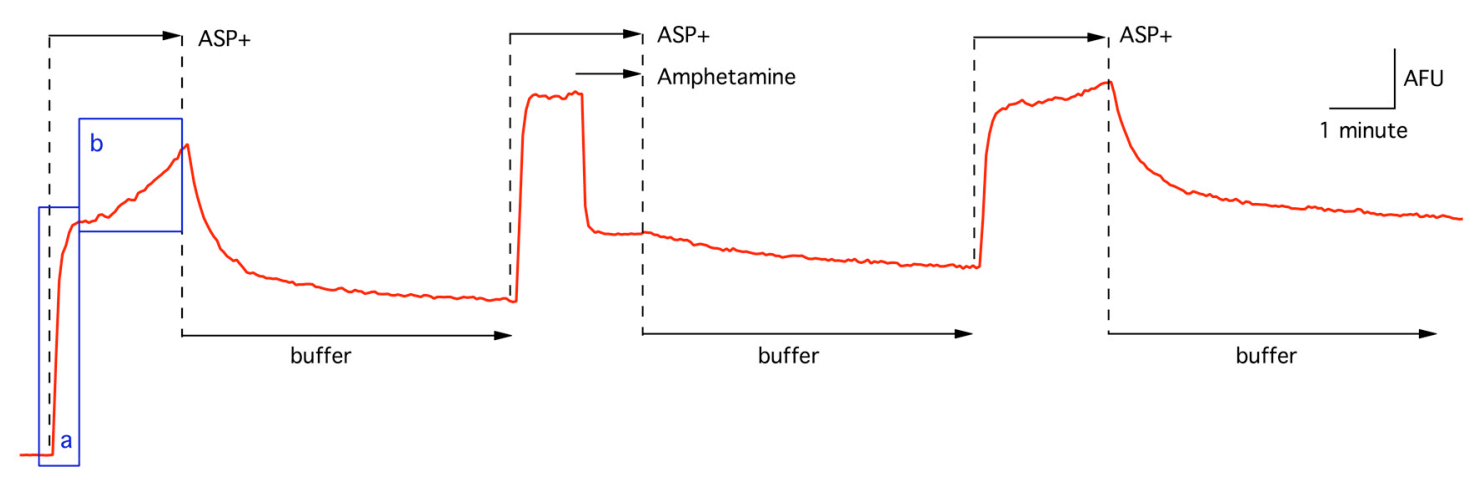

FIGURE 21 Amphetamine-induced ASP+ release in SH-DAT cells. A representative trace shows the intensity of ASP + of one single cell in arbitrary fluorescence units (AFU). Images were acquired at $0.3 \mathrm{~Hz}$. The arrows indicate the type and duration of the stimuli. Amphetamine was added together with $\mathrm{ASP}+$ to rule out a diluting effect. The application of $50 \mu \mathrm{M}$ of amphetamine for 1 minute was capable to generate a robust efflux of ASP+. Box "a" indicates the rise of fluorescence, in response to the binding of ASP+ to the DAT, and box "b" represents the actual DAT transport.

The mechanism by which amphetamine reverses dopamine transport has been debated for a long time. Interestingly, the data obtained with this method give us some insights that were not intended originally. If the first fast rise of fluorescence is really due to the binding of $\mathrm{ASP}+$ to the transporter, the remarkable drop in fluorescence after the application of amphetamine suggests that amphetamine not 
only induces dopamine (in this case $\mathrm{ASP}+$ ) to move out of the cell, but also that amphetamine is a dopamine transporter substrate which displaces $\mathrm{ASP}+$ from its binding site. This matter has not been fully resolved before (Sulzer et al., 2005).

Interestingly, after the application of $50 \mu \mathrm{M}$ carbachol we observed a similar, but less pronounced drop in fluorescence that the one obtained after the application of amphetamine (Figure 22) ( $\mathrm{n}=3)$.

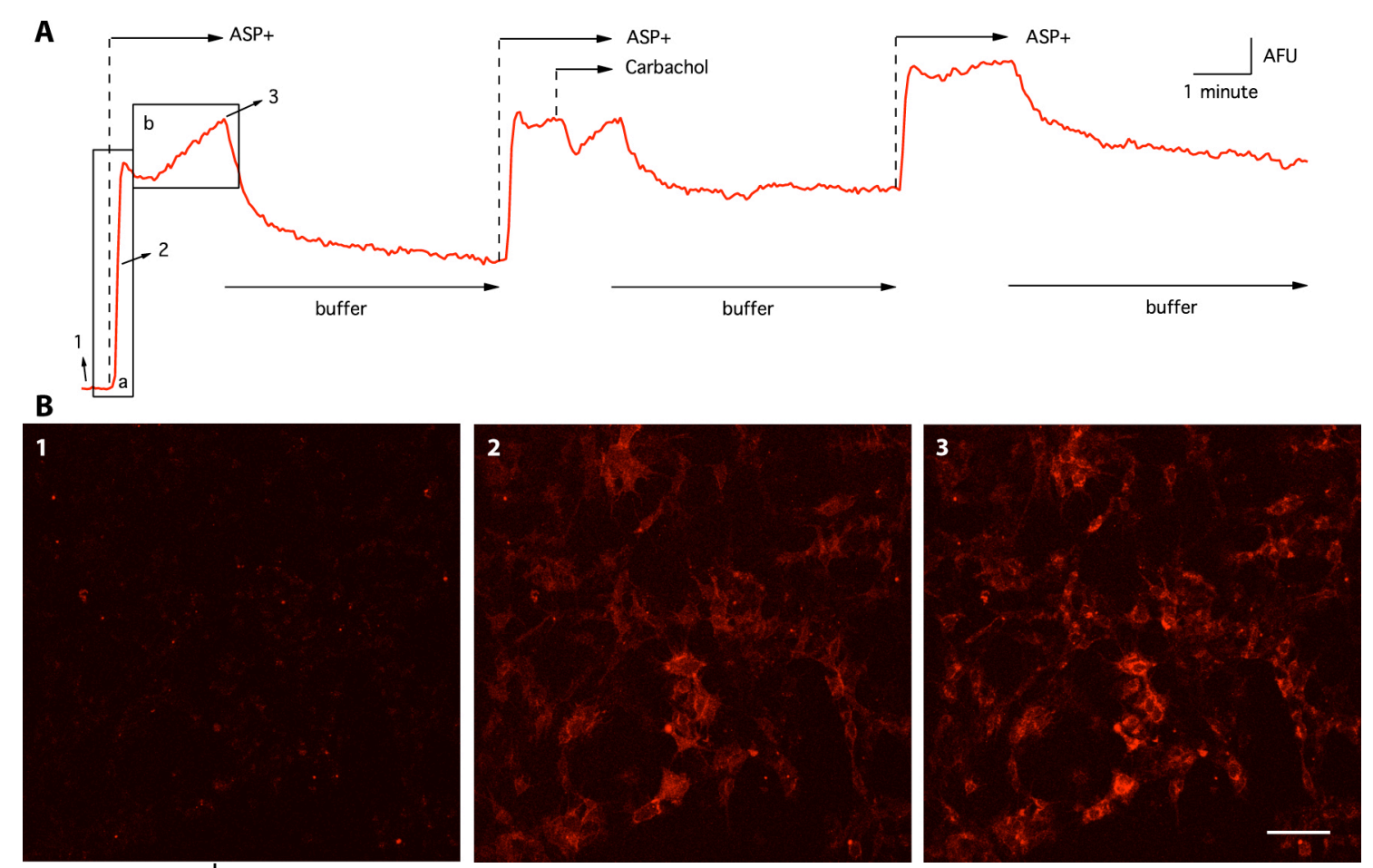

FIGURE 22 Asp+ released after application of carbachol in SH-DAT cells. A: The trace shows the intensity of ASP+ of a single cell in arbitrary fluorescence units (AFU). Images acquisition frequency was $0.3 \mathrm{~Hz}$. The arrows indicate the type and duration of the stimulus. Box "a" indicates the rise of fluorescence, in response to the binding of ASP+ to the transporter, and box "b" represents the actual DAT transport. During the second ASP+ application, we also applied for 1 minute $50 \mu \mathrm{M}$ carbachol diluted in the same ASP+ solution to avoid wash out of ASP+. A transient fall of fluorescence can be reproducibly observed after carbachol application $(\mathrm{n}=10$ cells and $\mathrm{n}=4$ independent experiments). A third ASP + application was done to check the normal functioning of the system. B: Pictures representing the three different states of the fluorescence. The numbers 1, 2 and 3 indicated in A, represent: without $\mathrm{ASP}+$, when $\mathrm{ASP}^{+}$binds to the transporter and when ASP+ is inside the cells respectively. The bar represents approximately 20 $\mu \mathrm{M}$.

We confirmed that ASP+ is a selective substrate of the DAT. We observed ASP+ release by amphetamine, which is a well known agent that causes the reversal of the 
DAT. Additionally, our evidence strongly suggests that carbachol is able to induce $\mathrm{ASP}+$ release.

To further characterize the carbachol effect, we also measured intracellular calcium changes using Fluo-4-AM in the SH-DAT.

We applied glutamate to control for possible presence of mGluR or ionotropic glutamate receptor in SH-DAT cells, but there was no change in intracellular calcium during glutamate application. On the contrary, the application of carbachol had a transient but strong increase in their cytosolic calcium concentration (Figure 23).

A

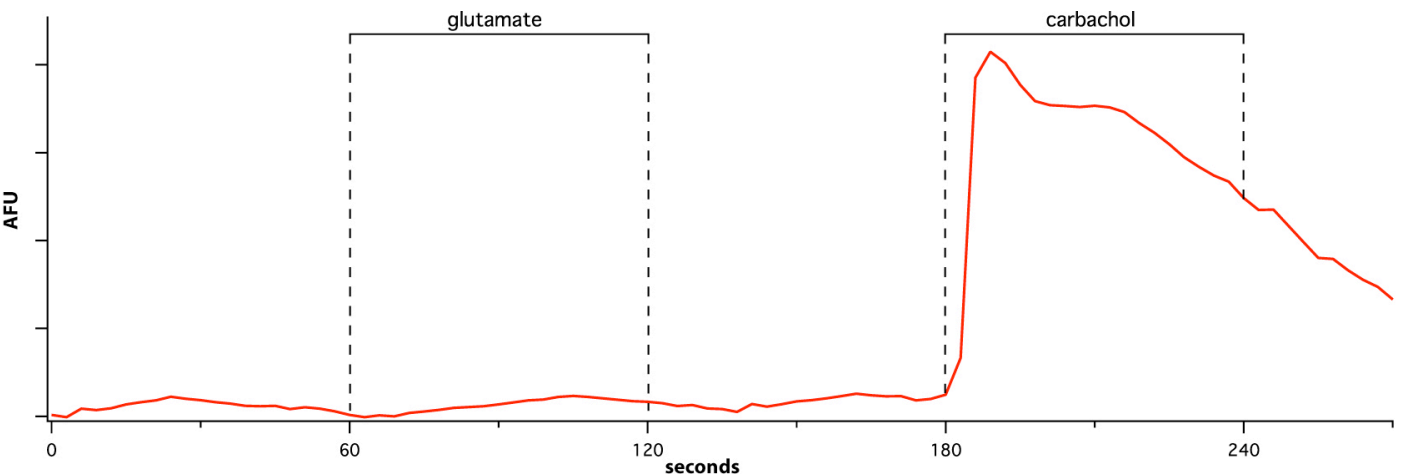

B

30 s
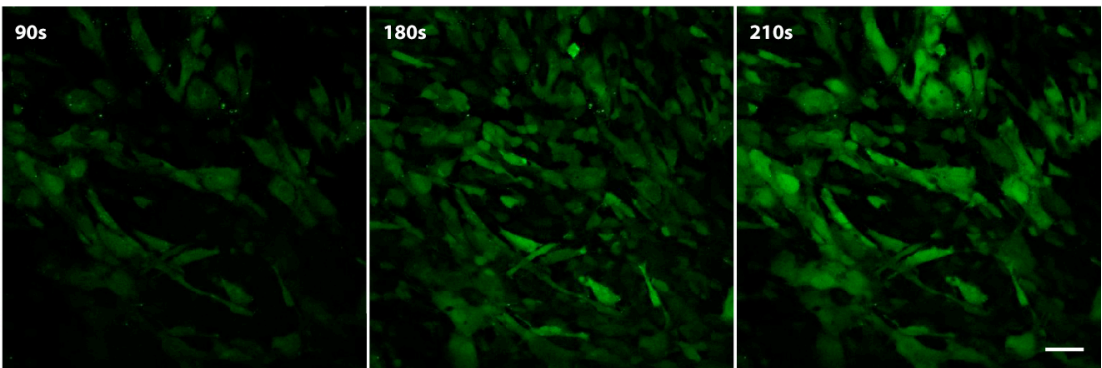

FIGURE 23 Intracellular calcium concentrations followed with AM-Fluo-4 calcium dye in SH-DAT cells. The trace shows the intensity of Fluo-4 of a single cell in arbitrary fluorescence units (AFU). Images acquisition frequency was $0.3 \mathrm{~Hz}$. The bars indicate the type and duration of the stimulus. $1 \mathrm{mM}$ glutamate was applied during 1 minute and no changes in calcium can be observed. However 50uM carbachol was sufficient to trigger a strong calcium response.

Even when carbachol was present during a minute, the cytosolic calcium seemed to be buffered after the first 15 seconds that carbachol was present. Interestingly we also observed in Figure 22 that during the application of carbachol the released $\mathrm{ASP}+$ had a maximum and then diminished, even if carbachol was present. This 
new method permits to study the reversal of the DAT using imaging technique (in comparison with the traditional radioactive dopamine methods) and it might lead to a better understanding of the DAT kinetics.

\subsection{Physiological release of dopamine in the $\mathrm{SN}$ is mediated by the DAT}

The following data are not my original work, but the experiments were done in collaboration and as a result of my work. The purpose of this was to put the study in a physiological context.

Whole cell patch clamp recordings were performed and analyzed by Lucian Medrihan ( $\mathrm{PhD}$ student in Physiology Department, University of Göttingen). We used the modulation of spontaneous excitatory postsynaptic potentials (sEPSC) by dopamine D2 receptors as a sensitive way to measure the small amounts of dopamine released by spontaneous neuronal activity.

Dopaminergic neurons receive glutamatergic afferents from the subthalamic nucleus (STN), which is spontaneously active (Falkenburger et al., 2001; Kass and Mintz, 2006). This projection is modulated by presynaptic D2 receptors (Ibañez-Sandoval et al., 2006). Consequently, dopamine reduced the frequency of spontaneous EPSCs in dopaminergic neurons of the ventral tegmental area (VTA) (Koga and Momiyama, 2000). If in an undisturbed slice the DAT would be mainly taking up dopamine, blocking the DAT by GBR12935 would have a similar effect as exogenously applying dopamine and reduce the frequency of sEPSCs. Conversely, if the DAT would mainly release dopamine, GBR12935 would have the opposite effect and increase the frequency of sEPSCs. We observed the latter; GBR12935 significantly increased the frequency of sEPSC (Figure 24A\&B), suggesting that the DAT mediates mainly dopamine release in an unstimulated $\mathrm{SNr}$ slice preparation. Sulpiride had no further effect in the presence of GBR12935, indicating that with the DAT blocked extracellular dopamine concentration was too low to activate $\mathrm{D} 2$ receptors. 
In summary, this experiment demonstrates that DAT-mediated dopamine release is induced by spontaneous neuronal activity in the slice and upholds a baseline concentration of extracellular dopamine.
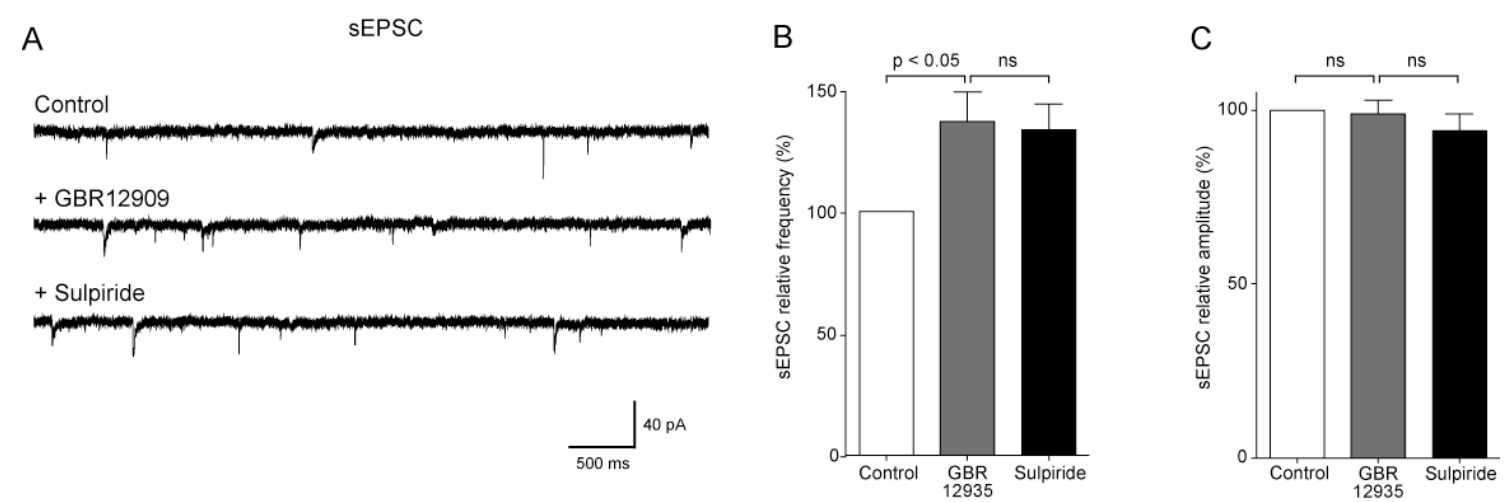

FIGURE 24 Spontaneous excitatory post-synaptic currents (sEPSC) of SNc dopaminergic neurons. A: Representative recordings of pharmacologically isolated spontaneous excitatory postsynaptic currents (sEPSCs) in pars compacta dopaminergic neurons from rat slices (in the presence of $1 \mu \mathrm{M}$ bicuculine). $20 \mu \mathrm{M}$ GBR12395 and $10 \mu \mathrm{M}$ sulpiride were added in the bath after recording of stable controls. B,C: Relative frequency (B) and amplitude (C) of spontaneous EPSC in neurons treated consecutively with $20 \mu \mathrm{M}$ GBR12909 and $10 \mu \mathrm{M}$ sulpiride, A two-tailed paired $t$ test was used for determining the statistical significance. ( $n / N=6 / 3$ for every column, where $n$ is the number of neurons and $\mathrm{N}$ is the number of animals), 


\section{DISCUSSION}

In this study we have demonstrated that the activation of G-protein coupled receptors transiently changes the function of the DAT to a reverse mode. In contrast to amphetamine-induced dopamine release, $\mathrm{N}$-terminal phosphorylation of the DAT by PKC was not necessary to induce DAT reversal. Instead, a PKCindueced influx of sodium appears to underlie dopamine efflux through the DAT.

\subsection{The SNr's DAT can function in reverse mode}

As an indirect way of measuring the small amounts of dopamine released in the $\mathrm{SNr}$ by STN spontaneous neuronal activity, we measured the modulation of excitatory postsynaptic potentials (sEPSC) by dopamine D2 receptors. In our experiments, the blockade of the DAT by GBR12935 was sufficient to increase the sEPSP frequency recorded in SNc neurons (Figure 24). Our interpretation of this result is that glutamatergic STN neurons induced physiologically the reversal of the DAT transport, since STN was shown to be spontaneously active (Falkenburger et al., 2001) and its stimulation induced release of dopamine in the $\mathrm{SNr}$ (Mintz et al., 1986).

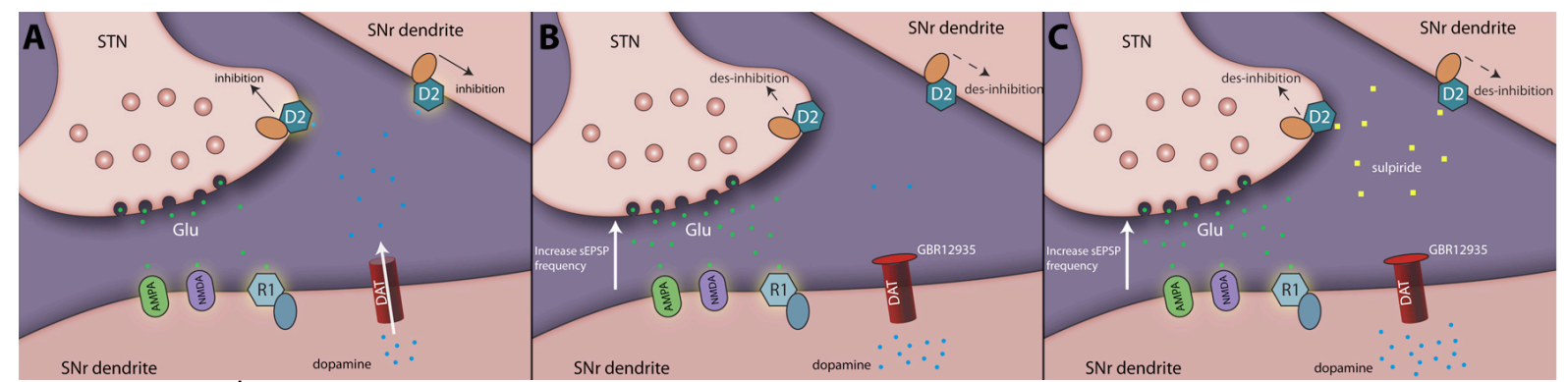

FIGURE 25 | Cartoon representation of the D2 receptors des-inhibition after the application of GBR12935 and sulpiride. A: Spontaneous glutamate release from SNT afferents in the SNr leads to DAT-mediated dopamine release. Presynaptic and postsynaptic D2 receptors modulate the neuronal activity. B: GBR12935 blocks dopamine release. In consequence, the presynaptic and postsynaptic D2 receptors are no longer active, and they stop silencing the neurons. This leads to an increase in the spontaneous firing. C: The addition of the D2 antagonist sulpiride after GBR12935 did not change the effect induced by GBR12935 alone. This proposes that the extracellular concentration of dopamine after GBR12935 was too low to activate D2 receptors and sulpired has not extra effect. 
The fact that GBR12935 decreased the dopamine levels in the SNr, suggest that dopamine is being released through the DAT. Moreover, we show that disturbances of the physiological DAT-mediated dopamine release are capable to modulate $\mathrm{SNr}$ activity. Our results are consistent with observations by Ibanez-Sandoval et al.. They showed that subthalamic-nigra projection is modulated by dopamine D2 receptors (Ibañez-Sandoval et al., 2006).

Using amperometric recordings in brain slices, we showed that the DAT could induce dopamine release after a local application of glutamate in the $\mathrm{SNr}$ (Figure 6). Dopamine release in the SN has been evidenced a long time ago (Geffen et al., 1976; Cheramy et al., 1981), but the exact mechanism by which dopamine is released has been controversial. Our experiments show that the $\mathrm{SNr}$ dopamine release is present in the absence of calcium and is GBR12935 sensitive (Figure 6).

Nevertheless, a calcium dependent dopamine release has been also shown in SNc neuronal soma (Jaffe et al., 1998) and also in the VTA (Rice et al., 1997).

To further substantiate and investiagate DAT-mediated dopamine release we use our SH-DAT in vitro model. The neuroblastoma cell line expressing the dopamine transporter was capable to take up and release dopamine through the DAT (Figure 9\&10). Moreover, carbachol-induced dopamine release was insensitive to the VMAT inhibitor reserpine (Figure 14) and independent of extracellular calcium (Figure 16). These data suggest that vesicular release is not underlying carbacholinduced dopamine release from SH-DAT cells. In coherence, independent evidences by Chen et al. (2001) and Falkenburger et al. (2001) showed dendritic dopamine release in the absence of extracellular calcium. Taking together, our physiological measurements with our in vitro characterization strongly suggest that dopamine can be released independent of vesicle fusion, mediated by the DAT and induced by G-protein coupled receptor activation. 


\subsection{Second messenger cascade is involved in the reversal of the DAT}

\subsection{1. metabotropic glutamate receptors}

Our observations of glutamate-induced dopamine release made us explore the possible implication of the mGluRs in the reversal of the DAT. Dopaminergic neurons primarily express $m$ GluR class $I$, which consists of mGluR 1 and mGluR5 (Testa et al., 1994; Kosinski et al., 1998). We therefore used trans-ACPD as a group I selective agonist. Our observations demonstrate that an $\mathrm{SNr}$ local application of the mGluR group I agonist, was sufficient to induce DAT-mediated dopamine release in the brain slices (Figure 7). This is consistent with previous observations, where glutamate-induced dopamine release in the $\mathrm{SNr}$ was not altered by the inhibition of ionotropic glutamate receptors (AMPA and NMDA)(Falkenburger et al., 2001).

The dopamine release signal we obtained by trans-ACPD application was relatively small when compared with the signal obtained after the application of glutamate or PMA. This can be explained by the lower potency of trans-ACPD to activate mGluRs. Pin et al. (1995) and Sayer et al. (1992), using patch-clamp recordings of mGluR-induced currents, have shown that trans-ACPD was 10 folds less potent than an equivalent concentration of glutamate in the activation of mGluRs (Sayer et al., 1992; Pin and Bockaert, 1995). For that reason, we also tried (S)-3,5-DHPG, which is another mGluR group I agonist, but unfortunately it produced an oxidative current signal by itself, disabling its use in the amperometric experiments.

We decided to manipulate downstream elements of the mGluR group I signalling cascade. The local application of the PKC activator PMA resulted in a strong DATmediated dopamine release (Figure 8). Accordingly, Cowell and co-workers (2000) also showed PMA-induced dopamine release in a striatal synaptosome preparation, suggesting that PKC activation can induce the DAT reversal (Cowell et al., 2000).

We then showed that glutamate-induced dopamine release in the $\mathrm{SNr}$ could be blocked by chelerythrine, a selective PKC inhibitor (Figure 8). This implies that 
glutamate-induced reversal of dopamine transport was mediated by PKC. Consistently, Kantor et al. (1998) showed in striatal synaptosomes preparation that amphetamine-mediated DAT reversal was dependent on PKC activity and extracellular calcium (Kantor and Gnegy, 1998). In contrast to Fog et al. (Fog et al., 2006) we did not observe an inhibition of dopamine release with the CaMKII inhibitor KN-93. Differently than us, they drive the system by adding in the patch pipette additional activated or inactivated CaMKII and they also used a relatively high sodium concentration in the internal solution $(30 \mathrm{mM})$, which would help in the DAT reversal. In addition, Fog and co-workers induced dopamine release with amphetamine. On our hand, DAT-mediated dopamine release in $\mathrm{SNr}$ seems to be linked with the PKC activation and not to CaMKII.

\subsubsection{Dissecting the signalling which induce the reversal of the DAT}

We used a neuronal cell line engineered with the human DAT to make a pharmacological study of the signalling involved in the reversal of the DAT. We obtained a DAT-mediated dopamine release in a dose-dependent manner by activating a muscarinic acetylcholine receptor $(\mathrm{mAChR})$ (Figure $11 \mathrm{~A})$. We also observed a decrease in ASP+ cellular fluorescence intensity after carbachol application (Figure 22). The $\mathrm{mAChR}$ agonist carbachol activates $\mathrm{M} 3 \mathrm{mAChR}$ subtypes in SH-SY5Y cells. The M3 subtype has been shown to similarly as mGluR group I use the $\mathrm{G}_{\mathrm{q}}-\mathrm{PLC}$ signalling cascade (Edwardson and Szekeres, 1999). This was evidenced when carbachol-induced dopamine release was dosedependently inhibited by chelerythrine (Figure 11B). These results corroborate our amperometric findings, where PKC activation was necessary and sufficient for DAT-mediated dopamine release (Figure $12 \& 13$, Table 1). These independent additional findings support the general idea that PKC mediates the DAT reversal, and show that the upstream activators of PKC may differ. This last factor implies that this phenomenon may occur in other brain areas than the $\mathrm{SNr}$. 
It is the advantage of the SH-DAT system that allowed the performance of a detailed pharmacological study (Table 1, 2 \& 3). Overall, we observed dopamine release after the activation of each element of the $\mathrm{G}_{\mathrm{q}}-\mathrm{PLC}$ signalling cascade (Figure 13, Table 1). Additionally, induced dopamine release by the activation of PLC or PKC, was blocked by the PKC inhibitor chelerythrine (Figure 13, Table 2). An interesting finding was that the calcium ionophore ionomycin induced dopamine release and it was inhibited by the PLC antagonist U73122, which means that calcium operated upstream of PKC in the signalling cascade (Figure 15). These findings have unexpected implications for the understanding the mechanism of action for commonly used drugs. For instance, caffeine, a well-known "wakefulness" drug, releases calcium from intracellular stores and binds antagonicaly to adenosine receptors (A1 and A2) (Fisone et al., 2004). Furthermore, caffeine has been shown to be protective in MPTP animal models (Chen et al., 2001; Xu et al., 2002). Our result of the $\mathrm{G}_{\mathrm{q}}-\mathrm{PLC}$-mediated transport reversal may be one explanation for this observation, since the rise of intracellular calcium induced DAT-mediated dopamine release (Figure 15). In addition to this, effects of caffeine alertness have not been studied in relation with an increase of extracellular neurotransmitters that are released by reversal transport.

Our data demonstrates that activation of $\mathrm{G}_{\mathrm{q}}$-PLC signalling, either through muscarinic or metabotropic glutamate receptors, leads to DAT-mediated dopamine release. Furthermore, inhibition of PKC abolished the dopamine release induced by these G-protein coupled receptors (GPCR). PKC is ubiquitously expressed and its activation could in principle be triggered in several manners. This suggests that the transporter-mediated neurotransmitter release might be a general phenomenon in the nervous system. 


\subsection{How does PKC activity induce DAT-mediated dopamine efflux?}

\subsubsection{PKC direct DAT phosphorylation}

Our physiological and in vitro findings support $\mathrm{PKC}$, but not $\mathrm{CaMKII}$ as an important element in the reversal of the DAT. It is important to note that the DAT has been shown to be phosphorylated by multiple kinases. However, this phosphorylation has been mainly implicated in the regulation of the DAT trafficking (Melikian and Buckley, 1999; Granas et al., 2003; Zahniser and Sorkin, 2004).

We showed that direct phosphorylation after PKC activation, at least in the first five serine residues, was not necessary for $\mathrm{G}_{\mathrm{q}}-\mathrm{PLC}$-induced dopamine release. The deletion of the first 19 amino acids of the DAT did not impair dopamine uptake and was not different in the carbachol-induced dopamine release paradigm (Figure 17).

In contrary, a recent work of Khoshbouei et al. (2004) suggests that direct phosphorylation of N-terminal sites of the DAT sets the DAT into a "willing" state to induce amphetamine-mediated dopamine efflux. This outcome proposed, in contrary to our metabotropic-induced release, that $\mathrm{N}$-terminal phosphorylation might induce sufficient conformational changes in the transporter to promote the “willing” state for amphetamine-induced dopamine release.

Although the amphetamine and GPCR-induced dopamine release appears to diverge in their mechanism, certainly more experiments are needed to reach such conclusion. Especially because there are several additional phosphorylation candidates close to the transmembrane domain V (Figure 3 in the introduction), which we believe could trigger a conformation change that may be more relevant to dopamine transport than the one caused by phosphorylation of the flexible Nterminus related to the amphetamine effect (Khoshbouei et al., 2004). Some of these conserved putative phosphorylation residues are part of the internal opening of the transition pore proposed (Jacobs et al., 2007). The latter suggests that the modification of this residue would be more likely to have an effect in the DAT function than the phosphorylation sites on the $\mathrm{N}$-terminus. 


\subsubsection{Activation of $P K C$ induced changes in sodium gradients}

As discussed in the previous section, PKC is a key element for the DAT reversal, but still not clear how it does it. While searching for a possible explanation of our DAT-phosphorylation-independent dopamine release mechanism, we thought that one possibility is that PKC activation lead to a change in the equilibrium of the DAT substrates. We know that increase in cytosolic dopamine from the vesicles (like the weak base hypothesis for amphetamine) was not the case since our experiment including reserpine did not altered the carbachol-induced dopamine release.

However, we found that the non-selective cation channel blocker lanthanum inhibited GPCR-induced dopamine release (Figure 18). Influx of sodium could thus underlie the reversal of dopamine transport. This influx could be mediated by a PKC gated cation channel family, the TRP channels (Ahmmed et al., 2004). One member of the TRP family (TRPC1) is expressed in SNc neurons (Bengtson et al., 2004) and activated by mGluR. Taking these together made the TRP channels good candidates to induce the reversal of the DAT.

We could not inhibit the carbachol or PMA-induced dopamine release when the non-selective TRP channel blocker SKF98365, was used. This could be explained by the fact that the TRP channels expressed in SH-DAT cells are not blocked by our relatively low concentration of SKF98365.

We also showed that carbachol was able to induce a similar DAT-mediated dopamine release in the presence or absence of extracellular calcium (Figure 16). This finding would discard calcium as one of the cations blocked by lanthanum, since TRP could let pass $\mathrm{Ca}^{+2}$ and $\mathrm{Na}^{+}$.

Our experiments of lanthanum inhibition of $\mathrm{PKC}$-induced dopamine release, together with the normal dopamine released observed in SH-D19 after carbachol stimulation, thus suggest that PKC might trigger a sodium influx rather than phosphorylate the DAT. 
The DAT transport is in some extent also dependent on $\mathrm{Cl}^{-}$. Therefore, it is a possibility that the modification of chloride levels could lead to the DAT reversal. In addition, a neuron depolarization could also leads to a DAT-mediated dopamine release. These last two possibilities were not tested in this study, but they seem necessary to totally clarify the PKC-mediated reversal of the DAT.

\subsubsection{Parallels between DAT and GAT1}

Interestingly, $\mathrm{Wu}$ et al. (2006) recently showed in hippocampal neurons that the GABA transporter GAT1 keeps a tonic GABA release insensitive to vesicular fusion inhibition and sensitive to TTX. They conclude that GAT1 can drive GABA to the extracellular compartment, and this action entirely depends on the intracellular sodium concentration. Similar to the work of $\mathrm{Wu}$ and colleagues, we would need more experiments to identify the specific sodium channel that is involved in the process. Nevertheless, these findings are significant, since the mechanistic hypothesis of the PKC activation and the sodium increase for the reversal of the DAT can be conciliated.

\subsection{Physiological implications of the DAT reversal}

\subsection{1. $\mathrm{SNr}$ physiology}

The subthalamic nucleus (STN) project glutamatergic efferents into the $\mathrm{SNr}$, which are spontaneously active (Falkenburger et al., 2001; Kass and Mintz, 2006). We have shown that the blockade of the DAT in the SN brains slice leads to an increase of the sEPSP frequency (Figure $24 \& 25$ ). By doing this we were actually partially mimicking the case of PD and its loss of dopamineregic neurons. Less dopaminergic dendrites (neurons) in the $\mathrm{SNr}$, should lead to less DAT-mediated dopamine release. 
Importantly, the dopamine content in $\mathrm{SNr}$ has been shown to modulate whole animal behaviours For instance, Andersson and co-workers showed that dopamine depletion in the $\mathrm{SNr}$ reduced the rats' motor performance in 58\% when compared with control (Andersson et al., 2006). We propose with this study that the presence of dopamine in the $\mathrm{SNr}$ is mediated by the reversal of the dendritic DAT. Our amperometric data suggest that the local activation of an mGluR group I in the $\mathrm{SNr}$ induced a DAT-mediated dopamine release. Taking this into account, we can speculate than STN activity on the SNr could maintain a regular dopamine level in the $\mathrm{SNr}$ by reversing the DAT and that this dopamine could modulate different D1 and/or D2 receptors present in the $\mathrm{SNr}$. There are several evidences that show $\mathrm{SNr}$ dopamine capable to modulate neurons through D1 or D2 receptors on nigrothalamic (Ruffieux and Schultz, 1980), striatal (Martin and Waszczak, 1994), and subthalamic afferents (Ibañez-Sandoval et al., 2006).

In Parkinson's disease, the STN is hyperactive. This hyperactivity could partially compensate for the loss of dopaminergic neurons and uphold the dopamine concentration in the SNr. Consistently, nigral dopamine has been found less reduced following degeneration of dopaminergic neurons than striatal dopamine.

\subsubsection{Therapeutic treatments}

In our work we focus in a specific region of the brain, where the dendrites of the dopaminergic neurons are extended (SNr). Many widely used therapeutic drugs aim to block catecholamine transporters at the axonal terminals where catecholamine transporters are normally located and perform their uptake function.

Our findings suggest that transporters located in dendrites or at the neuronal soma could have a physiological function by transiently reversing the direction of the monoamine translocation. If this is the case, the therapeutic effects observed with the catecholamine transporter blockers might not only be due to their classical 
synaptic action, but also by blocking the release in non-classical neurotransmitter release as we have show in this study.

Catecholamine inhibitors are extensively used, principally in the treatment of neuropsychiatric disorders including depressions, attention deficit hyperactive disorder (ADHD), addictions and eating disorders (Giros et al., 1992; Torres et al., 2003). Many of them are synthetic compounds that where developed by mimicking the structures of natural substrates.

Conversely, transporter blockers could have side effect resulting from the fact that they not only inhibit dopamine uptake but also dopamine release. For example, drugs that block the DAT could worsen symptoms of PD by reducing extracellular dopamine in the $\mathrm{SNr}$, one of the basal ganglia output structures. 


\section{SUMMARY}

Dopaminergic neurons release their transmitter not only from axon terminals in the striatum but also from their long apical dendrites in the substantia nigra pars reticulata $(\mathrm{SNr})$. Whether dendritic dopamine release is mediated by vesicle fusion or by the reversal of the dopamine transporter (DAT) remains controversial. Previous studies suggested that glutamate-induced dopamine release through the DAT was insensitive to ionotropic glutamate receptors inhibition. In this study we explored whether metabotropic glutamate receptors (mGluRs) are involved in DAT-mediated dendritic dopamine release. We used amperometric recordings to directly measure dopamine release in midbrain rat brain slices. Glutamate induced DAT-mediated dopamine release and was reversibly blocked by chelerythrine, a protein kinase $\mathrm{C}(\mathrm{PKC})$ inhibitor. A selective mGluR group I agonist induced dopamine release and was reversibly blocked by the DAT antagonist GBR12935. Additionally, the PKC activator PMA was also capable to elicit a DAT-mediated dopamine efflux. PKC-enhanced dopamine release has recently been associated with the effect of amphetamine on the DAT, but not with the activation of physiological mGluRs. To further decipher the responsible cell signalling elements of the reversal of the DAT, we generated stably transfected SH-SY5Y cells expressing a human wild-type DAT (SH-DAT). All metabotropic downstream signalling elements were able to induce dopamine release and were blocked by chelerythrine. To evaluate if PKC acts directly on the DAT, we generated a new stably transfected cell line only expressing a truncated dopamine transporter (SH-D19). Five serines, that were possible phosphorylation sites, were removed by deleting the first $19 \mathrm{~N}$-terminal amino acids of the DAT. However, PKC-induced dopamine release was not affected in SH-D19, when compared with SH-DAT. Interestingly, PKC-induced dopamine efflux in SH-DAT cells was blocked when the nonselective cation channel blocker, lanthanum $\left(\mathrm{La}^{+3}\right)$ was present. Our findings suggest that $\mathrm{PKC}$-induced dopamine release did not act by direct DAT phosphorylation. Instead, an influx of sodium is required downstream of PKC activation and could be 
mediated by PKC gated cation channels like the transient receptor potential (TRP) channels. Throughout this work, we demonstrate that the activation of a second messenger signalling cascade leads to a reversal of the DAT. Since metabotropic receptors are widely expressed in the nervous system, the new concept on PKCmediated reversal transport, suggests that this phenomenon may also occur in other locations and with other neurotransmitters of the nervous system. Even more, this study suggests that the release of neurotransmitters is not limited to a presynaptic location. 


\section{REFERENCES}

Ahmmed GU, Mehta D, Vogel S, Holinstat M, Paria BC, Tiruppathi C, Malik AB (2004) Protein kinase Calpha phosphorylates the TRPC1 channel and regulates store-operated $\mathrm{Ca} 2+$ entry in endothelial cells. J Biol Chem 279:20941-20949.

Andersson DR, Nissbrandt H, Bergquist F (2006) Partial depletion of dopamine in substantia nigra impairs motor performance without altering striatal dopamine neurotransmission. Eur J Neurosci 24:617-624.

Bengtson CP, Tozzi A, Bernardi G, Mercuri NB (2004) Transient receptor potential-like channels mediate metabotropic glutamate receptor EPSCs in rat dopamine neurones. J Physiol (Lond) 555:323-330.

Bergman H, Wichmann T, DeLong MR (1990) Reversal of experimental parkinsonism by lesions of the subthalamic nucleus. Science 249:1436-1438.

Bergquist F, Shahabi HN, Nissbrandt H (2003) Somatodendritic dopamine release in rat substantia nigra influences motor performance on the accelerating rod. Brain Res 973:81-91.

Björklund A, Lindvall O (1975) Dopamine in dendrites of substantia nigra neurons: suggestions for a role in dendritic terminals. Brain Res 83:531-537.

Bonifati V, Rizzu P, van Baren MJ, Schaap O, Breedveld GJ, Krieger E, Dekker $\mathrm{MC}$, Squitieri F, Ibanez P, Joosse M, van Dongen JW, Vanacore N, van Swieten JC, Brice A, Meco G, van Duijn CM, Oostra BA, Heutink P (2003) Mutations in the DJ-1 gene associated with autosomal recessive early-onset parkinsonism. Science 299:256-259.

Cervinski MA, Foster JD, Vaughan RA (2005) Psychoactive substrates stimulate dopamine transporter phosphorylation and down-regulation by cocainesensitive and protein kinase $\mathrm{C}$-dependent mechanisms. J Biol Chem 280:40442-40449.

Chen BT, Rice ME (2001) Novel Ca2+ dependence and time course of somatodendritic dopamine release: substantia nigra versus striatum. J Neurosci 21:7841-7847. 
Chen BT, Moran KA, Avshalumov MV, Rice ME (2006) Limited regulation of somatodendritic dopamine release by voltage-sensitive $\mathrm{Ca}$ channels contrasted with strong regulation of axonal dopamine release. J Neurochem 96:645-655.

Chen JF, Xu K, Petzer JP, Staal R, Xu YH, Beilstein M, Sonsalla PK, Castagnoli K, Castagnoli N, Schwarzschild MA (2001) Neuroprotection by caffeine and $\mathrm{A}(2 \mathrm{~A})$ adenosine receptor inactivation in a model of Parkinson's disease. J Neurosci 21:RC143.

Cheramy A, Leviel V, Glowinski J (1981) Dendritic release of dopamine in the substantia nigra. Nature 289:537-542.

Ciliax BJ, Heilman C, Demchyshyn LL, Pristupa ZB, Ince E, Hersch SM, Niznik HB, Levey AI (1995) The dopamine transporter: immunochemical characterization and localization in brain. J Neurosci 15:1714-1723.

Cobb WS, Abercrombie ED (2003) Relative involvement of globus pallidus and subthalamic nucleus in the regulation of somatodendritic dopamine release in substantia nigra is dopamine-dependent. Neuroscience 119:777-786.

Corey JL, Guastella J, Davidson N, Lester HA (1994) GABA uptake and release by a mammalian cell line stably expressing a cloned rat brain GABA transporter. Mol Membr Biol 11:23-30.

Cowell RM, Kantor L, Hewlett GH, Frey KA, Gnegy ME (2000) Dopamine transporter antagonists block phorbol ester-induced dopamine release and dopamine transporter phosphorylation in striatal synaptosomes. Eur J Pharmacol 389:59-65.

DeLong MR (1990) Primate models of movement disorders of basal ganglia origin. Trends Neurosci 13:281-285.

Ding WQ Larsson C, Alling C (1998) Stimulation of muscarinic receptors induces expression of individual fos and jun genes through different transduction pathways. J Neurochem 70:1722-1729.

Edvardsen O, Dahl SG (1994) A putative model of the dopamine transporter. Brain Res Mol Brain Res 27:265-274.

Edwardson JM, Szekeres PG (1999) Endocytosis and recycling of muscarinic receptors. Life Sci 64:487-494. 
Elverfors A, Jonason J, Jonason G, Nissbrandt H (1997) Effects of drugs interfering with sodium channels and calcium channels on the release of endogenous dopamine from superfused substantia nigra slices. Synapse 26:359-369.

Fahn S, Sulzer D (2004) Neurodegeneration and neuroprotection in Parkinson disease. NeuroRx : the journal of the American Society for Experimental NeuroTherapeutics 1:139-154.

Falkenburger BH, Barstow KL, Mintz IM (2001) Dendrodendritic inhibition through reversal of dopamine transport. Science 293:2465-2470.

Fisone G, Borgkvist A, Usiello A (2004) Caffeine as a psychomotor stimulant: mechanism of action. Cell Mol Life Sci 61:857-872.

Floor E, Meng L (1996) Amphetamine releases dopamine from synaptic vesicles by dual mechanisms. Neurosci Lett 215:53-56.

Fog J, Khoshbouei H, Holy M, Owens W, Vaegter C, Sen N, Nikandrova Y, Bowton E, Mcmahon D, Colbran R (2006) Calmodulin Kinase II Interacts with the Dopamine Transporter C Terminus to Regulate AmphetamineInduced Reverse Transport. Neuron 51:417-429.

Fornstedt B, Rosengren E, Carlsson A (1986) Occurrence and distribution of 5-Scysteinyl derivatives of dopamine, dopa and dopac in the brains of eight mammalian species. Neuropharmacology 25:451-454.

Fortin GD, Desrosiers CC, Yamaguchi N, Trudeau LE (2006) Basal somatodendritic dopamine release requires snare proteins. J Neurochem 96:1740-1749.

Freed C, Revay R, Vaughan RA, Kriek E, Grant S, Uhl GR, Kuhar MJ (1995) Dopamine transporter immunoreactivity in rat brain. J Comp Neurol 359:340-349.

Galli A, Blakely RD, DeFelice LJ (1998) Patch-clamp and amperometric recordings from norepinephrine transporters: channel activity and voltage-dependent uptake. Proc Natl Acad Sci USA 95:13260-13265.

Gao HM, Hong JS, Zhang W, Liu B (2002) Distinct role for microglia in rotenoneinduced degeneration of dopaminergic neurons. J Neurosci 22:782-790. 
Geffen LB, Jessell TM, Cuello AC, Iversen LL (1976) Release of dopamine from dendrites in rat substantia nigra. Nature 260:258-260.

German DC, Manaye KF (1993) Midbrain dopaminergic neurons (nuclei A8, A9, and A10): three-dimensional reconstruction in the rat. J Comp Neurol 331:297-309.

Giros B, Caron MG (1993) Molecular characterization of the dopamine transporter. Trends Pharmacol Sci 14:43-49.

Giros B, el Mestikawy S, Godinot N, Zheng K, Han H, Yang-Feng T, Caron MG (1992) Cloning, pharmacological characterization, and chromosome assignment of the human dopamine transporter. Mol Pharmacol 42:383-390.

Granas C, Ferrer J, Loland CJ, Javitch JA, Gether U (2003) N-terminal truncation of the dopamine transporter abolishes phorbol ester- and substance $\mathrm{P}$ receptor-stimulated phosphorylation without impairing transporter internalization. J Biol Chem 278:4990-5000.

Gu H, Wall SC, Rudnick G (1994) Stable expression of biogenic amine transporters reveals differences in inhibitor sensitivity, kinetics, and ion dependence. J Biol Chem 269:7124-7130.

Heikkila RE, Orlansky H, Mytilineou C, Cohen G (1975) Amphetamine: evaluation of $\mathrm{d}$ - and 1 -isomers as releasing agents and uptake inhibitors for $3 \mathrm{H}$-dopamine and $3 \mathrm{H}$-norepinephrine in slices of rat neostriatum and cerebral cortex. J Pharmacol Exp Ther 194:47-56.

Hoffman AF, Gerhardt GA (1999) Differences in pharmacological properties of dopamine release between the substantia nigra and striatum: an in vivo electrochemical study. J Pharmacol Exp Ther 289:455-463.

Hoffman BJ, Hansson SR, Mezey E, Palkovits M (1998) Localization and dynamic regulation of biogenic amine transporters in the mammalian central nervous system. Frontiers in neuroendocrinology 19:187-231.

Ibañez-Sandoval O, Hernández A, Florán B, Galarraga E, Tapia D, Valdiosera R, Erlij D, Aceves J, Bargas J (2006) Control of the subthalamic innervation of substantia nigra pars reticulata by D1 and D2 dopamine receptors. J

Neurophysiol 95:1800-1811. 
Jacobs MT, Zhang YW, Campbell SD, Rudnick G (2007) Ibogaine, a noncompetitive inhibitor of serotonin transport, acts by stabilizing the cytoplasm-facing state of the transporter. J Biol Chem 282:29441-29447.

Jaffe EH, Marty A, Schulte A, Chow RH (1998) Extrasynaptic vesicular transmitter release from the somata of substantia nigra neurons in rat midbrain slices. J Neurosci 18:3548-3553.

Javitch JA, D'Amato RJ, Strittmatter SM, Snyder SH (1985) Parkinsonism-inducing neurotoxin, N-methyl-4-phenyl-1,2,3,6 -tetrahydropyridine: uptake of the metabolite $\mathrm{N}$-methyl-4-phenylpyridine by dopamine neurons explains selective toxicity. Proc Natl Acad Sci USA 82:2173-2177.

Jenner P (1998) Oxidative mechanisms in nigral cell death in Parkinson's disease. Mov Disord 13 Suppl 1:24-34.

Johnson LA, Guptaroy B, Lund D, Shamban S, Gnegy ME (2005) Regulation of amphetamine-stimulated dopamine efflux by protein kinase $\mathrm{C}$ beta. J Biol Chem 280:10914-10919.

Kahlig KM, Binda F, Khoshbouei H, Blakely RD, McMahon DG, Javitch JA, Galli A (2005) Amphetamine induces dopamine efflux through a dopamine transporter channel. Proc Natl Acad Sci USA 102:3495-3500.

Kantor L, Gnegy ME (1998) Protein kinase C inhibitors block amphetaminemediated dopamine release in rat striatal slices. J Pharmacol Exp Ther 284:592-598.

Kantor L, Hewlett GH, Gnegy ME (1999) Enhanced amphetamine- and K+mediated dopamine release in rat striatum after repeated amphetamine: differential requirements for $\mathrm{Ca} 2+-$ and calmodulin-dependent phosphorylation and synaptic vesicles. J Neurosci 19:3801-3808.

Kass JI, Mintz IM (2006) Silent plateau potentials, rhythmic bursts, and pacemaker firing: three patterns of activity that coexist in quadristable subthalamic neurons. Proc Natl Acad Sci USA 103:183-188.

Khoshbouei H, Wang H, Lechleiter JD, Javitch JA, Galli A (2003) Amphetamineinduced dopamine efflux. A voltage-sensitive and intracellular $\mathrm{Na}+-$ dependent mechanism. J Biol Chem 278:12070-12077. 
Khoshbouei H, Sen N, Guptaroy B, Johnson L, Lund D, Gnegy ME, Galli A, Javitch JA (2004) N-terminal phosphorylation of the dopamine transporter is required for amphetamine-induced efflux. PLoS Biol 2:E78.

Kim SJ, Kim YS, Yuan JP, Petralia RS, Worley PF, Linden DJ (2003) Activation of the TRPC1 cation channel by metabotropic glutamate receptor mGluR1. Nature 426:285-291.

Kitada T, Asakawa S, Hattori N, Matsumine H, Yamamura Y, Minoshima S, Yokochi M, Mizuno Y, Shimizu N (1998) Mutations in the parkin gene cause autosomal recessive juvenile parkinsonism. Nature 392:605-608.

Koga E, Momiyama T (2000) Presynaptic dopamine D2-like receptors inhibit excitatory transmission onto rat ventral tegmental dopaminergic neurones. J Physiol (Lond) 523 Pt 1:163-173.

Kosinski CM, Standaert DG, Testa CM, Penney JB, Young AB (1998) Expression of metabotropic glutamate receptor 1 isoforms in the substantia nigra pars compacta of the rat. Neuroscience 86:783-798.

Kowsky S, Pöppelmeyer C, Kramer ER, Falkenburger BH, Kruse A, Klein R, Schulz JB (2007) RET signaling does not modulate MPTP toxicity but is required for regeneration of dopaminergic axon terminals. Proc Natl Acad Sci USA 104:20049-20054.

Krueger BK (1990) Kinetics and block of dopamine uptake in synaptosomes from rat caudate nucleus. J Neurochem 55:260-267.

Langston JW, Ballard P, Tetrud JW, Irwin I (1983) Chronic Parkinsonism in humans due to a product of meperidine-analog synthesis. Science 219:979980.

LaVoie MJ, Hastings TG (1999) Peroxynitrite- and nitrite-induced oxidation of dopamine: implications for nitric oxide in dopaminergic cell loss. J Neurochem $73: 2546-2554$.

Leng Y, Chase TN, Bennett MC (2001) Muscarinic receptor stimulation induces translocation of an alpha-synuclein oligomer from plasma membrane to a light vesicle fraction in cytoplasm. J Biol Chem 276:28212-28218. 
Martin LP, Waszczak BL (1994) D1 agonist-induced excitation of substantia nigra pars reticulata neurons: mediation by $\mathrm{D} 1$ receptors on striatonigral terminals via a pertussis toxin-sensitive coupling pathway. J Neurosci 14:4494-4506.

Martorana A, Giampà C, DeMarch Z, Viscomi MT, Patassini S, Sancesario G, Bernardi G, Fusco FR (2006) Distribution of TRPC1 receptors in dendrites of rat substantia nigra: a confocal and electron microscopy study. Eur J Neurosci 24:732-738.

Mason JN, Farmer H, Tomlinson ID, Schwartz JW, Savchenko V, DeFelice LJ, Rosenthal SJ, Blakely RD (2005) Novel fluorescence-based approaches for the study of biogenic amine transporter localization, activity, and regulation. J Neurosci Methods 143:3-25.

Masson J, Sagné C, Hamon M, El Mestikawy S (1999) Neurotransmitter transporters in the central nervous system. Pharmacol Rev 51:439-464.

McCormack AL, Thiruchelvam M, Manning-Bog AB, Thiffault C, Langston JW, Cory-Slechta DA, Di Monte DA (2002) Environmental risk factors and Parkinson's disease: selective degeneration of nigral dopaminergic neurons caused by the herbicide paraquat. Neurobiol Dis 10:119-127.

McElvain JS, Schenk JO (1992) A multisubstrate mechanism of striatal dopamine uptake and its inhibition by cocaine. Biochem Pharmacol 43:2189-2199.

Melega WP, Williams AE, Schmitz DA, DiStefano EW, Cho AK (1995) Pharmacokinetic and pharmacodynamic analysis of the actions of Damphetamine and D-methamphetamine on the dopamine terminal. J Pharmacol Exp Ther 274:90-96.

Melikian HE, Buckley KM (1999) Membrane trafficking regulates the activity of the human dopamine transporter. J Neurosci 19:7699-7710.

Mintz I, Hammond C, Guibert B, Leviel V (1986) Stimulation of the subthalamic nucleus enhances the release of dopamine in the rat substantia nigra. Brain Res 376:406-408.

Newton AC (2003) Regulation of the ABC kinases by phosphorylation: protein kinase $\mathrm{C}$ as a paradigm. Biochem J 370:361-371. 
Nirenberg MJ, Vaughan RA, Uhl GR, Kuhar MJ, Pickel VM (1996) The dopamine transporter is localized to dendritic and axonal plasma membranes of nigrostriatal dopaminergic neurons. J Neurosci 16:436-447.

Oorschot DE (1996) Total number of neurons in the neostriatal, pallidal, subthalamic, and substantia nigral nuclei of the rat basal ganglia: a stereological study using the cavalieri and optical disector methods. J Comp Neurol 366:580-599.

Paton DM (1973) Mechanism of efflux of noradrenaline from adrenergic nerves in rabbit atria. Br J Pharmacol 49:614-627.

Pin JP, Bockaert J (1995) Get receptive to metabotropic glutamate receptors. Curr Opin Neurobiol 5:342-349.

Polymeropoulos MH, Lavedan C, Leroy E, Ide SE, Dehejia A, Dutra A, Pike B, Root H, Rubenstein J, Boyer R, Stenroos ES, Chandrasekharappa S, Athanassiadou A, Papapetropoulos T, Johnson WG, Lazzarini AM, Duvoisin RC, Di Iorio G, Golbe LI, Nussbaum RL (1997) Mutation in the alpha-synuclein gene identified in families with Parkinson's disease. Science 276:2045-2047.

Rice ME, Cragg SJ, Greenfield SA (1997) Characteristics of electrically evoked somatodendritic dopamine release in substantia nigra and ventral tegmental area in vitro. J Neurophysiol 77:853-862.

Roberts RC, Force M, Kung L (2002) Dopaminergic synapses in the matrix of the ventrolateral striatum after chronic haloperidol treatment. Synapse 45:78-85.

Robertson GS, Robertson HA (1989) Evidence that L-dopa-induced rotational behavior is dependent on both striatal and nigral mechanisms. J Neurosci 9:3326-3331.

Rosales MG, Flores G, Hernández S, Martínez-Fong D, Aceves J (1994) Activation of subthalamic neurons produces NMDA receptor-mediated dendritic dopamine release in substantia nigra pars reticulata: a microdialysis study in the rat. Brain Res 645:335-337.

Rudnick G, Wall SC (1992) The molecular mechanism of "ecstasy" [3,4methylenedioxy-methamphetamine (MDMA)]: serotonin transporters are targets for MDMA-induced serotonin release. Proc Natl Acad Sci USA 89:1817-1821. 
Ruffieux A, Schultz W (1980) Dopaminergic activation of reticulata neurones in the substantia nigra. Nature 285:240-241.

Sayer RJ, Schwindt PC, Crill WE (1992) Metabotropic glutamate receptormediated suppression of L-type calcium current in acutely isolated neocortical neurons. J Neurophysiol 68:833-842.

Schwartz JW, Blakely RD, DeFelice LJ (2003) Binding and transport in norepinephrine transporters. Real-time, spatially resolved analysis in single cells using a fluorescent substrate. J Biol Chem 278:9768-9777.

Seidel S, Singer EA, Just H, Farhan H, Scholze P, Kudlacek O, Holy M, Koppatz K, Krivanek P, Freissmuth M, Sitte HH (2005) Amphetamines take two to tango: an oligomer-based counter-transport model of neurotransmitter transport explores the amphetamine action. Mol Pharmacol 67:140-151.

Sonders MS, Amara SG (1996) Channels in transporters. Curr Opin Neurobiol 6:294-302.

Sonders MS, Zhu SJ, Zahniser NR, Kavanaugh MP, Amara SG (1997) Multiple ionic conductances of the human dopamine transporter: the actions of dopamine and psychostimulants. J Neurosci 17:960-974.

Sulzer D, Rayport S (1990) Amphetamine and other psychostimulants reduce pH gradients in midbrain dopaminergic neurons and chromaffin granules: a mechanism of action. Neuron 5:797-808.

Sulzer D, Sonders MS, Poulsen NW, Galli A (2005) Mechanisms of neurotransmitter release by amphetamines: a review. Prog Neurobiol 75:406433.

Sulzer D, Chen TK, Lau YY, Kristensen H, Rayport S, Ewing A (1995) Amphetamine redistributes dopamine from synaptic vesicles to the cytosol and promotes reverse transport. J Neurosci 15:4102-4108.

Testa CM, Standaert DG, Young AB, Penney JB (1994) Metabotropic glutamate receptor $m R N A$ expression in the basal ganglia of the rat. J Neurosci 14:3005-3018.

Thiruchelvam M, Richfield EK, Baggs RB, Tank AW, Cory-Slechta DA (2000) The nigrostriatal dopaminergic system as a preferential target of repeated 
exposures to combined paraquat and maneb: implications for Parkinson's disease. J Neurosci 20:9207-9214.

Torres GE, Gainetdinov RR, Caron MG (2003) Plasma membrane monoamine transporters: structure, regulation and function. Nat Rev Neurosci 4:13-25.

Tozzi A, Bengtson CP, Longone P, Carignani C, Fusco FR, Bernardi G, Mercuri NB (2003) Involvement of transient receptor potential-like channels in responses to $\mathrm{mGluR}-\mathrm{I}$ activation in midbrain dopamine neurons. Eur J Neurosci 18:2133-2145.

Trevitt JT, Carlson BB, Nowend K, Salamone JD (2001) Substantia nigra pars reticulata is a highly potent site of action for the behavioral effects of the D1 antagonist SCH 23390 in the rat. Psychopharmacology (Berl) 156:32-41.

Trevitt T, Carlson B, Correa M, Keene A, Morales M, Salamone JD (2002) Interactions between dopamine D1 receptors and gamma-aminobutyric acid mechanisms in substantia nigra pars reticulata of the rat: neurochemical and behavioral studies. Psychopharmacology (Berl) 159:229-237.

Uhl GR (1998) Hypothesis: the role of dopaminergic transporters in selective vulnerability of cells in Parkinson's disease. Ann Neurol 43:555-560.

Van Den Eeden SK, Tanner CM, Bernstein AL, Fross RD, Leimpeter A, Bloch DA, Nelson LM (2003) Incidence of Parkinson's disease: variation by age, gender, and race/ethnicity. Am J Epidemiol 157:1015-1022.

Wang Z, Kai L, Day M, Ronesi J, Yin HH, Ding J, Tkatch T, Lovinger DM, Surmeier DJ (2006) Dopaminergic control of corticostriatal long-term synaptic depression in medium spiny neurons is mediated by cholinergic interneurons. Neuron 50:443-452.

Whitby LG, Hertting G, Axelrod J (1960) Effect of cocaine on the disposition of noradrenaline labelled with tritium. Nature 187:604-605.

Windels F, Kiyatkin EA (2006) Stability of substantia nigra pars reticulata neuronal discharge rates during dopamine receptor blockade and its possible mechanisms. Neuroreport 17:1071-1075.

Wise RA (1996) Neurobiology of addiction. Curr Opin Neurobiol 6:243-251. 
$\mathrm{Xu} \mathrm{K}, \mathrm{Xu}$ YH, Chen JF, Schwarzschild MA (2002) Caffeine's neuroprotection against 1-methyl-4-phenyl-1,2,3,6-tetrahydropyridine toxicity shows no tolerance to chronic caffeine administration in mice. Neurosci Lett 322:13-16.

Yamashita A, Singh SK, Kawate T, Jin Y, Gouaux E (2005) Crystal structure of a bacterial homologue of $\mathrm{Na}+/ \mathrm{Cl}-$-dependent neurotransmitter transporters. Nature 437:215-223.

Zahniser NR, Sorkin A (2004) Rapid regulation of the dopamine transporter: role in stimulant addiction? Neuropharmacology 47 Suppl 1:80-91.

Zarow C, Lyness SA, Mortimer JA, Chui HC (2003) Neuronal loss is greater in the locus coeruleus than nucleus basalis and substantia nigra in Alzheimer and Parkinson diseases. Arch Neurol 60:337-341.

Zhang ZX, Roman GC, Hong Z, Wu CB, Qu QM, Huang JB, Zhou B, Geng ZP, Wu JX, Wen HB, Zhao H, Zahner GE (2005) Parkinson's disease in China: prevalence in Beijing, Xian, and Shanghai. Lancet 365:595-597.

Zimprich A, Biskup S, Leitner P, Lichtner P, Farrer M, Lincoln S, Kachergus J, Hulihan M, Uitti RJ, Calne DB, Stoessl AJ, Pfeiffer RF, Patenge N, Carbajal IC, Vieregge P, Asmus F, Müller-Myhsok B, Dickson DW, Meitinger T, Strom TM, Wszolek ZK, Gasser T (2004) Mutations in LRRK2 cause autosomal-dominant parkinsonism with pleomorphic pathology. Neuron 44:601-607. 


\section{ACKNOWLEDGMENTS}

I very much would like to thank professor Jörg Schulz for giving me the opportunity of working in his lab and for his great guidance and help during my doctoral thesis.

I would especially want to thank my supervisor Björn Falkenburger, who was always available for excellent discussions, and who with his vast knowledge, his great scientific and human dedication gave me all the support someone could get during his $\mathrm{PhD}$.

I would also like to thank all technical assistants in the lab, especially Kirsten Fladung for her unrestricted help.

I want to thank Ellen Gerhard and Simone Gräber for sharing their knowledge and experience with me, and for creating such a nice atmosphere in the lab with their unlimited good mood and humor.

I would also like to thank Cathy Ludwig for her assistance in all the necessary matters.

I want to thank all the people in the lab that I have shared time and work with. It was a real pleasure to spend three and a half years among such nice people.

I would like to thank Jörg Schulz, Björn Falkenburger, Mathias Bärh, Walter Stühmer and Fred Wouters for their valuable time evaluating my work and all the fructiferous discussions full of constructive criticism.

I want to thank the Graduate Program of the International Max Planck Research School for the incredible possibility they gave me of learning and meeting wonderful friends here in Germany. I want to thank the administrative members, all my teachers and my tutors for their great work.

I want to thank all my dearest friends in Göttingen. I hope to keep in contact with all the incredible people I have met and shared experiences with during these last years. I want to especially thank my best friends, classmates, Mitbewohner, travel mates and comrades Alexandros Poulopoulos, Lucian Medrihan and Stephan Junek.

Thanks to all my family, for their unconditional support during my whole life, without them I couldn't be here in the first place. I especially want to thank my parents Enrique and Cristina.

Finally I want to thank Corinna for all the love and warmth she gives to me. For helping me to surpass every difficulty I encounter. And for the family we are about to start together. 


\section{CURRICULUM VITAE}

\section{Luis Felipe Opazo Dávila}

Waldweg 33, 37073 Göttingen

$055139-13548$

fopazo@gwdg.de

Born on May 22 1978, Buenos Aires, Argentina

Nationality: Chilean

\begin{tabular}{ll}
\hline Education & \\
\hline $1997-2001$ & $\begin{array}{l}\text { Universidad de Chile, Santiago, Chile } \\
\text { Bachelor in Molecular biotechnology engineering }\end{array}$ \\
$2001-2003$ & $\begin{array}{l}\text { Universidad de Chile, Santiago, Chile } \\
\text { Master in Biological Sciences }\end{array}$ \\
$2003-2004$ & $\begin{array}{l}\text { Max Planck International Research School, Göttingen, Germany } \\
\text { Master in Neurosciences }\end{array}$ \\
$2005-2008$ & $\begin{array}{l}\text { DFG Center for Molecular Physiology of the Brain (CMPB), Göttingen, } \\
\text { Germany } \\
\text { PhD student in the Department of Neurodegeneration and Restorative } \\
\text { Research }\end{array}$
\end{tabular}

Scholarships

2002-2003 Millennium Institute for Advanced Studies in Cell Biology (CBB)

2003-2004 Stipend International Max Planck Research School

2008 Short term stipend Hertie Foundation 


\section{LIST OF PUBLICATIONS}

Published papers:

1. Dietz GP, Stockhausen KV, Dietz B, Falkenburger BH, Valbuena P, Opazo F, Lingor P, Meuer K, Weishaupt JH, Schulz JB, Bähr M. "Membrane-permeable Bcl-xL prevents MPTP-induced dopaminergic neuronal loss in the substantia nigra”. J Neurochem. 2008 Feb;104(3):757-65. Epub 2007 Nov 6. PMID: 17995935

2. Zapata-Torres G, Opazo F, Salgado C, Muñoz JP, Krautwurst H, Mascayano C, Sepúlveda-Boza S, Maccioni RB, Cassels BK. "Effects of natural flavones and flavonols on the kinase activity of Cdk5". J Nat Prod. 2004 Mar;67(3):416-20. PMID: 15043421

Manuscripts submitted or in preparation for submission:

1. Felipe Opazo, Antje Krenz, Stephan Heermann, Jörg B. Schulz, Björn H. Falkenburger. "Accumulation and clearance of $\alpha$-synuclein aggregates demonstrated by time-lapse imaging" (in review)

2. Felipe Opazo, Lucian Medrihan, Stephan Junek, Weiqi Zhang, Jörg B. Schulz and Björn H. Falkenburger. "Glutamate-induced reversal of dopamine transport is mediated by the PKC signaling pathway" (submition by the end of April 2008)

3. Asparouh I. Iliev, Jasmin Roya Djannatian ${ }^{\S}$, Felipe Opazo ${ }^{\S}$, Roland Nau, Timothy J. Mitchell, Fred S. Wouters. "Rapid microtubule bundling and stabilization by the Streptococcus pneumoniae cytolysin pneumolysin in a cholesterol-dependent, non-lytic and Src-kinase dependent manner". (in review)

$\S=$ equal contribution 